University of Massachusetts Amherst

ScholarWorks@UMass Amherst

Doctoral Dissertations 1896 - February 2014

$1-1-1977$

\title{
Effect of scar skin and dapple apple diseases on certain groups of phenolic compounds in apple.
}

\author{
Min-Chi Huang \\ University of Massachusetts Amherst
}

Follow this and additional works at: https://scholarworks.umass.edu/dissertations_1

\section{Recommended Citation}

Huang, Min-Chi, "Effect of scar skin and dapple apple diseases on certain groups of phenolic compounds in apple." (1977). Doctoral Dissertations 1896 - February 2014. 5964.

https://scholarworks.umass.edu/dissertations_1/5964

This Open Access Dissertation is brought to you for free and open access by ScholarWorks@UMass Amherst. It has been accepted for inclusion in Doctoral Dissertations 1896 - February 2014 by an authorized administrator of ScholarWorks@UMass Amherst. For more information, please contact scholarworks@library.umass.edu. 


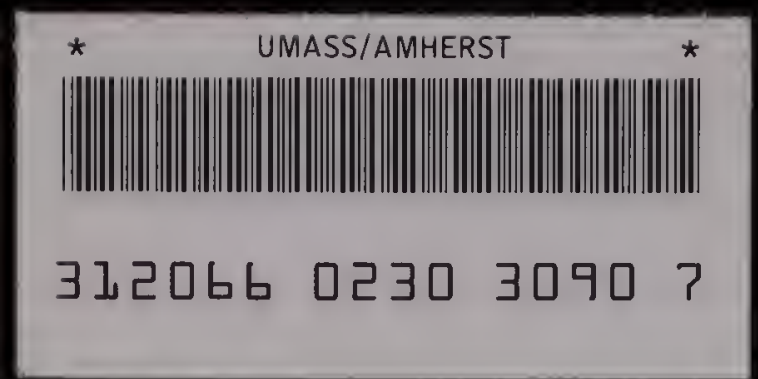


EFFECT OF SCAR SKIN AND DAPPLE APPLE DISEASES ON

CERTAIN GROUPS OF PHENOLIC COMPOUNDS IN APPLE

A Dissertation Presented

By

Min-Chi Huang

Submitted to the Graduate School of the University of Massachusetts in partial fulfillment

of the requirements for the degree of

DOCTOR OF PHILOSOPHY

December $\quad 1977$

Department of Plant Pathology 
(c) Min-Chi Huang 1977

Al1 Rights Reserved 
EFFECT OF SCAR SKIN AND DAPPLE APPLE DISEASES ON CERTAIN GROUPS OF PHENOLIC COMPOUNDS IN APPLE

A Dissertation Presented

By

Min-Chi Huang

M.ś.

Approved as to style and content by:
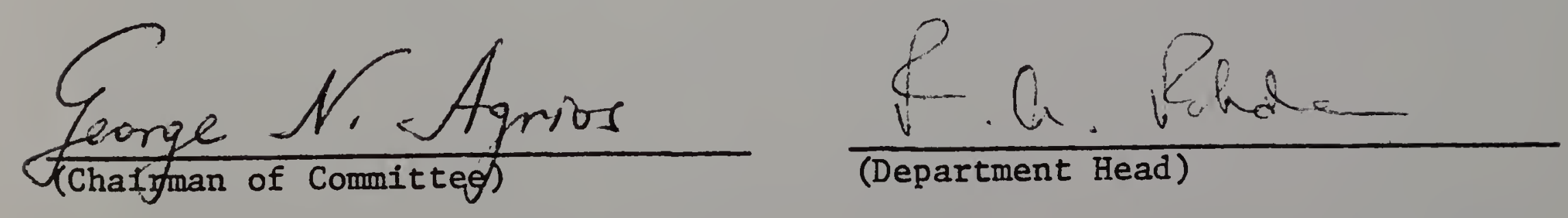

$\frac{\text { Trenor Rolinions }}{\text { (Menter) }}$

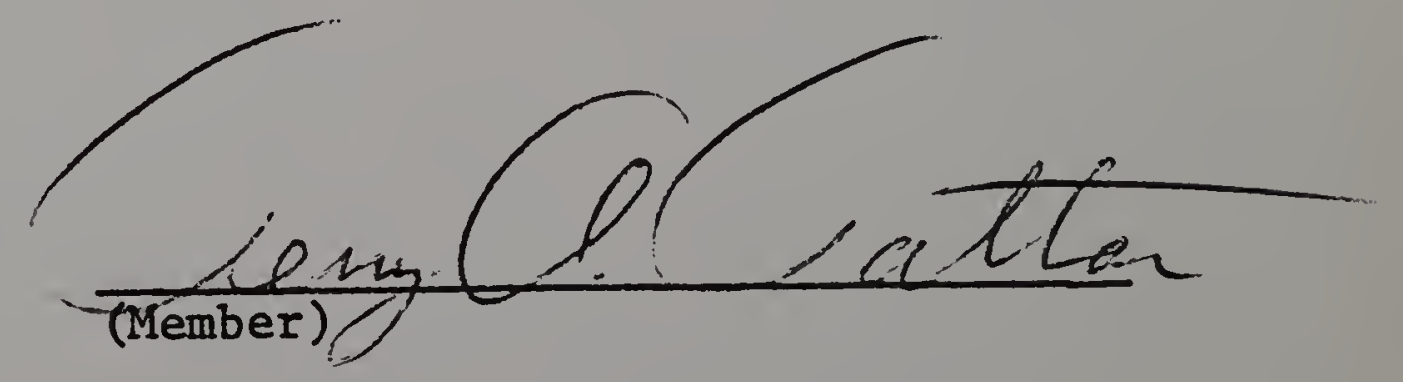

$\frac{\text { December } \quad 1977}{\text { (Month) }}$ 


\section{ACKNOWLEDGMENTS}

I would like to express my heartiest thanks to my major advisor, Dr. George N. Agrios for his encouragement, guidance and constructive criticism throughout the course of this study. To the members of my advisory committee, Dr. Terry A, Tattar and Dr. Trevor Robinson, I owe my deep thanks for their suggestions and inspiration.

I would also like to express my appreciation to Dr. Richard A. Rhode, Dr. Mark S. Mount, the secretaries and all the graduate students of the department. Their innumerable ways of assistance will always be gratefully remembered. 


\section{EFFECT OF SCAR SKIN AND DAPPLE APPLE DISEASES ON CERTAIN GROUPS OF PHENOLIC COMPOUNDS IN APPLE}

\section{February 1978}

\section{Min-Chi Huang, B.S., Chung Hsing University, Taiwan \\ M.S., Eastern Kentucky University \\ Ph.D., University of Massachusetts \\ Directed by: Professor George N. Agrios}

Scar skin and dapple apple are graft transmissible diseases of presumed but as yet unproven viral etiology. Scar skin-infected Red Delicious apples form corky, scarred patches on the surface, whereas dapple apple-infected Hyslop Crab apples show discoloration but no necrosis.

Changes in the concentration of total phenols, chlorogenic acids, flavonols and anthocyanins were determined in apple peel of healthy and scar skin-infected Red Delicious and of healthy and dapple apple-infected Hyslop Crab during the entire period of fruit development. Crude extracts containing chlorogenic acids, flavonols and anthocyanins from both healthy and infected fruits were chromotographically separated. Quantitative rather than qualitative differences in phenolic contents of apple fruits were observed after infection. Scar skin infection results in consistently higher amounts of total phenols, flavonols and chlorogenic acids but in lower amounts of anthocyanins in Red Delicious apple. Dapple apple infection appeared to have no significant effect on the levels of total phenols, flavonols, or chlorogenic acids, but 
resulted in remarkably lower levels of anthocyanins in Hyslop Crab apple.

Comparison of the effects of these two diseases on phenolic metabolism with the symptoms caused by the diseases on the fruits indicates that changes in phenolic metabolism are associated with the events observed in symptom development. 
TABLE OF CONTENTS

INTRODUCTION

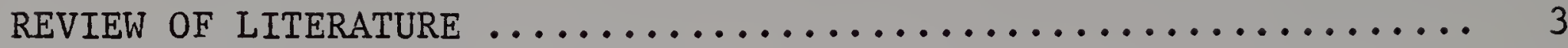

MATERIAL AND METHODS $\ldots \ldots \ldots \ldots \ldots \ldots \ldots \ldots \ldots \ldots \ldots \ldots \ldots \ldots \ldots$

Extraction and Quantitative Determination $\ldots \ldots \ldots \ldots \ldots \ldots$

1. Total Phenolics ........................... 16

2. Chlorogenic Acids ......................... 17

3. Flavonols Extracted for Paper Chromatography ......... 17

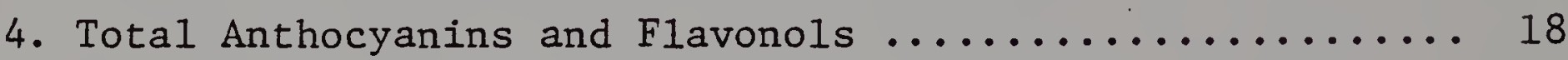

Separation by Paper Chromatography .................. 19

1. Chlorogenic Acids ........................ 19

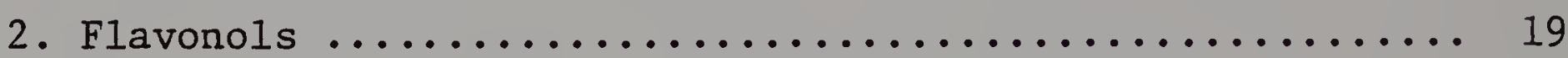

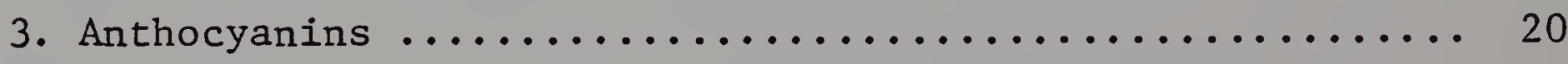

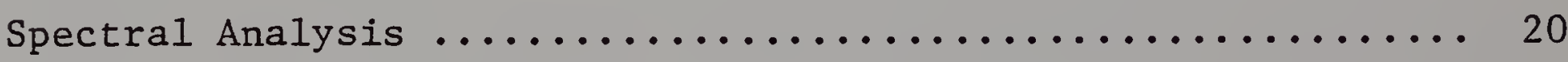

1. Chlorogenic Acid ......................... 20

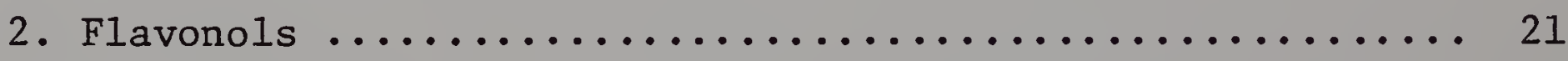

3. Anthocyanins $\ldots \ldots \ldots \ldots \ldots \ldots \ldots \ldots \ldots \ldots \ldots \ldots \ldots \ldots \ldots \ldots \ldots$

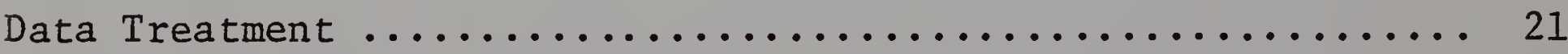

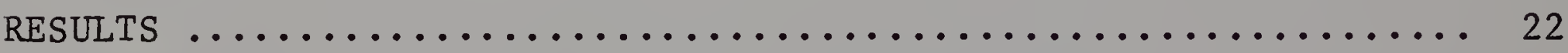

Total Phenols ................................ 22

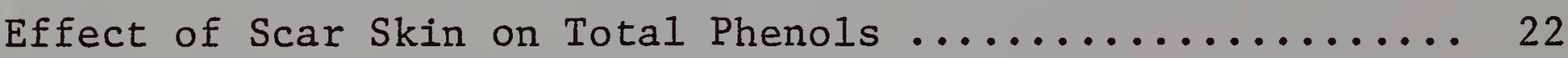

Effect of Dapple Apple on Total Phenols .............. 30

Chlorogenic Acids ........................... 30

Effects of Scar Skin on Chlorogenic Acids ............ 30

Effect of Dapple Apple on Chlorogenic Acids ............ 41

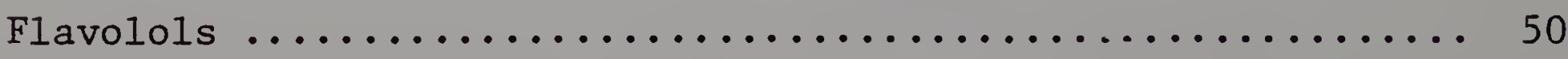

Effect of Scar Skin on Flavonols ................. 50

Effect of Dapple Apple Flavonols .................. 62

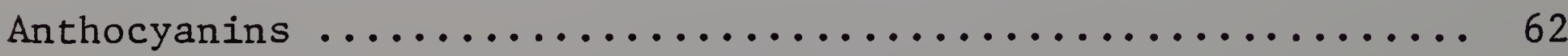

Effect of Scar Skin on Anthocyanins ................ 62

Effect of Dapple Apple on Anthocyanins ............... 81 
DISCUSSION 


\section{LIST OF TABLES}

Table

1. Total Phenol Content of Apple Peel of Healthy and Scar Skin-Infected Red Delicious at Various Stages of Fruit Development (mg/g of Fresh Tissue). . . . . .

2. Total Phenol Content of Apple Peel of Healthy and Dapple Apple-Infected Hyslop Crab at Various Stages of Fruit Development (mg/g of Fresh Tissue). . . . . .

3. Chlorogenic Acid Content of Peel of Healthy and Scar Skin-Infected Red Delicious Apples at Various Stages of Fruit Development (mg/g of Fresh Tissue) . . .

4. Concentration of Chromatographically Separated Chlorogenic Acids Obtained from 95\% Ethanol Extracts of Apple Peel of Healthy and Scar Skin-Infected Red Delicious at Various Stages of Fruit Development (mg/g of Fresh Tissue) . . . . . . . . . . ...

5. Concentration of Chromatographically Separated Chlorogenic Acids Obtained from Ethyl Ether and Ethyl Acetate Extracts of Apple Peel of Healthy and Scar Skin-Infected Red Delicious at Various Stages of Fruit Development (mg/g of Fresh Tissue) . : . . . . .

6. Rf Values, Spectral Properties, Fluorescence and Color Reagent Reactions of Band $6_{\mathrm{A}}$ Component Isolated from Red Delicious and from Hyslop Crab Apples. . . . . . . . . . . . . . . .

7. Chlorogenic Acid Content of Apple Peel of Healthy and Dapple Apple-Infected Hyslop Crab at Various Stages of Fruit Development (mg/g of Fresh Tissue) . .

8. Concentration of Chromatographically Separated Chlorogenic Acids Obtained from 95\% Ethanol Extracts of Apple Peel of Heaithy and Dapple Apple-Infected Hyslop Crab at Various Stages of Fruit Development (mg/g of Fresh Tissue) . . . . . . . . . . . . . 
9. Concentration of Chromatographically Separated Chlorogenic Acids Obtained from Ethyl Ether and Ethyl Acetate Extracts of Apple Peel of Healthy and Dapple Apple Infected Hyslop Crab at Various Stages of Fruit Development (mg/g of Fresh Tissue). . . . . .

10. Flavonol Content of Apple Peel of Healthy and Scar Skin-Infected Red Delicious at Various Stages of Fruit Development (mg/g of Fresh Tissue)........

11. Concentration of Chromatographically Separated Flavonols Obtained from Ethyl Ether and Ethyl Acetate Extracts or Apple Peel of Healthy and Scar Skin-Infected Red Delicious at Various Stages of Fruit Development (mg/g of Fresh Tissue). . . . . .

12. Spectral Data of Chromatographically Separated Flavonols Obtained from Peel of Red Delicious Apples . . . . . . . . . . . . . . . . . .

13. Flavonol Content of Apple Peel of Healthy and Dapple Apple Infected Hyslop Crab at Various Stages of Fruit Development (mg/g of Fresh Tissue). . . . : .

14. Concentration of Chromatographically Separated Flavonols Obtained from Ethyl Ether and Ethyl Acetate Extracts of Apple Peel of Healthy and Dapple Apple-Infected Hyslop Crab at Various Stages of Fruit Development (mg/g of Fresh Tissue). . . .

15. Anthocyanin Content of Apple Peel of Healthy and Scar Skin-Infected Red Delicious at Various Stages of Fruit Development (mg/g of Fresh Tissue). . . . . .

16. Concentration of Chromatographically Separated Anthocyanins from Apple Peel of Healthy and Scar SkinInfected Red Delicious at Various Stages of Fruit Development (mg/g of Fresh Tissue) . . . . . . . .

17. Rf Values and Spectral Properties of Separated Anthocyanins from Apple Peel of Red Delicious and Hyslop $\mathrm{Crab}$. . . . . . . . . . . . . . . . .

18. Anthocyanin Content of Apple Feel of Healthy and Dapple Apple-Infected Hyslop Crab at Various Stages of Fruit Development (mg/g of Fresh Tissue). . . . .

19. Concentration of Separated Anthocyanins from Apple Peel of Healthy and Dapple Apple-Infected Hyslop Crab at Various Stages of Fruit Development (mg/g of Fresh Tissue) . . . . . . . . . . . . . . . 


\section{LIST OF FIGURES}

Figure

Page

1. Sequential Development of Symptoms on Scar SkinInfected Red Delicious Apples as Compared to

Healthy Apple Development. . . . . . . . . . . .

2. Sequential Development of Symptoms on Dapple AppleInfected Hyslop Crab Apples as Compared to Healthy Apple Development. . . . . . . . . . . . . . . .

3. Changes in Concentration of Total Phenols in the Apple Peel During Development of Healthy and Scar Skin-Infected Red Delicious Fruits . . . . . . . . .

4. Changes in Concentration of Total Phenols in the Apple Peel During Development of Healthy and Dapple Apple-Infected Hyslop Crab Fruits. . . . . . ....

5. Changes in Concentration of Chlorogenic Acids in the Apple Peel During Development of Healthy and Scar Skin-Infected Red Delicious. . . . . . . . . . .

6. One-way Chromatograms of $95 \%$ Ethanol Extracts Containing Chlorogenic Acids from Pairs of Healthy and Scar Skin-Infected Red Delicious Apples.......

7. Changes in Concentration of Chlorogenic Acids in the Apple Peel During Development of Healthy and Dapple Apple-Infected Hyslop Crab Fruits . . . . . . . .

8. One-way Chromatograms of $95 \%$ Ethanol Extracts Containing Chlorogenic Acids from Healthy and Dapple Apple-Infected Hyslop Crab Apples . . . . . .

9. Changes in Concentration of Flavonols in the Apple Peel During Development of Healthy and Scar SkinInfected Red Delicious Fruit . . . . . . . . . . .

10. One-way Chromatograms of Ethyl Ether and Ethyl Acetate Extracts Containing Flavonols and Chlorogenic Acids from Healthy and Scar Skin-Infected Red Delicious Apples 
11. Changes in Concentration of Chromatographically Separated Flavonols from Apple During Development of Healthy and Scar Skin-Infected Red Delicious Fruits . . . . . . . . . . . . . . . . . .

12. Changes in Concentration of Flavonols in the Apple

Peel During Development of Healthy and Dapple Apple-Infected Hyslop Crsb Fruits. . . . . . . . .

13. One-way Chromatograms of Ethyl Ether and Ethyl Acetate Extracts Containing Flavonols and Chlorogenic Acids from Healthy and Dapple AppleInfected Hyslop Crab Apples. . . . . . . . . . .

14. Changes in Concentration of Chromatographically Separated Flavonols in the Apple Peel During Development of Healthy and Dapple AppleInfected Hyslop Crab Fruits. . . . . . . . . . .

15. Changes in Concentration of Anthocyanins in the Apple Peel During Development of Healthy and Scar Skin-Infected Red Delicious Fruits. . . . . . .

16. One-way Chromatogram of Acidified Ethanol Extracts Containing Anthocyanins from Healthy and Scar SkinInfected Red Delicious Apples. . . . . . . . . .

17. Changes in Concentration of Chromatographically Separated Anthocyanins in the Apple Peel During Development of Healthy and Scar Skin-Infected Red Delicious Fruits . . . . . . . . . . . . .

18. Changes in Concentration of Anthocyanins in the Apple Peel During Development of Healthy and Dapple Apple-Infected Hyslop Crab Fruits. . . . . . . . .

19. One-way Chromatogram of Acidified Ethanol Extracts Containing Anthocyanins from Healthy and Dapple Apple-Infected Hyslop Crab . . . . . . . . . . .

20. Changes in Concentration of Chromatographically Separated Anthocyanins in the Apple Peel During Development of Healthy and Dapple Apple-Infected Hyslop Crab Fruits . . . . . . . . . . . . . 


\section{INTRODUCTION}

Scar skin, a graft-transmissible disease of Red Delicious apples, Pyrus malus, causes corky, scarred, necrotic areas on the surface of affected fruits: brown necrotic tissue may cover up to $50 \%$ or more of the fruit surface. On the other hand, dapple apple disease, which is also graft-transmissible, causes discoloration but no necrosis on the surface of infected Hyslop Crab apples. Both diseases are of presumed but as yet unproven viral etiology. It is generally accepted that the browning of apples in response to injury and the development of necrotic symptoms in plants in response to infection result from the accumulation of phenolic compounds, which are subsequently oxidized and polymerized to form the brown substances observed after injury or infection. This generally accepted statement contains the implication that symptom development is associated with altered phenolic metabolism due to infection. Therefore, it appeared of interest to study the metabolism of certain groups of phenolic compounds in apples infected with one or the other of these two diseases, one of which causes necrotic symptoms, while the other causes discoloration but no necrosis.

The purpose of this study was to determine the effects of scar skin and dapple apple diseases on the quantity and quality of certain groups of phenolic compounds in the peel of apples fruits. Changes in concentration of total phenols, chlorogenic acids, flavonols and anthocyanins were determined in both healthy and infected apples during the various stages of fruit development, and an attempt was being made to 
correlate these changes with symptom appearance and development in the infected fruit. 


\section{REVIEW OF LITERATURE}

Scar skin, a graft-transmissible disease of apple, was first reported by Millikan in 1955. Symptoms on Red Delicious fruit commenced with the formation of light, water-soaked blemishes which radiated out from the calyx end. Later, scar tissue developed in the epidermis (Millikan, 1957). Scar skin symptoms are also observed on other varieties such as Virginia Crab, Jonathan, Red Gold, Stayman, and Rome Beauty •

The internal histological changes responsible for the formation of external symptoms were studied by Parker and Agrios (1973), who reported that early symptoms consist of raised, red, pimple-like areas, the red coloration preceding the appearance of brown necrotic scar tissue. Certain points of the fruit surface tissue appear raised due to hyperplastic activity beneath the epidermis. Pressure from the hyperplastic tissue and the periderm cause fracturing of the cuticle and the epidermis.

A virus has been mechanically transmitted from apple trees affected with scar skin disease to a number of indicator plants such as

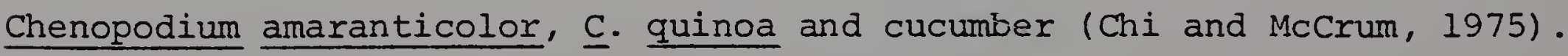
A flexuous, rod-shaped virus was isolated from inoculated cucumber cotyledons.

Dapple apple, also a graft-transmissible disease of apple, was first observed by Smith et al in 1956. In the early stage, infected 
apples show superficial, small, pale, circular spots. Later, the spots enlarge and sometimes may coalesce to form large discolored, patchy areas. Barrat (1958) postulated that development of dapple apple is dependent on two latent viruses, both of which must be present in the same tree for dapple apple symptoms to occur. Rich (1967), studying the influence of dapple apple on tree growth and fruit yields over a fourteen year period, found that dapple apple did not reduce the yield or growth of infected Cortland apple trees, but it did reduce the storage life, keeping quality and marketability of infected apples.

A wide variety of phenolic compounds have been found in apple, but their distribution varies from one part of the plant to another. Little difference can be seen in the phenolic patterns of leaf and bark of different apple varieties, but the phenolic substances in fruits show large varietal differences (William, 1960). In the apple peel of Grimes Golden, Siegelman (1955) found six quercetin-3-glycocides, qu-3galactoside, qu-3-glucoside, qu-3-arabinoside, qu-3-rhamnoside, qu-3rutinoside and qu-3-xyloside. Hulme and Edney (1960) detected at least 10 compounds in an extract of fruit peel of Cox's orange Pippin, primarily quercetin, various catechins, chlorogenic acid and probably pcoumaryl-quinic acid. Hoester-Auer (1964) identified three quercetin glycosides and free quercetin in the apple peel of Golden Delicious. In a methanol extract of the apple peel of Democrat fruits, Fisher (1963) identified seven quercetin-3-glycosides (quercetrin, isoquercetrin, hyperin, avicularin, reynoutrin, rutin and meratin), p-coumaric acid, pcoumaryl-quinic acid, chlorogenic acid and traces of phloridzin. 
Sondheimer (1958) detected, in McIntosh fruits, primary chlorogenic acid and traces of isochlorogenic acid, neochlorogenic acid and caffeic acid as well as an isomer of chlorogenic acid, possibly 4-0-caffeoylquinic acid. Herrmann (1959) found flavans such as (+) catechin, (-)epicatechin and some other hydroxycinnamic acid derivatives in apples. Morel and Herrmann (1974) summarized that the hydroxycinnamic acid derivatives and catechins detected in apples are chlorogenic acid, neochlorogenic acid, cryptochlorogenic acid, isochlorogenic acid, esters of 4-hydroxycinnamic acid, p-coumaryl quinic acids, glucosides of 4hydroxycinnamic acid, esters of ferulic acid, (t) catechin, (-) epicatechin and gallocatechin. Besides quercetin glycosides, kaempferol glycosides are also noted by Williams (1960) and Van Buren (1970). Whiting and Coggins (1975) pointed out that the main isomer of p-coumaryl quinic acid in apple cultivar Yarlington Mill was 4-ester, not the previously reported 3-ester.

Idaein (cyanidin-3-galactoside) has long been known to be the major pigment responsible for the red color of apples, but various minor pigments have also been detected in apples. Pais and Gombkoto (1967) identified three minor anthocyanins of Jonathan peel as acylated cyanidin-3-galactoside and two forms of acylated cyanidin-3-glucosides. Sun and Francis (1968) identified two minor components in Red Delicious as cyan $n_{n}^{i}$ in-3-arabinoside and cyanidin-7-arabinoside. Timberlake and Bridle (1971) examined the anthocyanins in a number of apple cultivars including Red Delicious, Stoke Red, Jonathan, Tremletts Bitter, French Red Delicious, Cox's Orange Pippin and Ingrid Marie. They confirmed that the major pigment is a cyanidin-3-galactoside and the minor pigments are 
cy-3-glucoside, cy-3-arabinoside and cy-3-xyloside as well as acylated derivatives of all four glycosides. Studying the formation of anthocyanins in callus tissue culture, Ibrahim et al (1971) identified cyanidin-3-5-diglucoside in the callus tissue culture of McIntosh apple. Bazarova and Sanorodova-Bianki (1971) reported only one pigment identified as cy-arabinosyl galactoside in the peel of apples and the amount of this anthocyanin decreased during storage. Other phenolics, like leucoanthocyanidins and tannins, are also found in apples (Van Buren, 1970). The amount of these phenolic compounds in apples has been reported by Van Buren (1970) .

Various factors such as light, temperature, water, mineral nutrition, carbohydrate levels and growth regulators are known to affect the phenolic metabolism of plants. These factors affect the metabolism by either influencing activity of enzymes or by supplying energy and building blocks required in the metabolic pathway of phenolic compounds. Generally, phenylalanine ammonia lyase (PAL) is considered as the major enzyme that regulates phenolic biosynthesis. Activation of this enzyme is not specific. It has been reported that the activity of PAL is increased in plants following infection by pathogens or injury (Minamikawa and Uritani, 1964; Zucker, 1968).

Hahlbrock et al (1976) showed that in suspension culture of parsley most enzymes of the flavonoid pathway are light-enhanced or related. Wellmann and Schopeer (1975) demonstrated that de novo synthesis of PAL is mediated by phytochrome.

In apple, Siegelman and Hendricks (1958) demonstrated the effect of light of 600 and $650 \mathrm{~nm}$ wavelength on accumulation of anthocyanins. 
Creasy (1968) found that anthocyanin levels are decreased by cold treatment of fruit. Faust (1965) reported that application of cobalt caused marked decrease in anthocyanins in peels of fruits. He also found that various treatments known to increase the activity of the pentose pathway were correlated with increased anthocyanin accumulations. Ibrahim et al (1971) reported that kinetin and IAA are required for the formation of anthocyanins in callus tissue cultures of apple. Ulrychova and Sosnova (1970) showed that phosphorus deficiency resulted in an evident increase in anthocyanin content of tomato fruit but accumulation of anthocyanins is limited by temperature. Synthesis stopped above $30^{\circ} \mathrm{C}$. Walker (1963) showed that the concentrations of p-coumaryl-quinic acid and chlorogenic acid fall during the ripening stage of apple fruit and reach a steady level at maturity. Similar observations for phenolics were reported by Mosel and Herrmann (1974), who found that the concentrations of phenolic compounds in apple rise sharply until age of about 2 to 3 months. Large quantities of catechins and hydroxycinnamic acid derivatives are formed in the early fruit. After a few weeks these concentrations decline very sharply, especially during the progressive growth of fruits, to reach a more steady level at maturity. Walker (1962) demonstrated that the enzymatic browning of apple fruits is related to the chlorogenic acid level rather than to the total phenolic content. Ingel and Hyde (1968) reported that bruising of postharvest apples causes a reduction in the concentration of total phenolics, flavonols and chlorogenic acid. Chlorogenic acid and flavonols are important substrates involved in the browning of apple following bruising. 
A great deal of work on the pathological metabolism of phenolic compounds in various plant diseases has been done. Several extensive reviews on this line have been written (Kosuge, 1969; Ingham, 1972; Kuc, 1972). In general, phenolic compounds accumulate after infection; the accumulated phenolics may or may not be present in the healthy plants. In fact many phytoalexins such as pisatin, phaseollin, hydroxyphaseollin, coumesterol, medicarpin and trifolirhizin are phenolic compounds. These are flavonoids isolated from diseased legume plants. Frequently, a more rapid increase of phenolic compounds is observed in resistant than in susceptible tissue.

The accumulation of the oxidized phenolic compounds in diseased tissue is the result of increased activity of phenol oxidizing enzymes due to infection. The products of phenol oxidation (quinones) formed in this system are toxic materials and their localized accumulation results in the formation of necrotic local lesions. Solymosy, Farkas and Kiraly (1959) have shown a considerable increase in the activity of polyphenoloxidase in leaves of tobacco inoculated with tobacco mosaic virus and tobacco necrosis virus. They postulate that if lesions form because of accumulation of oxidized phenols, reduction of oxidized phenols should inhibit necrosis. They found, accordingly, that ascorbic acid infiltrated into infected leaves became oxidized and that, under these conditions, lesion formation was almost completely inhibited. This hypothesis was supported by the observation of Parish et al (1955), who by infiltrating tissues with ascorbic acid, also showed that lesion numbers are reduced although not to the extent reported by Farkas et al. Studying phenol metabolism associated with induced systemic resistance to 
TMV in Samsun NN tobacco, Simons and Ross (1971) also supported the hypothesis that accelerated necrotic and metabolic responses of resistant leaves after challenge inoculation are due to rapid peroxidase-mediated of quinone accumulation at the point ${ }_{\wedge}$ infection. The phenol oxidizing enzymes are peroxidase and phenoloxidases. The latter are classified into two types: (1) o-Diphenol:oxygen oxidoreductase: phenolase, polyphenol oxidase, tyrosinase and DOPA-oxidase belong to this type; and (2) p-Diphenol:oxygen oxidoreductase is named laccase (Fric 1976). In McIntosh apples inoculated with Penicillium sp or Physalospora obtusa, Wilson and Darby (1971) reported that peroxidase activity was low in decayed areas, while the activity at the edge of uninvaded tissue and peel of both rots increased 2.5 times over controls. O-diphenol oxidase activity was not detectable in rotted areas. When $\underline{\mathrm{P}}$. obtusa affected apples were in the process of darkening, o-diphenol oxidase activity was again present. Studying phenolase activity in apple leaves after grafting with healthy and virus-infected Golden Delicious buds, Millikan and Saniewski (1972) noted that three weeks after grafting with virusinfected buds, the phenolase activity was reduced in the sensitive cultivars, but not in the tolerant one. Three weeks after inoculation, . infected sensitive cultivars had increased phenolase activity, whereas those grafted with healthy buds had reduced activity.

Addy (1976) demonstrated that apple leaves infiltrated with virulent and avirulent strains of Erwinia amylovora showed a linear relationship of leakage of electrolytes and total phenol during the first 5 hours. Both occurred well in advance of visible browning symptoms which were evident about 12 hours after infiltration. Since Loper (1968) 
found that coumestrol concentrations above 2000 pm cause tissue necrosis in alfalfa, Keen et al (1972) suggested that cell death in the resistant responding soybean hypocotyls inoculated with phytophthora may also be due to the accumulation of isoflavonoids. However, Kosuge (1969) suggests that the involvement of phenolase and phenolic compounds appears to be secondary to the event that triggers necrosis. The triggering event might involve a change in membrane permeability leading to loss of cell compartmentalization. Once this occurs, regulation of cellular metabolism would be lost, phenolase could be activated, and this and other oxidative and hydrolytic enzymes and substrates, previously separated by compartmentalization, would come together. The resulting degenerative activities would then lead to the formation of lesions. Symptom formation may also result from the altered metabolism of growth substances due to changes in phenolic metabolism. It has been suggested that phenolic compounds possibly regulate the activity of the growth substance IAA by virtue of their effects on peroxidase activity. The oxidation of IAA is strongly stimulated by $10^{-5} \mathrm{M}$ p-coumaric acid. Chlorogenic acid at $3 \times 10^{-7} \mathrm{M}$ is inhibitory to IAA oxidase, as are caffeic acid and dihydroxyphenylalanine at $10^{-6} \mathrm{M}$. Ferulic acid is stimulatory at $2 \times 10^{-4} \mathrm{M}$ but inhibitory at $2 \times 10^{-5} \mathrm{M}$. Generally, monophenols tend to stimulate, while ortho-dihydroxyl phenols tend to inhibit the activity of IAA oxidase (Kosuge, 1969). MCClure (1975) described that some flavonoids even function as plant growth regulators. Naringenin is regarded as an endogenous regulator of dormancy. Phloridzin acts as a cofactor of IAA oxidase in plants at very low concentrations and is inhibitory to the growth of apple seedling in water 
culture, while $(-)$ catechin and rutin stimulate the growth of Daucus carota tissue in callus cultures.

Most of the phenolics mentioned here are present in fairly good amounts in leaves, bark or roots of apple. However, no attempt has been made to elucidate whether a relationship exists between the altered activity of growth substances due to phenolic metabolism and symptom formation in diseased apples. A great deal of work has been done on the association of phenolic metabolism with the resistance of apple to Venturia inaequalis (Williams and Kuc, 1969). Kirkham (1954, 1957) suggested that the resistance of apple to Venturia is related to the phenolic contents in the host tissue. He found that water-soluble plant phenols may be strongly inhibitory to the growth and sporulation of $\underline{v}$. inaequalis, depending on the amount and source of nitrogen in the medium. Barnes and Williams (1960) found that a fluorescent phenolic compound increased in concentration in the peel of fruits and leaves of several apple selections infected with either $\underline{\mathrm{V}}$. inaequalis or Podosphaera leucotricha. The response is not specific to $\underline{\mathrm{V}}$. inaequalis since $\underline{\mathrm{P}}$. leucotricha also induced production of the fluorescent compound, but mechanical injury failed to increase the concentration of the compound. Many studies have centered on post-infection changes occurring in the compound phloridzin, which is the most abundant phenolic glycoside in the leaves of apples. It has been suggested that the resistance of apple to $\underline{\mathrm{V}}$. inaequalis was attributed to oxidation products of phloridzin or its aglycone phloretin rather than to the intact phloridzin content of the host (Raa, 1968; Williams and Kuc, 1969). Other workers (Raa and Overemm, 1968; Noveroske, 1962) showed that there was no relation between 
phloridzin content of the host and resistance. Recently, Nicholson et al (1977) found that inhibition of $\underline{V}$. inaequalis growth in etiolated hyocotyl of apple seedling occurred well before the changes in phloridzin and phloretin content of host could be detected. Therefore, they concluded that containment of $\underline{\mathrm{V}}$. inaequalis in the hypersensitive response is not mediated by changes in phloridzin or phloretin as previously assumed.

Investigating inhibitory compounds involved in the resistance of apple fruits to the brown rot fungus Sclerotinia fructigena, Fawcett and Spencer $(1966,1967)$ found that several inhibitory compounds accumulated in the infected tissues and two of these were identified as 4hydroxybenzoic acid and vanillic acid. Neither of these compounds could be detected in uninfected tissues. The production of 4-hydroxybenzoic acid resulted from the action of $\underline{\mathrm{s}}$. fructigena on either chlorogenic acid or quinic acid (Fawcett and Spencer, 1968). Similarly, Swinburne (1964) suggested that the resistance of immature apple fruits to infection by Nectria galligena was due to an antifungal principle produced after infection. One of these antifungal components was later confirmed as benzoic acid (Ingham, 1972).

Virus infection often involves yellow mottling and yellowing of leaves. Such effects appear to involve a loss of chlorophyll resulting in the yellowish coloration due to the unmasking of carotene and xanthophyll. The reduction in the amount of leaf pigments can be due either to an inhibition of chloroplast development or to the destruction of pigments in mature chloroplasts (Matthews, 1970). 
Martin (1958) found inhibition of anthocyanin synthesis in young potato plants infected by potato virus $Y$, the amount of anthocyanins being indirectly proportional to virus synthesis. In tobacco plants infected with TMV, the normal pink color of petals, may be broken by white stripes. Matthews (1970) found virus present only in the white areas. Also sweet peas infected with bean yellow mosaic, pale pink flowers become flecked with darker pink and white areas. This could be caused by two strains of virus due to their different effects on petal pigment development. Feenstra et al (1963) found that virus infection in Matthiola incana appears to block accumulation of an acylated pelargonidin glycoside while stimulating kaempferol derivatives and sinapic acid. Geissman (1956) reported that kaempferol and quercetin. glycosides are increased significantly in virus-infected leaves of prunus persica and Prunus avium. Viral infection also increases hesperitin content of Citrus sinensis (Hanks and Feldman, 1969). Sosnova and Mrychova (1972) found that viral infection of tomato plants decreases anthocyanins below $20 \mathrm{C}$, but increases anthocyanins above $20 \mathrm{C}$. However, the effect of virus infection on phenolic metabolism of apple fruits has been little studied so far.

Viral infections are generally found to cause an increase in respiration, a decrease in photosynthesis and also to interfere with nitrogen metabolism. In apple, virus infection alters the RNA content of leaf tissue (Millikan and Koirtyohann, 1966). Virus infection also causes changes in protein and nucleic acid fractions in leaf (Carling et al, 1969). However, apple mosaic virus or russet ring virus have no significant effect on respiration, organic acid and sugar composition of apple fruits collected from infected trees (Makarski and Agrios, 1973). 
Phenolic compounds are reported to inactivate plant virus in vitro, through formation of oxidized products of phenolics which are highly active. Hampton and Fulton (1961) showed that phenol oxidized by polyphenol oxidase causes loss of infectivity of prune dwarf and sour cherry necrotic ringspot viruses in crude extracts. Mink (1965) demonstrated that chlorogenic acid caused some inactivation of purified tulare mosaic virus, while its oxidation product, o-quinone, caused rapid and total inactivation of the virus. Mink and Saksena (1972) studied inactivation of six viruses by o-quinones and found that these six viruses differed both in the amount of quinone required to produce complete inactivation and in the manner in which they were inactivated. Inactivation of all viruses was proportional to the logarithm of the quinone concentration, used. Similar results are reported by wood and Agrios (1974) who proposed that inactivation may be due to the reaction between quinone and amino groups present on RNA molecules.

In brief, phenolic compounds accumulate in plants after infection. Such accumulation has been thought to result from the increased activity of PAL and pentose phosphate shunt (Kosuge, 1969).

Diverse physiological roles are played by phenolic compounds. They play an essential role in lignification; contribute to plant coloration; some phenolics are potent growth regulators by influencing auxin activity in and ${ }_{n}$ other cases, phenolics themselves act as growth substances. Phenolics may also interfere with growth by uncoupling oxidative phosphorylation.

In diseased plants, phenolic compounds such as phytoalexins, function as antimicrobial substances. Phenolic accumulation following 
infection is regarded as a major defense mechanism of plants. Oxidation of phenolics yields highly reactive quinones which play an important role in lesion formation in the hypersensitive response. According to Kuc (1975), if phenolic compounds (Phytoalexins) play an essential role in plant resistance, it is the timing and magnitude of their accumulation, rather than the ability to accumulate such compounds that distinguish susceptible plants from resistant ones. 


\section{MATERIALS AND METHODS}

The apple fruits used in this study were taken from trees of the cultivars Hyslop Crab and Red Delicious growing in the university orchard in Belchertown, Massachusetts. Hyslop Crab trees had been inoculated with buds from dapple apple infected trees and Red Delicious with/scar skin infected trees since 1968, Fruits of healthy and infected apples were collected every 20 days from June 10 through october 8, 1975. In the first collection, the fruit was cored and then used for analysis, while later the fruit was peeled and only the peel was analyzed. In order to get a uniform thickness of apple peel, all fruits, except the first collection, were peeled with a house potato peeler. Ten grams of sample was used for each replication, three replications used for each assay. The same experiments were repeated in the summer of 1976.

\section{Extraction and Quantitative Determination}

\section{Total Phenolics}

Ten grams of fresh apple peel was placed in $150 \mathrm{ml}$ of absolute methanol immediately after peeling and was boiled for 20 minutes. The methanol extract was then decanted and $150 \mathrm{ml}$ of $50 \%$ methanol was added to the tissues which then macerated at high speed in a Waring blender for 2 minutes. The macerate was boiled for 20 minutes after which the supernatant was decanted while the bottom slurry was boiled again with 50\% methanol. Finally the last boiled preparation and decanted supernatants were pooled and filtered through whatman No. 1 filter paper. 
The final volume of the extract was made up to $150 \mathrm{ml}$ with absolute methanol. The amount of total phenols was determined by the colorimetric method of Swain and Hillis (1959). An aliquot of extract containing no more than $0.5 \mathrm{ml}$ methanol was diluted with water and reacted with phenol reagent. One $\mathrm{ml}$ of saturated sodium carbonate solution was added. An hour later, a reading was taken at $725 \mathrm{~nm}$ wavelength of a spectronic 20 Bauch and Lomb colorimeter, using water and reagents only as a blank.

\section{Chlorogenic Acids}

Ten grams of apple peel was macerated in a waring blender with 50 $\mathrm{ml}$ of $95 \%$ ethanol containing $200 \mathrm{mg}$ ascorbic acid to prevent browning. The extract was then filtered through whatman No. 1 paper while the residue was further washed with $95 \%$ ethanol until a total of $100 \mathrm{ml}$ extract was collected. Chlorogenic acids were estimated by the method of Zucker and Ahrens (1958). An aliquat of extract $(0.2 \mathrm{ml})$ was added to a column of chromatographic alumina previously washed with water. The chlorogenic acids were absorbed at the top of the column, the column was washed with water and a freshly mixed solution of $0.5 \% \mathrm{NaNO}_{2}$ and $5 \%$ acetic acid. After washing with water again, $5 \mathrm{~N} \mathrm{NaOH}$ was added to the column to bring the total volume of eluate to $10 \mathrm{ml}$. The absorptivity of the eluate was measured at $525 \mathrm{~nm}$ wavelength of a colorimeter against a water blank.

\section{Flavonols Extracted for Paper Chromatography}

Ten grams of apple peel was macerated with $70 \%$ methanol in a Waring blender at high speed for 2 minutes. The slurry was covered with parafilm and stored overnight at $4^{\circ} \mathrm{C}$. The supernatant was decanted. 
The residue was macerated again with extracting solvent and stored at $4^{\circ}$ C. The later extract and the previous supernatants were pooled and filtered through whatman No. 1 filter paper. The total volume of the filtrate was made up to $200 \mathrm{ml}$. Three extracts obtained by this procedure were combined and concentrated approximately to $80 \mathrm{ml}$ in a rotary evaporator. The extract was washed with equal volume of petroleum ether twice and re-extracted four times with each of ethyl ether and ethyl acetate. Ethyl ether and ethyl acetate extracts were combined and dried in a rotary evaporator. The flavonols were then taken up in $10 \mathrm{ml}$ of $95 \%$ ethanol and stored at $4^{\circ} \mathrm{C}$. for further separation by paper chromatography.

\section{Total Anthocyanins and Flavonols}

The method of Lees and Francis. (1971, 1972) was followed with minor modifications. Ten grams of apple peel was macerated with a mixture of $95 \%$ ethanol and $1,5 \mathrm{~N} \mathrm{HCL}(85: 15 \mathrm{v} / \mathrm{v})$ in a waring blender at high speed for 2 minutes. The macerate was covered with parafilm and stored overnight at $4^{\circ} \mathrm{C}$. The supermatant was decanted, and the residue was mixed with extracting solvent and stirred for a few minutes. This and the decanted supernatant were combined and filtered through whatman No. I filter paper. The residue was further washed with solvent until a total of $100 \mathrm{ml}$ of extract was collected. The absorptivity of this ethanolic extract containing anthocyanins and flavonols was measured at the wavelength of $374 \mathrm{~nm}$ for flavonols and $535 \mathrm{~nm}$ for anthocyanins. The quantity of total anthocyanins and total flavonols per gram of tissues was determined by employing the equations described by Lees and Francis (1972) : 


$$
\begin{aligned}
& \frac{\text { Total anthocyanins }}{10 \text { grams of tissue }}=\frac{\text { Absorbance } x \text { Dilution factor }}{98.2} \\
& \frac{\text { Total flavonols }}{10 \text { grams of } \text { tissue }}=\frac{\text { Absorbance } x \text { Dilution factor }}{76.6}
\end{aligned}
$$

where 98.2 is an average extinction coefficient for anthocyanins and 76.6 a similar coefficient for flavonols.

\section{Separation by Paper Chromatography}

1. Chlorogenic Acids

An aliquot of a crude 95\% ethanol extract containing chlorogenic acids from all 6 collections was applied as a streak (about $2 \mathrm{~cm}$ long) across a Whatman No. 3M paper. The chromatograms were developed with water for 8 hours. The separated cholorgenic acid bands were cut and eluted with $95 \%$ ethanol, and their absorptivities measured at $330 \mathrm{~nm}$.

\section{Elavonols}

Whatman No. 3M paper was used for separation and purification. An aliquot of ethyl ether and ethyl acetate extracts containing flavonols was applied as a streak across the paper and developed by the descending method with aistilled water for 7 hours in a chromatographic cabinet. The separated bands were cut and eluted with $95 \%$ ethanol. The absorptivity of eluates was measured at $374 \mathrm{~nm}$. For comparison of diseased extracts with healthy ones, an aliquot of extract from all six collections was applied on the same paper and developed with the same procedure as described above. 


\section{Anthocyanins}

Whatman No. 3 paper was also used for separation and purification of anthocyanins. An aliquot of the acidified ethanol extract containing anthocyanins was applied as a streak across the top of the paper and developed with a mixture of butanol:acetic acid:water $(6: 1: 2)$ for 24 hours. The separated bands were cut and eluted with a mixutre of methanol:acetic acid:water $(9: 5: 5)$. The eluate was quantitatively determined by the method described for total anthocyanins. A Chromatogram of extracts from the last five collections was run for comparison,

Rf data for each separated phenolic was obtained by using Whatman No. 1 paper. The following solvent systems were selected for chromatography :

1. BAW: Butanol:Acetic acid:Water $(6: 1: 2)$

2. $\mathrm{H}_{2} \mathrm{O}$ : Distilled water

3. HAC: $3 \%$ Acetic acid

4. BuHCl: 1-butanol-2N HCl

5. Forestal: Glacial acetic acid:Conc. $\mathrm{HCl}: \mathrm{H}_{2} \mathrm{O}(30: 3: 10)$

6. Formic: Formic acid:Conc. $\mathrm{HCl}: \mathrm{H}_{2} \mathrm{O} \quad(5: 2: 3)$

\section{Spectral Analysis}

\section{Chlorogenic Acid}

Chlorogenic acid bands were cut out from the chromatogram eluted with $95 \%$ ethanol and rechromatographed in BAW. The bands from the BAW chromatograms were eluted again and rechromatographed once more in $3 \%$ acetic acid. The purified band was cut and eluted with $100 \%$ methanol 
(spectral grade). The absorption spectrum was obtained in the range of 200 to $400 \mathrm{~nm}$ with DBG Beckman spectrophotometer using as a blank the eluate of a blank area cut from the same chromatograms. For comparison, standard chlorogenic acid was treated the same way as samples.

\section{Flavonols}

Flavonol bands separated with the above procedure were cut, eluted and rechromatographed in BAW (4:1:5, upper phase). Spectral analysis of purified flavonols was done by following the method described by Mabry et al (1970).

\section{Anthocyanins}

Pigments separated with the procedure described above were rechromatographed in $15 \%$ acetic acid for 12 hours and eluted with MAW $(9: 1: 2)$. The eluate was rechromatographed with BAW $(6: 1: 2)$. The absorption spectrum of this concentrated purified pigment was obtained with the DBG Beckman spectrophotometer.

\section{Data Treatment}

Quantitative differences in phenolic compounds between diseased and healthy apple were compared statistically by estimating the standard deviation among the samples in each treatment and plotted on a graph. 
RESULTS

Scar skin-infected Red Delicious apples and dapple apple-infected Hyslop Crab apples developed typical symptoms during the years 1975 and 1976 in which collections were made for phenolic compound analysis (Figure 1 and Figure 2).

The results are grouped according to the kind of phenolic compounds (total phenols, flavonols, anthocyanins and chlorogenic acids) that were examined in diseased and healthy fruits. The changes in quantity or quality of these compounds in healthy and virus-infected fruit are reported as they were determined by the colorimetric method and by paper chromatography.

\section{Total Phenols}

\section{Effect of Scar Skin on Total Phenols}

Consistently higher amounts of total phenols were found in infected than in healthy tissues (Table 1). The increased concentration in total phenols of the diseased as compared to the healthy apples became evident starting with the third collection in 1975 and the second collection in 1976. The concentration of total phenols reached a maximum at the second collection in the healthy and at the third collection in the diseased apples. Subsequently, the concentration of total phenols tended to decrease in both during ripening of fruits (Figures $3 a$ and $3 b$ ). . Scar skin-infected apples had from 9-73\% more total phenols in 1975 and from 28-114\% more total phenols in 1976 than did healthy apples (Table 1). 
Figure 1. Sequential development of symptoms on scar skin-infected Red Delicious apples (upper in $1 \mathrm{a}$ and $1 \mathrm{~b}$; lower in $2 \mathrm{c}$ ) as compared to healthy apple development (lower in $1 \mathrm{a}$ and $1 \mathrm{~b}$; upper in $2 \mathrm{c}$ ). Samples were taken at 10 day intervals from June 10 to July 10 (la) and from July 20 to August $19(1 \mathrm{~b})$ in 1975, and on september 18 and October 8, 1977 (1c). 

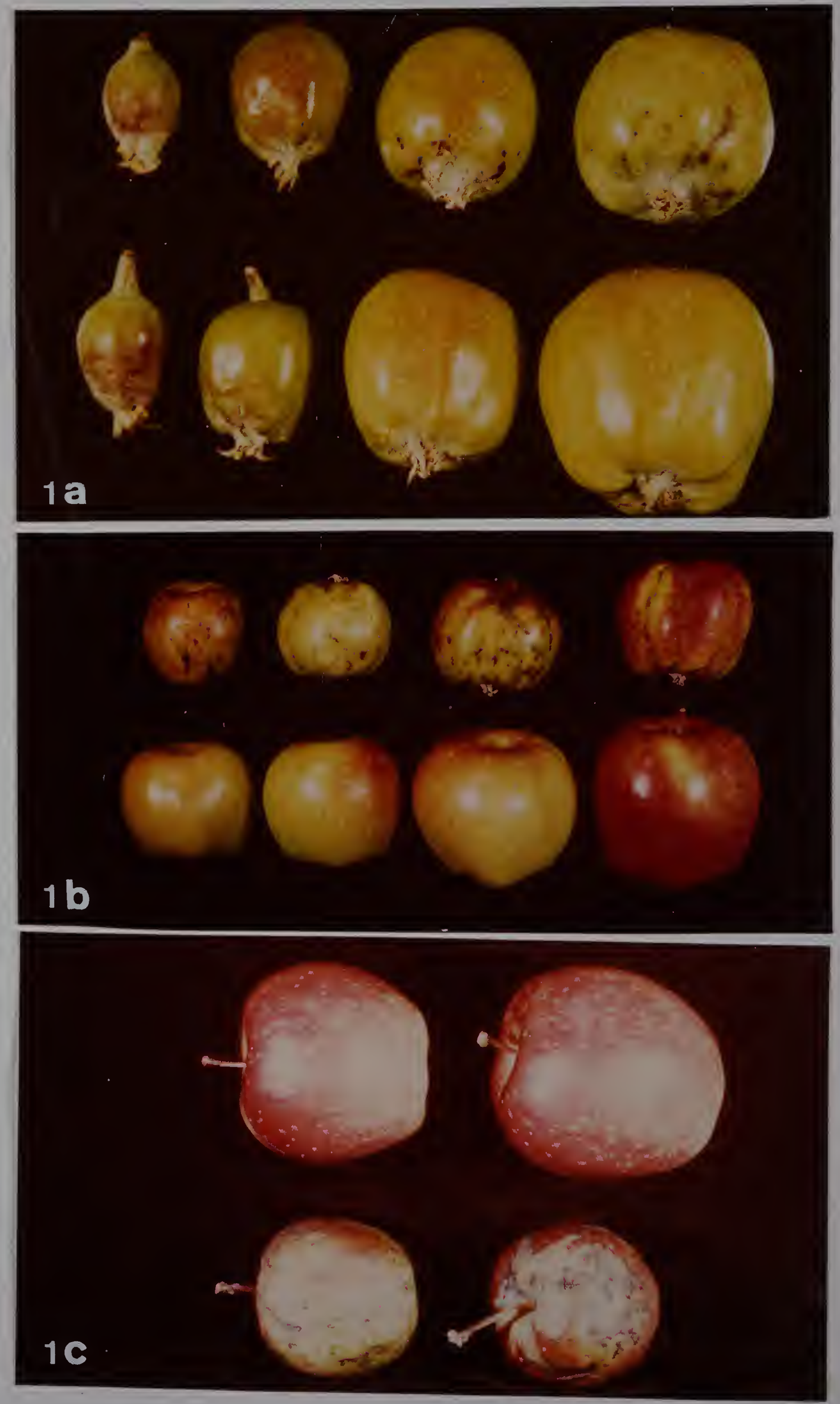
Figure 2. Sequential development of symptoms on dapple apple-infected Hyslop Crab apples (upper in $2 \mathrm{a}$ and $2 \mathrm{~b}$; lower in $2 \mathrm{c}$ ) as compared to healthy apple development (lower in $2 \mathrm{a}$ and $2 \mathrm{~b}$; upper in $2 \mathrm{c}$ ). Samples were taken at 10 day intervals from June 10 to July 10 (2a) and from July 20 to August 19 (2b) in 1975, and on september 18 and October 8, 1977 (2c). 


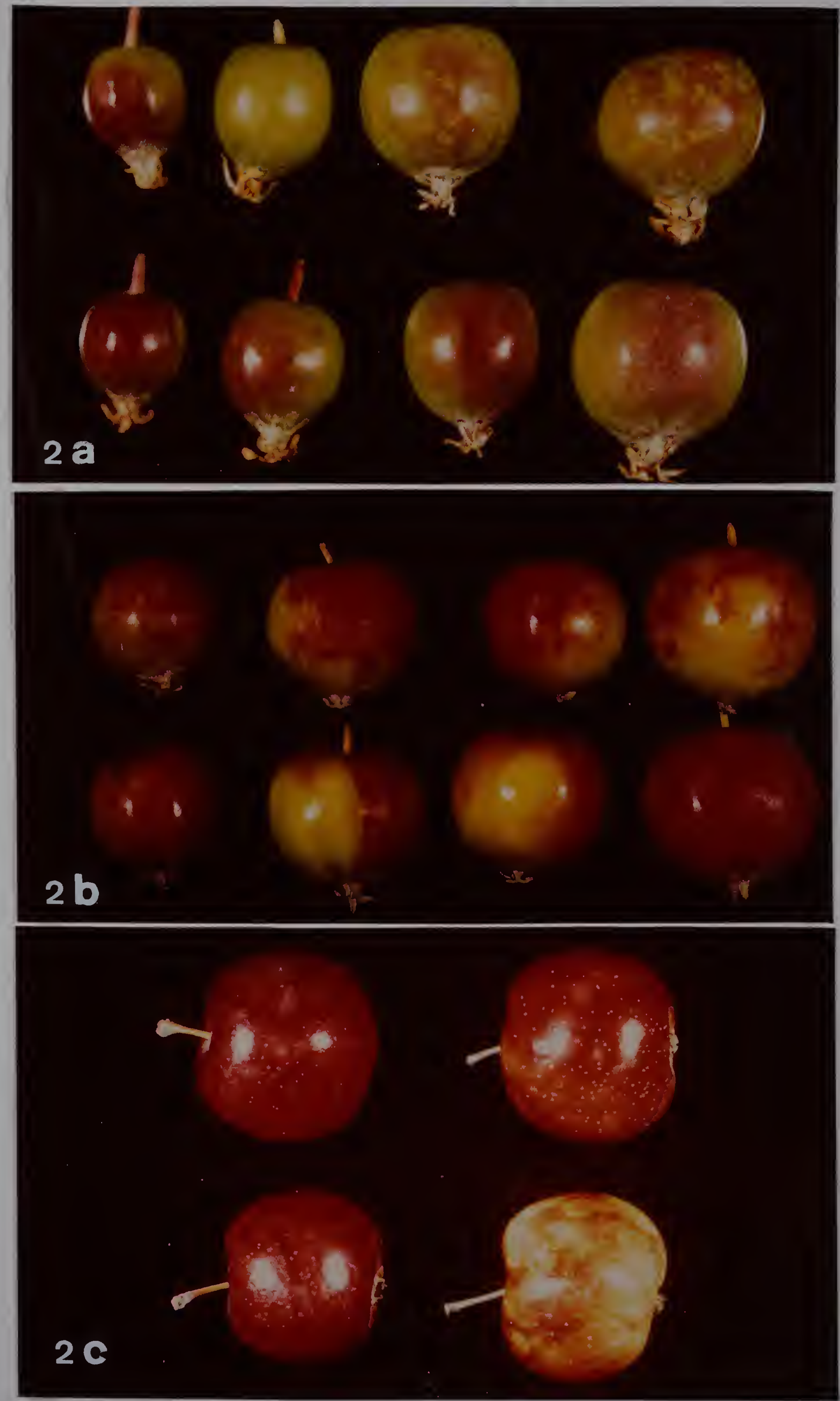




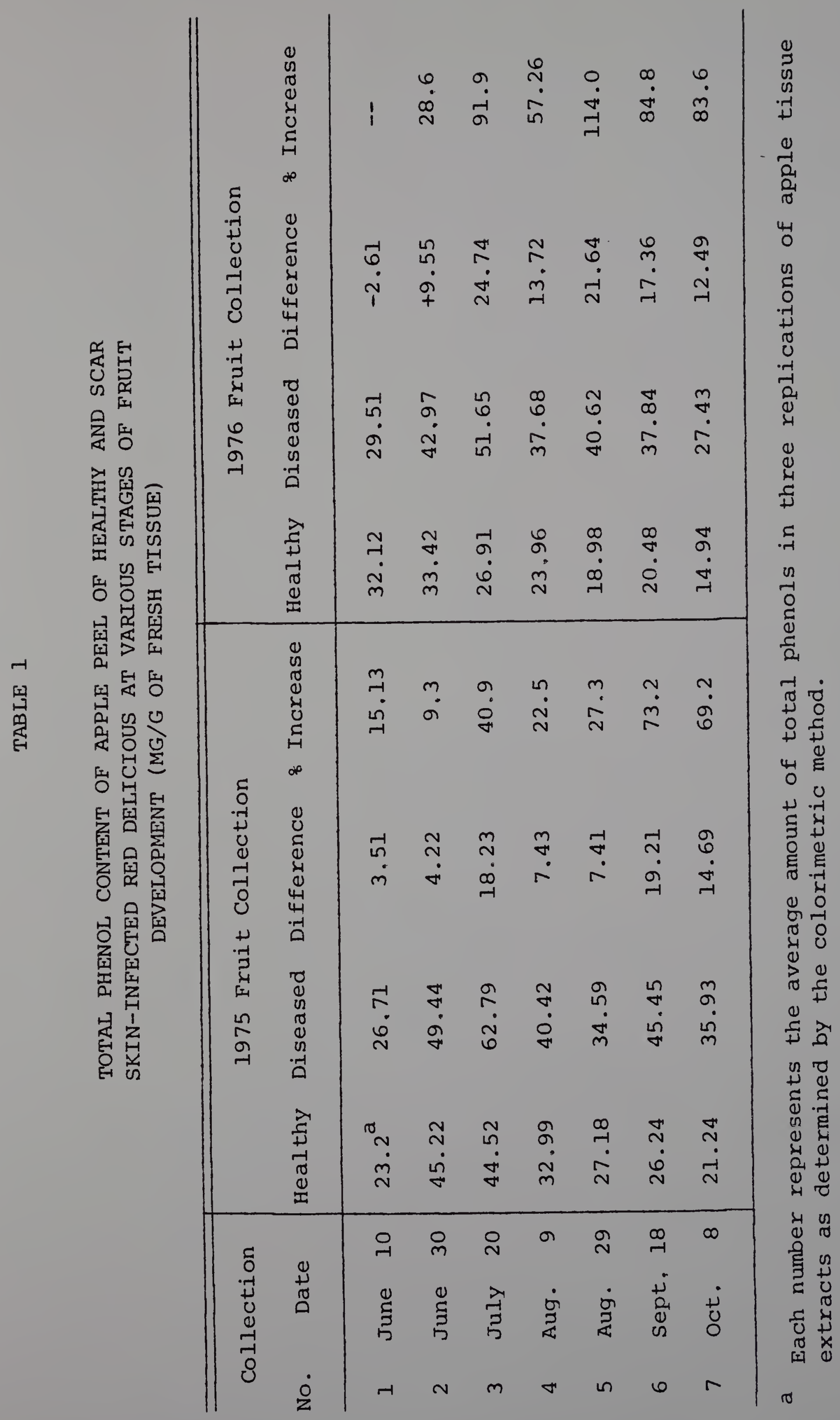


Figure 3. Changes in concentration of total phenols in the apple peel during development of healthy and scar skin-infected Red Delicious fruits. Each point represents the average of three replications; the bar represents the standard deviation of these measurements. Figure $3 a$ is Data of 1975 fruit samples; Figure $3 b$ is Data of 1976 fruit samples. 
0



a
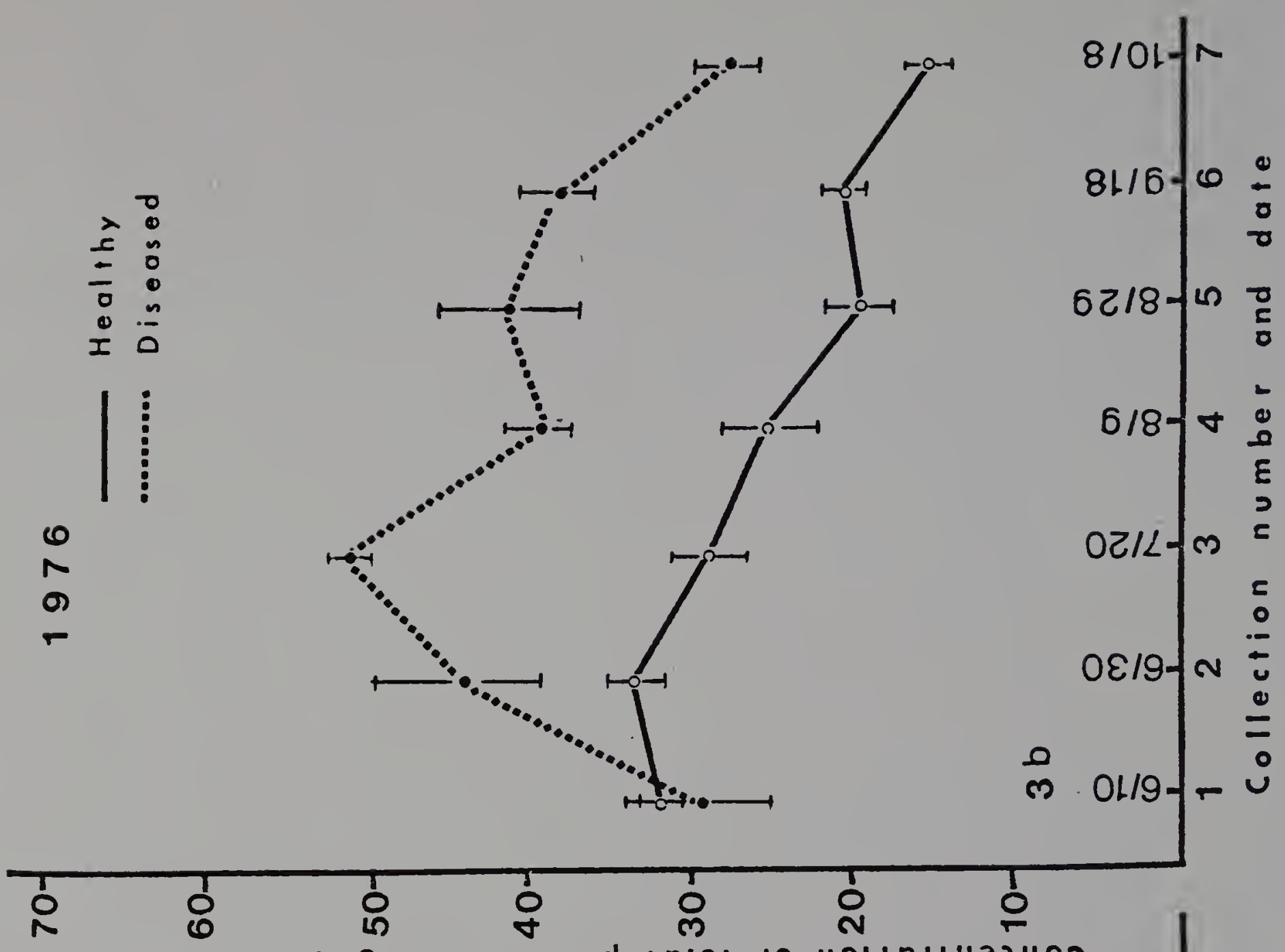

anss!t 4sadf to $6 / 6 \mathrm{~m}$ u! s/ouayd fotot fo lo!todfuasuog

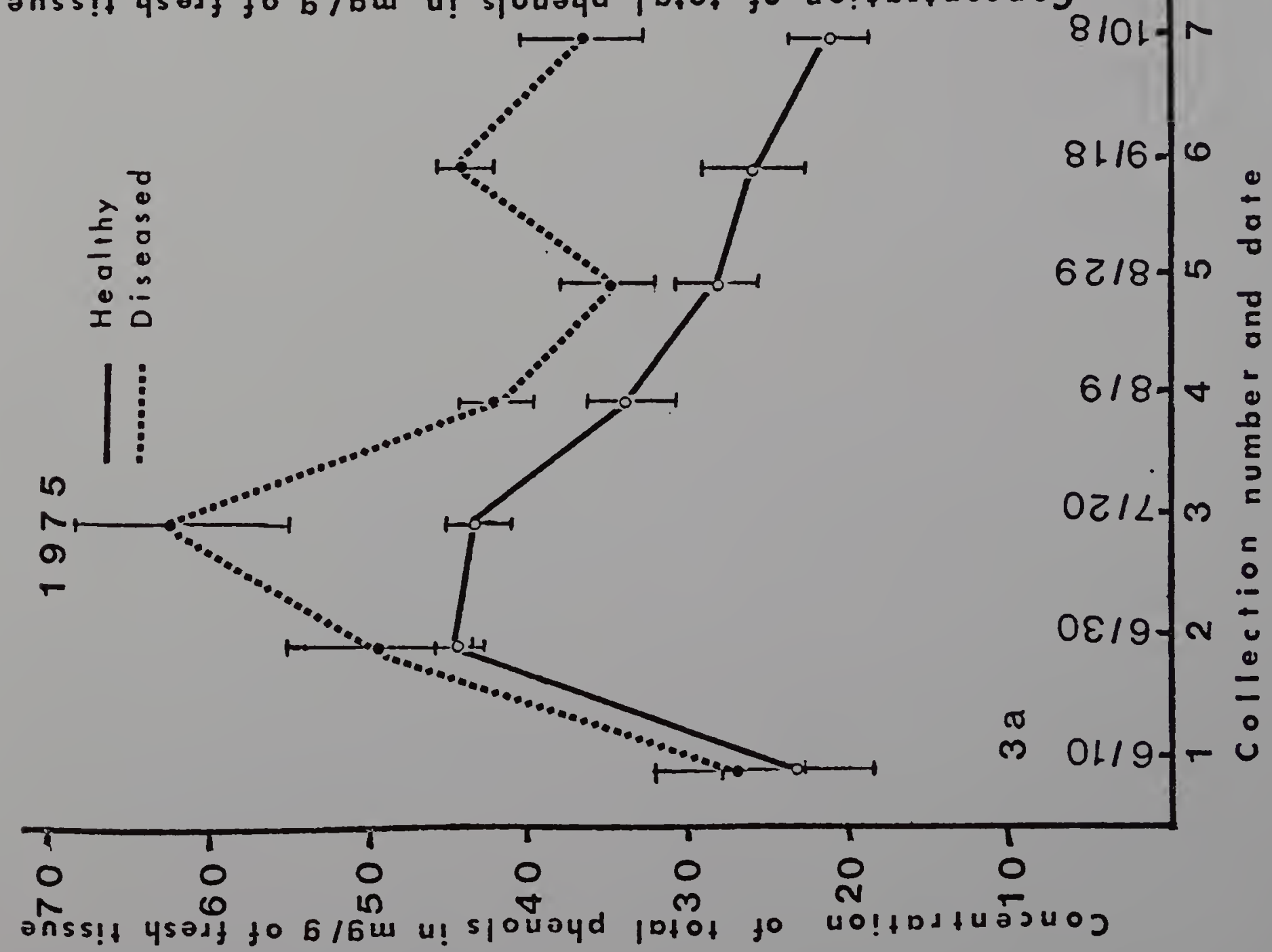


Effect of Dapple Apple on Total Phenols

No significant differences in the amount of total phenols was observed between healthy and dapple apple-infected Hyslop Crab apples (Table 2). The maximum concentration of total phenols in both healthy and diseased apples appeared at the second collection in 1975 and at the first collection in 1976. Subsequently, the concentration of total phenols decreased rapidly as fruit matured. The pattern of total phenol changes during fruit development was similar in both healthy and diseased apples (Figures $4 a$ and $4 b$ ).

\section{Chlorogenic Acids}

Effect of Scar Skin on Chlorogenic Acids

Determination of chlorogenic acids by the colorimetric method. As shown in Table 3 and Figure 5a, scar skin resulted in higher concentration of chlorogenic acids compared to healthy apples. The chlorogenic acid content of both healthy and diseased fruits reached a maximum at the third collection, and then decreased rapidly as fruits ripened. Increased accumulation of chlorogenic acids was detected in infected tissues at the first collection, when symptoms were not yet visible.

Determination of chlorogenic acids by paper chromatography. At least 9 bands were observed under UV light on one-way paper chromatograms of crude 95\% ethanolic extracts of apple peel (Figure 6). On the basis of the fluorescent color under UV light, these bands were classified into two groups: the group of yellow to brown bands and the group of blue fluorescent bands. The former ones were considered to be flavonols and 


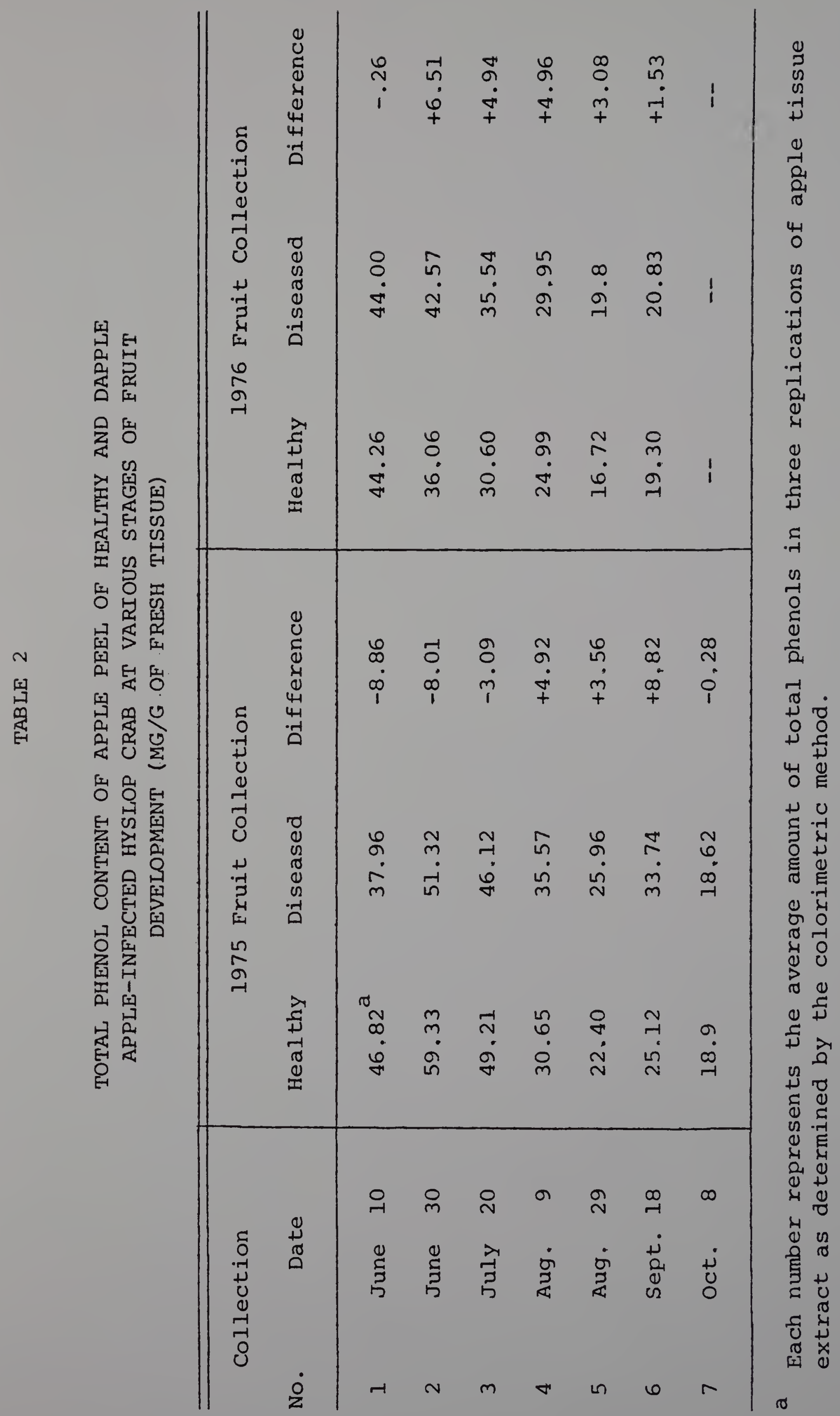


Figure 4. Changes in concentration of total phenols in the apple peel during development of healthy and dapple apple-infected Hyslop Crab fruits. Each point represents the average of three replications; the bar represents the standard deviation of these measurements. Figure $4 \mathrm{a}$ is Data of 1975 fruit samples; Figure $4 \mathrm{~b}$ is Data of 1976 fruit samples. 
$\begin{array}{rr}\lambda & 0 \\ = & 0 \\ 0 & 0 \\ 0 & 0 \\ 0 & 0 \\ 1 & 0 \\ 1 & \vdots \\ & \vdots\end{array}$
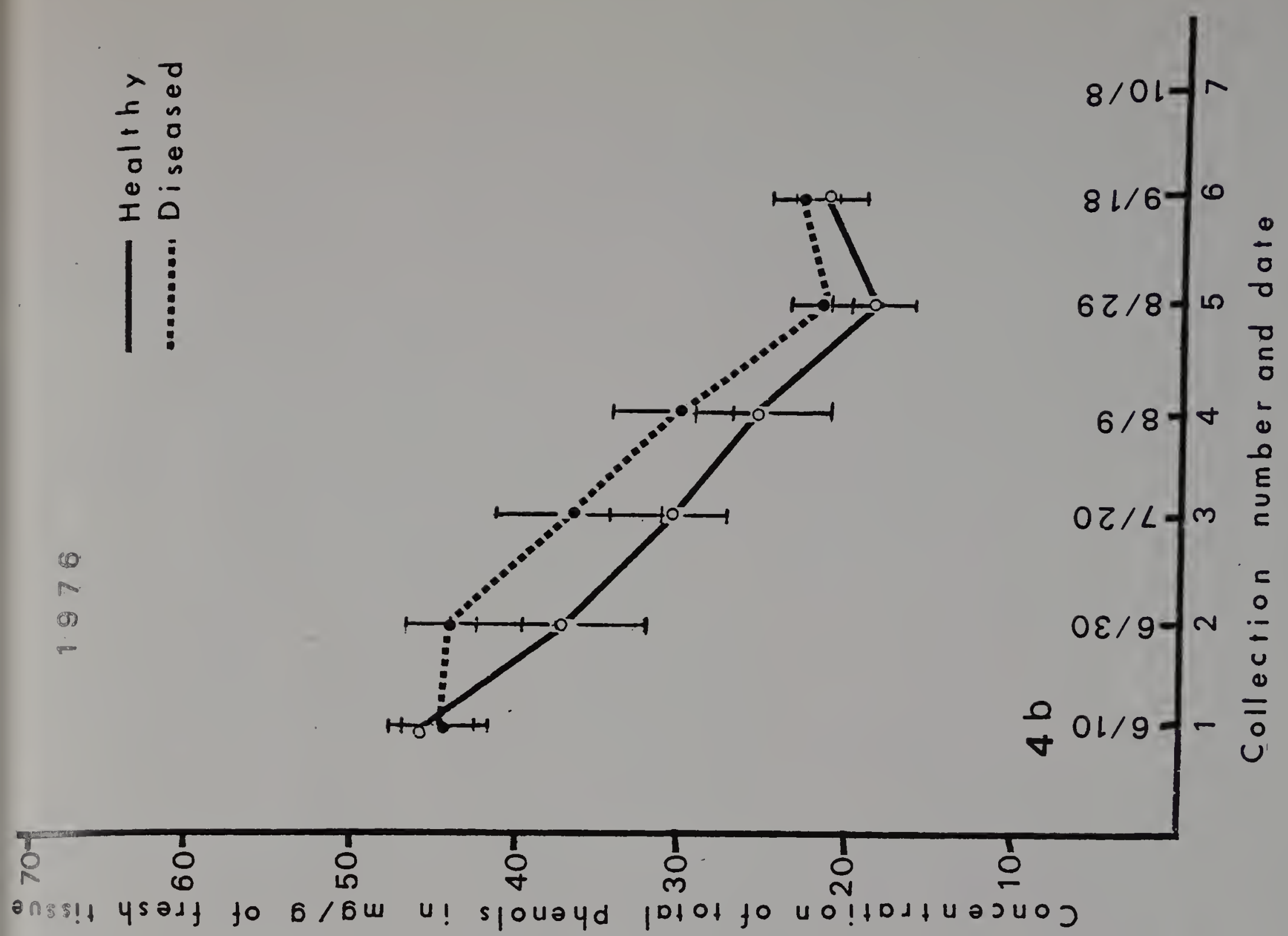

$\begin{array}{rr} & 0 \\ = & 0 \\ = & 0 \\ 0 & 0 \\ 0 & n \\ 1 & 0\end{array}$

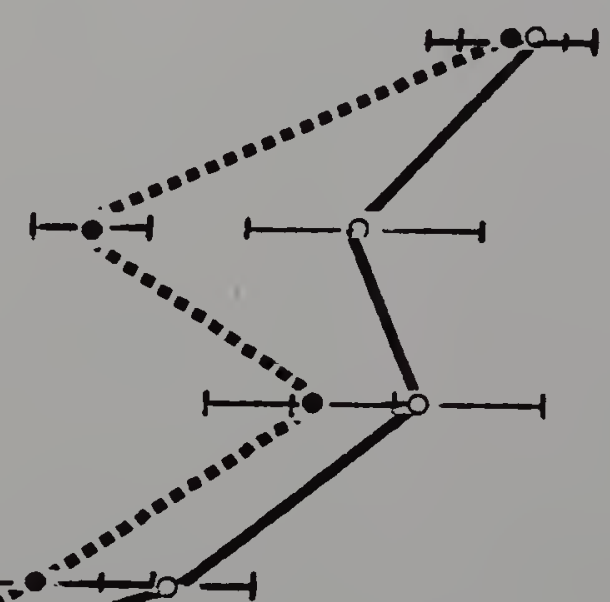

$8 / 01-1$

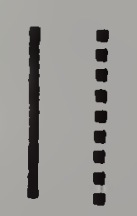

10

10

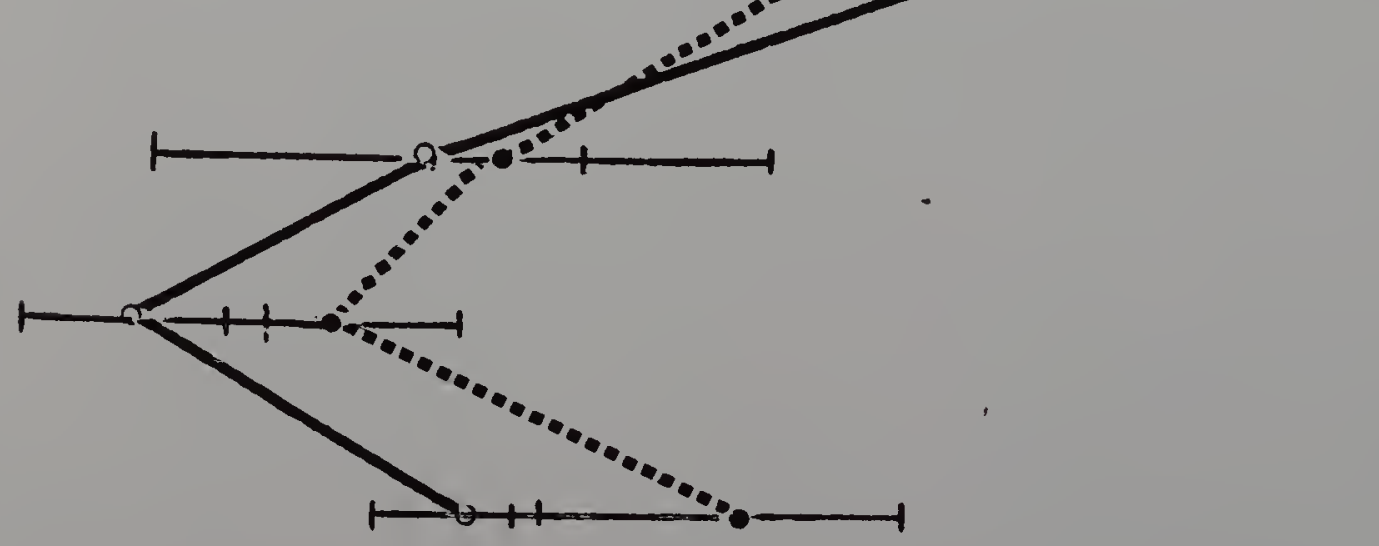

$\stackrel{1}{1}$ 
TABLE 3

CHLOROGENIC ACID CONTENT OF PEEL OF

HEALTHY AND SCAR SKIN-INFECTED RED

DELICIOUS APPLES AT VARIOUS STAGES

OF FRUIT DEVELOPMENT (MG/G OF FRESH

TISSUE)

\begin{tabular}{llccccc}
\hline \multicolumn{2}{c}{$\begin{array}{c}\text { Collection } \\
\text { No. }\end{array}$} & Date & Healthy & Diseased & Difference & \% Increase \\
\hline 1 & June 10 & $11.02^{\mathrm{a}}$ & 12.82 & 1.8 & 16.3 \\
2 & June & 30 & 11.37 & 13.37 & 2.0 & 17.6 \\
3 & July 20 & 12.27 & 17.50 & 5.23 & 42.6 \\
4 & Aug. & 9 & 8.41 & 13.16 & 4.75 & 56.5 \\
5 & Aug. 29 & 5.73 & 8.38 & 2.65 & 46.2 \\
6 & Sept. 18 & 5.93 & 10.61 .98 & 4.68 & 78.9 \\
\hline
\end{tabular}

a Each number represents the average amount of chlorogenic acids in three replications of apple tissue extracts as determined by the colorimetric method. 
Figure 5. Changes in concentration of chlorogenic acids in the apple peel during development of healthy and scar skin-infected Red Delicious. Each point represents the average of three replications in Figure $5 a$ and two replications in Figures $5 b$ and $5 c$. The bar in Figure $5 a$ represents the standard deviation of these measurements. Figure $5 a$ is in crude extracts; Figure $5 b$ is in band chromatographically separated from $95 \%$ ethanol extracts; Figure $5 \mathrm{c}$ is in band chromatographically separated form ethyl ether and ethyl acetate extracts. 


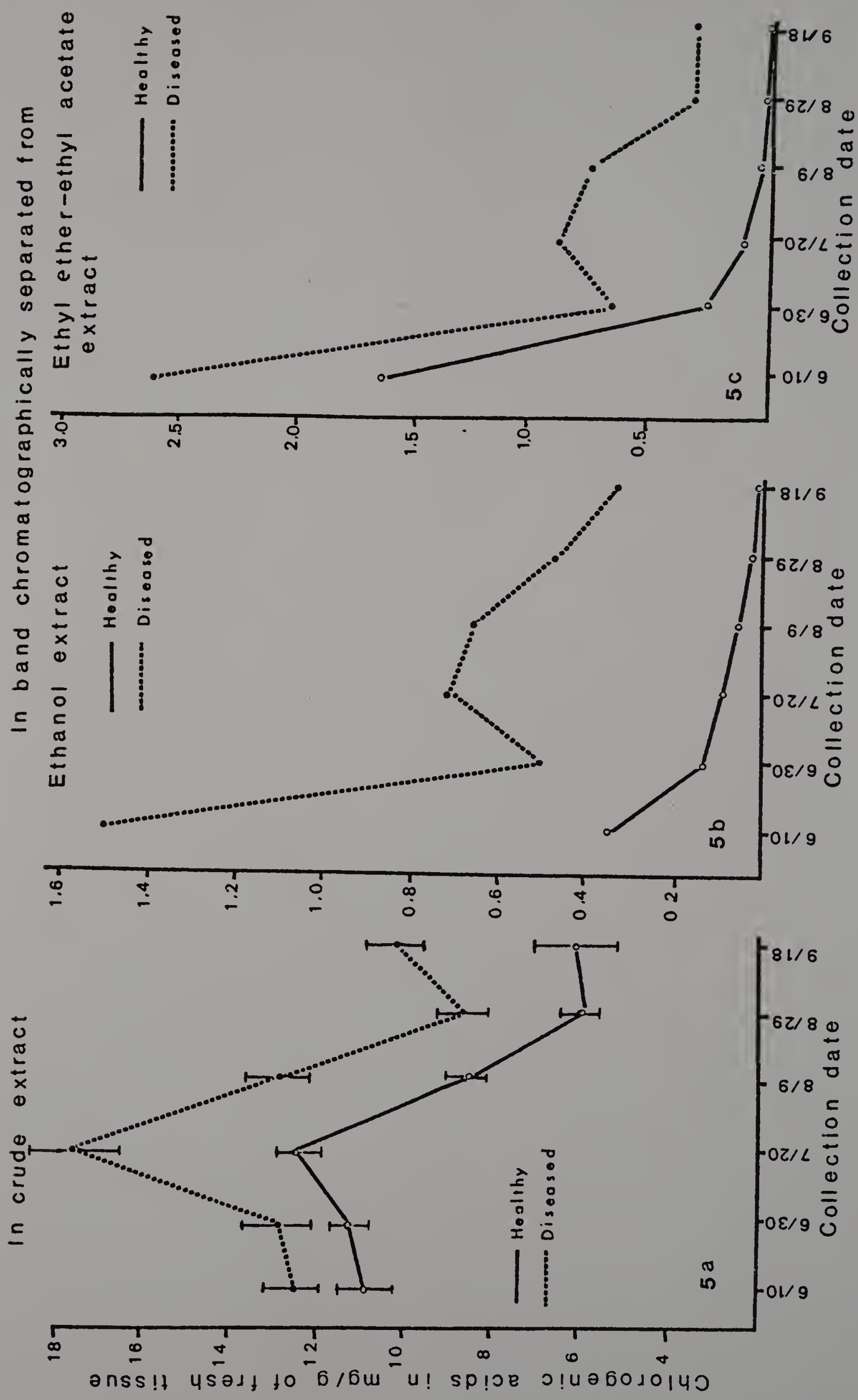


Figure 6 . One-way chromatograms of $95 \%$ ethanol extracts containing chlorogenic acids from pairs of healthy and scar skin-infected Red Delicious apples. Each pair of streaks from left to right represent samples of healthy (left) and infected (right) fruit collected at 20-day intervals starting June 10 and ending October 8, 1976. Figure 6a was photographed in UV light; Figure $6 \mathrm{~b}$ was marked with pencil under UV light and photographed in visible light. 


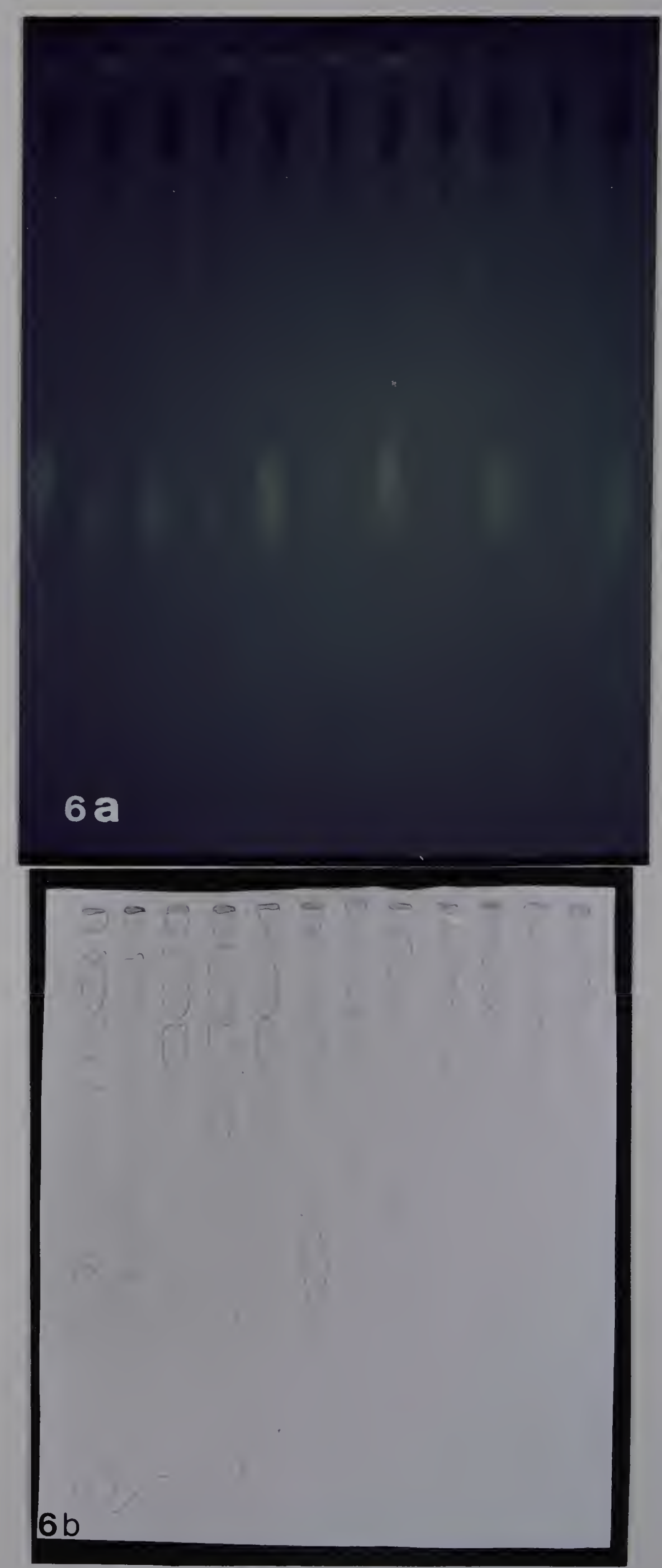


the latter phenolic acids. Paper chromatograms of scar skin-infected extracts showed differences in the color intensity of certain blue fluorescent bands. The changes in the bright blue band labelled as band 6 were particularly prominent. In healthy apples, band 6 showed a sharp decrease in color intensity as the apples enlarged and it disappeared in the later stages of fruit growth. In diseased fruit, the same band retained its bright color intensity throughout the period of fruit growth. This indicated that components of band 6 , which was later identified as chlorogenic acids, accumulated in infected tissues. The changes in the concentration of band 6 components were determined and plotted on Figure $5 b$ and clearly show the differences in chlorogenic acid concentration in healthy and in diseased fruit. The increase of chlorogenic acids in scar skin-infected fruit ranged from 2 to 15 times that of the control (Table 4) and became evident before symptoms were visible. Similar results were obtained from chromatography of chlorogenic acids from ethyl ether and ethyl acetate extracts obtained primarily for the determination of flavonols (Figure 5c). However, the pattern of changes and the quantities of chlorogenic acids obtained after chromatographic separation of the bands were quite different from those measured in crude extracts by the colorimetric method. Much smaller amounts of chlorogenic acids were detected after paper chromatography than in crude extracts and the maximum concentration appeared at the first instead of the third collection. Components of band 6 were further resolved into two bands with $3 \%$ acetic acid. These bands were indicated as band $6_{A}$ and $6_{B}$. Band 5 also appeared brighter in the diseased than in the healthy apple extracts at the third, fourth, and fifth collections 
TABLE 4

CONCENTRATION OF CHROMATOGRAPHICALLY SEPARATED CHLOROGENIC ACIDS OBTAINED

FROM 95\% ETHANOL EXTRACTS OF APPLE

PEEL OF HEALTHY AND SCAR SKIN-INFECTED

RED DELICIOUS AT VARIOUS STAGES OF

FRUIT DEVELOPMENT (MG/G OF FRESH TISSUE)

Collection

\begin{tabular}{llccccc} 
No. & \multicolumn{2}{c}{ Date } & Healthy & Diseased & . Difference & \% Increase \\
\hline 1 & June & 10 & 0.334 & 1.50 & 1.166 & 349.1 \\
2 & June & 30 & 0.157 & 0.523 & 0.366 & 233.1 \\
3 & July & 20 & 0.087 & 0.733 & 0.646 & 742.5 \\
4 & Aug. & 9 & 0.070 & 0.680 & 0.610 & 871.4 \\
5 & Aug. & 29 & 0.028 & 0.471 & 0.443 & 1582.1 \\
6 & Sept. 18 & 0.031 & 0.349 & 0.318 & 1024.8 \\
\hline
\end{tabular}


(Figure 10b, see paragraph on flavonols), but its identity and quantity were not determined.

Attempts at identification of band 6 component. On the basis of Rf values in several solvents, the reaction of color reagents and the color under UV light, the component of band ${ }_{A}$ was indistinguishable from authentic chlorogenic acid (Table 6). Also, the UV absorption spectrum of band $6_{A}$ component was in agreement with that of chlorogenic acid. Band $\sigma_{B}$ component had the same $R f$ values as did caffeic acid in $3 \%$ acetic acid and BAW solvent.

\section{Effect of Dapple Apple on Chlorogenic Acid}

Determination of chlorogenic acids by the colorimetric method. No significant difference in the quantity or in the pattern of changes of chlorogenic acid content was observed in healthy and in dapple appleinfected apples. The chlorogenic acid content of both healthy and diseased apples decreased rapidly as the fruits matured (Figure 7a, Table 7).

Determination of chlorogenic acids by paper chromatography. The crude extracts of both healthy and diseased apples were separated by paper chromatography into 7 bands (Figure 8). Paper chromatography showed no significant difference in the major phenolic acid components of healthy and dapple apple-infected apples. The amount of the brightest blue fluorescent band referred to as band 6 was determined (Table 8). Figure $7 \mathrm{~b}$ illustrates the pattern of changes of band 6 in infected and uninfected fruits. In contrast to the observations in Red Delicious (Figures 5 and 6), this component was still present in fairly high 


\title{
TABLE 5
}

\begin{abstract}
CONCENTRATION OF CHROMATOGRAPHICALLY
SEPARATED CHLOROGENIC ACIDS OBTAINED

FROM ETHYL ETHER AND ETHYL ACETATE EXTRACTS

OF APPLE PEEL OF HEALTHY AND SCAR SKIN-

INFECTED RED DELICIOUS AT VARIOUS STAGES

OF FRUIT DEVELOPMENT (MG/G OF .FRESH. TISSUE)
\end{abstract}

\begin{tabular}{|c|c|c|c|c|c|c|}
\hline \multicolumn{3}{|c|}{ Collection } & \multirow[b]{2}{*}{ Heal thy } & \multirow[b]{2}{*}{ Diseased } & \multirow[b]{2}{*}{ Difference } & \multirow[b]{2}{*}{ \& Increased } \\
\hline No. & $\mathrm{Da}$ & te & & & & \\
\hline 1 & June & 10 & 1.65 & 2.71 & +1.06 & 64.24 \\
\hline 2 & June & 30 & 0.215 & 0.687 & +0.472 & 219.5 \\
\hline 3 & July & 20 & 0.114 & 0.850 & +0.736 & 646.6 \\
\hline 4 & Aug. & 9 & 0.044 & 0.733 & +0.689 & 1565.9 \\
\hline 5 & Aug. & 29 & 0.029 & 0.308 & +0.279 & 962.1 \\
\hline 6 & Sept. & 18 & 0.023 & 0.308 & +0.285 & 1239.1 \\
\hline
\end{tabular}




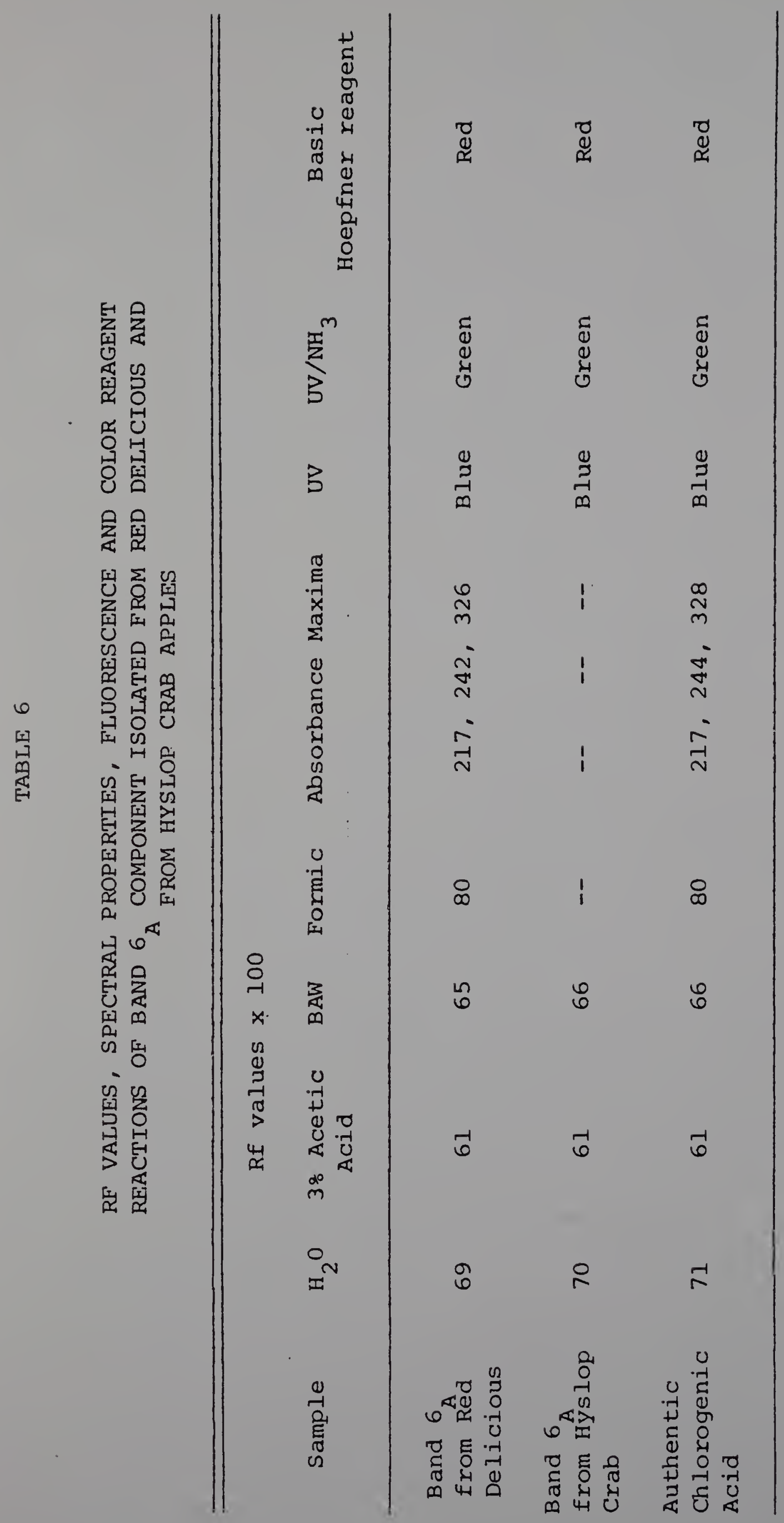


Figure 7. Changes in concentration of chlorogenic acids in the apple peel during development of healthy and dapple apple-infected Hyslop crab fruits. Each point represents the average of three replications in Figure $7 a$ and two replications in Figures $7 b$ and $7 c$. The bar in Figure $7 a$ represents the standard deviation of these measurements. Figure $7 a$ is in crude extracts; Figure $7 \mathrm{~b}$ is in band chromatographically separated from $95 \%$ ethanol extracts; Figure $7 \mathrm{c}$ is in band chromatographically separated from ethyl ether and ethyl acetate extracts. 


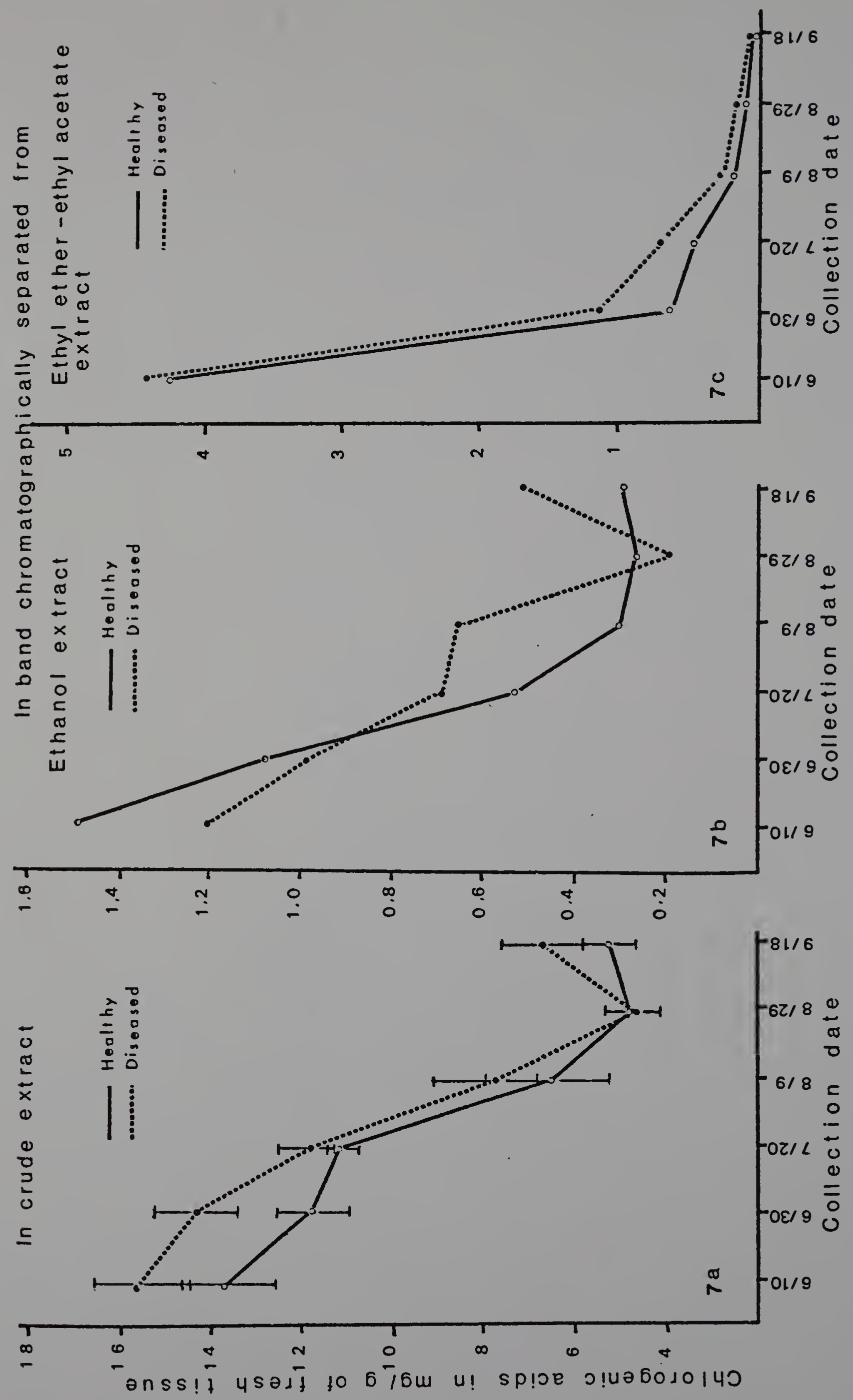


CHLOROGENIC ACID CONTENT OF APPLE PEEL

OF HEALTHY AND DAPPLE APPLE-INFECTED

HYSIOP CRAB AT VARIOUS STAGES OF FRUIT

DEVELOPMENT (MG/G OF FRESH TISSUE)

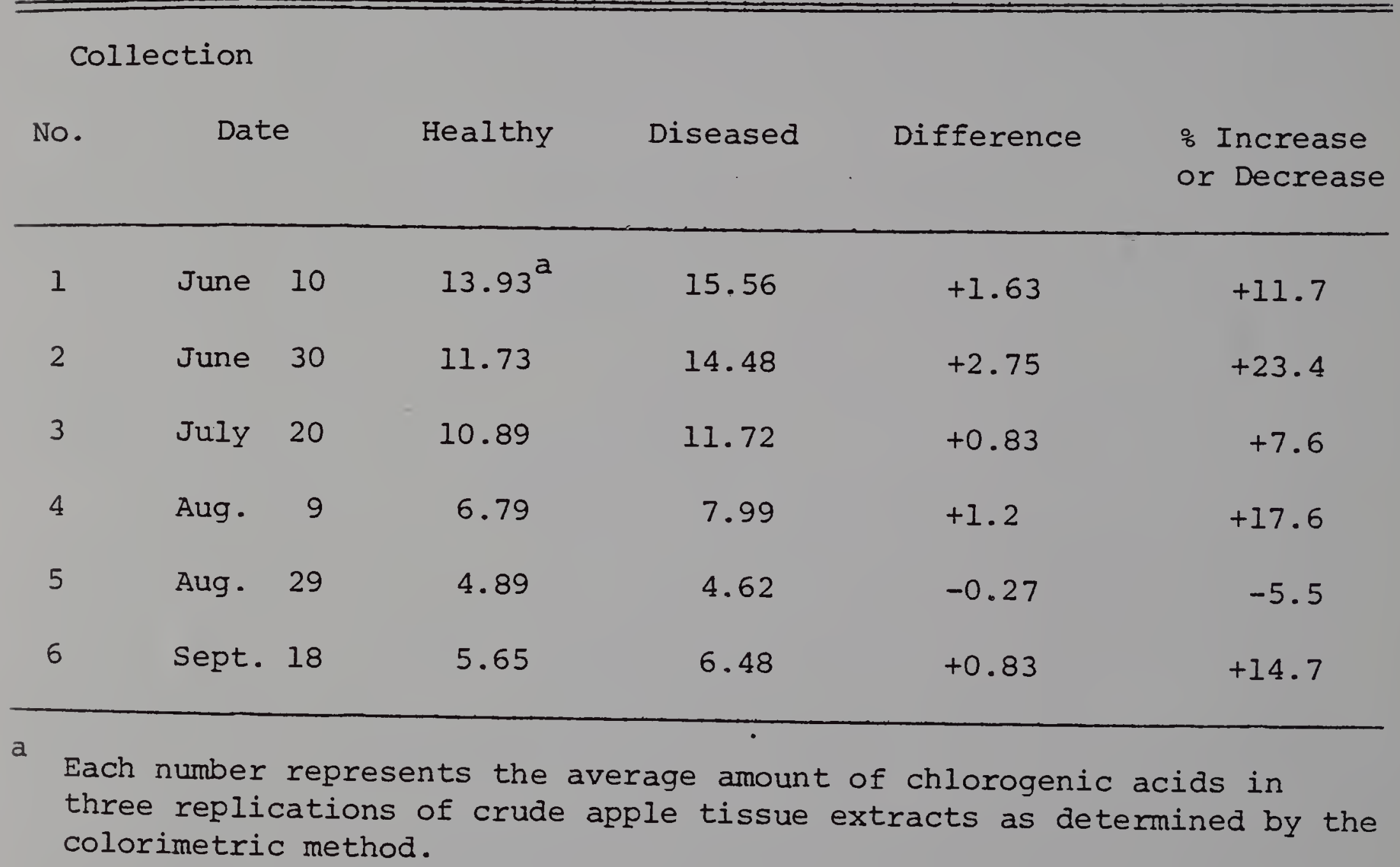


Figure 8. One-way chromatograms of $95 \%$ ethanol extracts containing chlorogenic acids from healthy and dapple apple-infected Hyslop Crab apples. Each pair of streaks from left to right represent healthy (left) and diseased (right) fruit samples from fruits collected at 20-day intervals starting June 10 and ending October 8, 1976. 
48

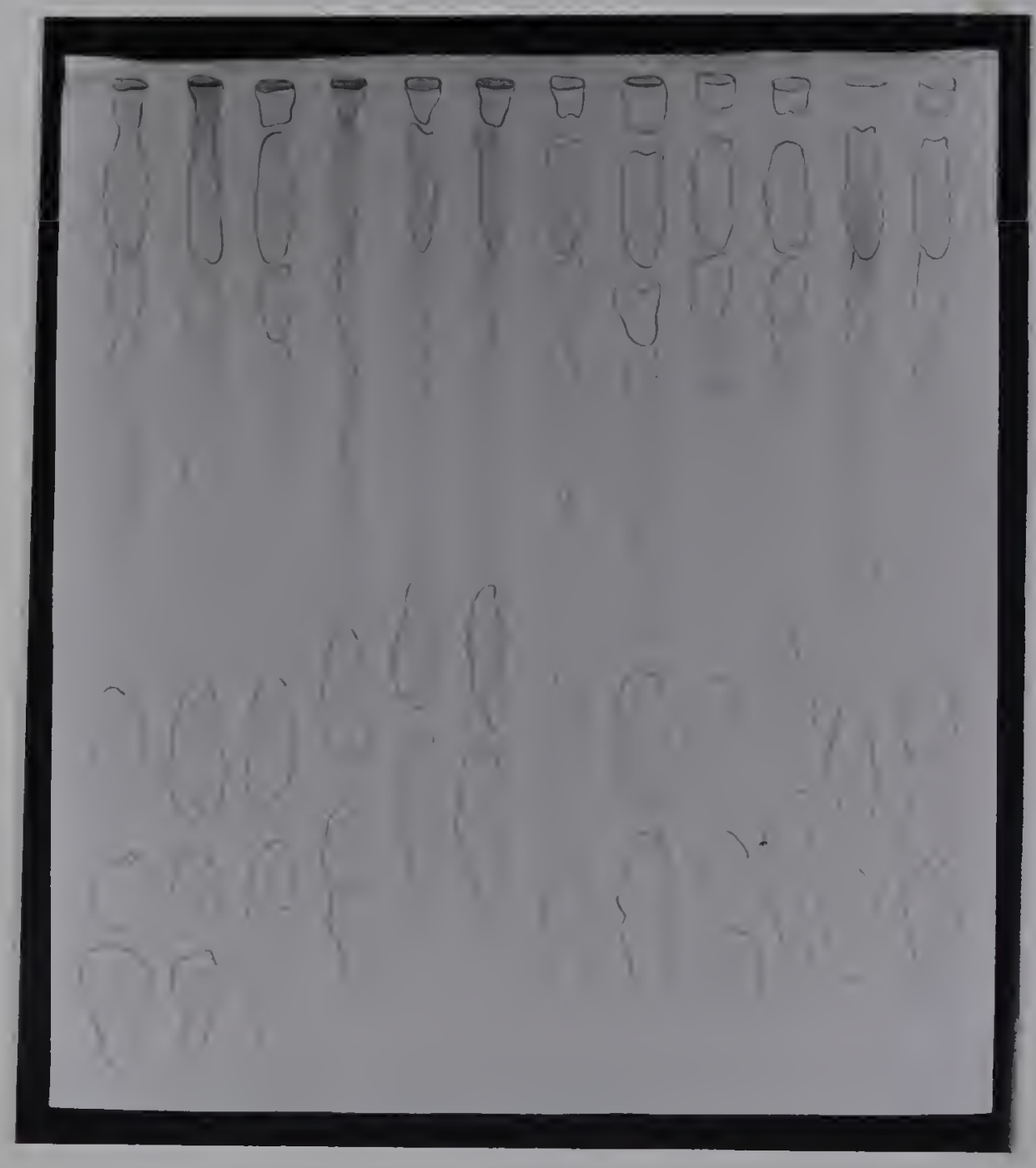


TABLE 8

CONCENTRATION OF CHROMATOGRAPHICALLY SEPARATED CHLOROGENIC ACIDS OBTAINED FROM 95\% ETHANOL EXTRACTS OF APPLE PEEL OF HEALTHY AND DAPPLE APPLE-INFECTED HYSLOP CRAB AT VARIOUS STAGES OF FRUIT DEVELOPMENT (MG/G. OF FRESH TISSUE)

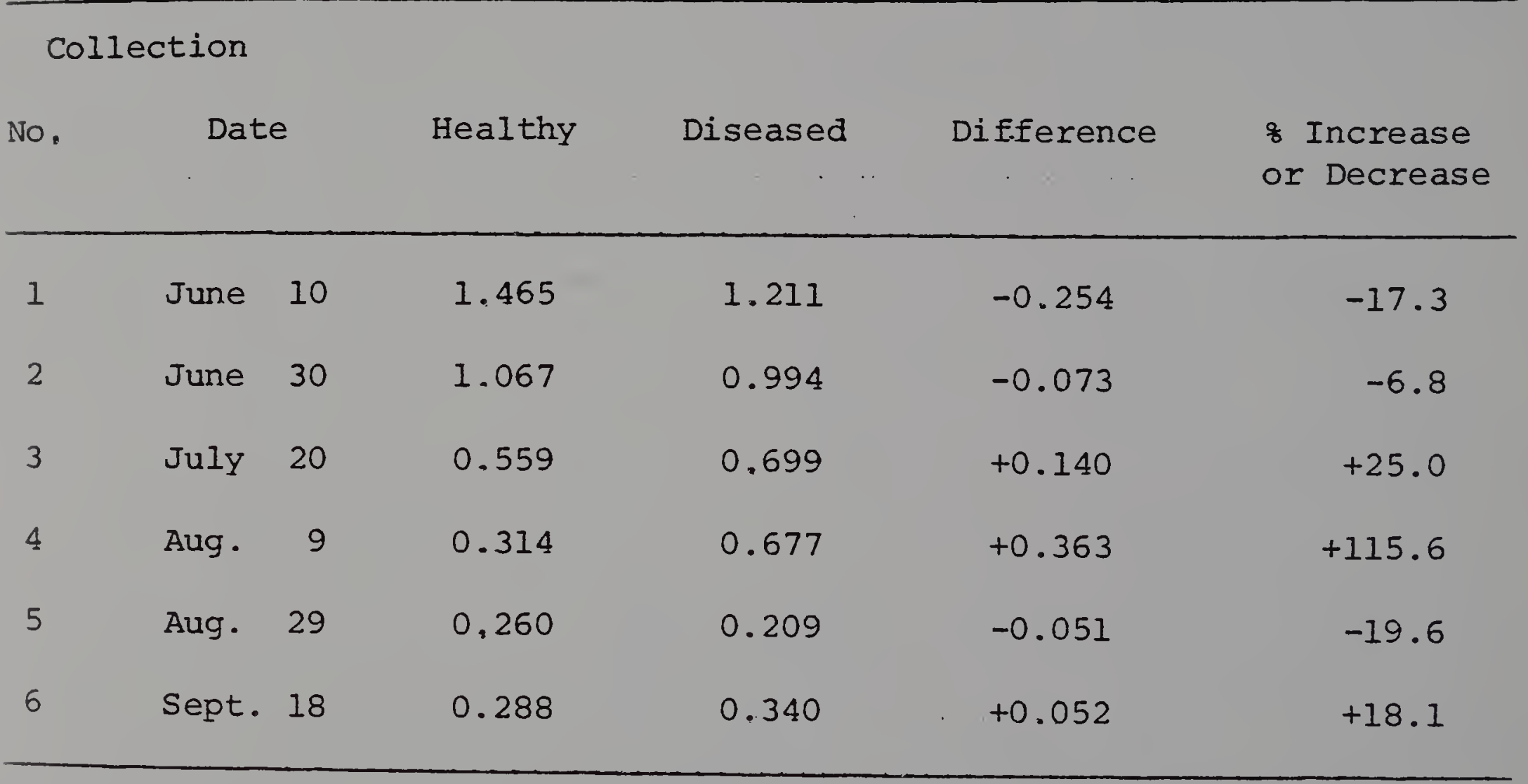


concentration in peels of mature healthy fruits of Hyslop Crab. Chromatography of chlorogenic acids from ethyl ether and ethyl acetate extracts obtained primarily for flavonols showed a similar pattern of changes. (Table 9, Figure 13, see paragraph on flavonols). Band 6 component was further separated into two bands, band $\sigma_{A}$ and band $\sigma_{B}$. Attempts at identification of the band 6 component. Band 6 A component from crab apples appeared to be identical to chlorogenic acid on the basis of $\mathrm{Rf}$ values in several solvent systems, the reaction with color reagents, and the color under UV light (Table 6). Band $6_{B}$ was not further characterized.

\section{Flavonols}

\section{Effect of Scar Skin on Flavonols.}

Determination of flavonols by the colorimetric method. The concentration of flavonols in healthy apples varied with the stages of fruit development (Table 10, Figures $9 a$ and $9 b$ ). It reached a maximum level at the second collection and subsequently it decreased slightly as fruits ripened. Scar skin-infected apples contained considerably higher levels of flavonols than did healthy apples. The increase in flavonols became evident at the second collection, when symptoms had just begun to appear, and remained steadily higher throughout the growing season. The flavonol content of diseased apples was higher by $30.2-98.5 \%$ in 1975 and by $40.4-98.28$ in 1976 as compared to healthy apples (Table 10).

\section{Determination of flavonols by paper chromatography. Paper}

chromatography of ethyl ether and ethyl acetate apple extracts containing the flavonols gave at least 9 bands (Figure $10 \mathrm{a}$ and 10b). The bands are 
TABLE 9

CONCENTRATION OF CHROMATOGRAPHICALLY SEPARATED CHLOROGENIC ACIDS OBTAINED

FROM ETHYL ETHER AND ETHYL ACETATE

EXTRACTS OF APPLE PEEL OF HEALTHY AND

DAPPLE APPLE INFECTED HYSLOP CRAB AT

YARIOUS STAGES OF FRUIT DEVELOPMENT

(MG/G OF FRESH TISSUE).

\begin{tabular}{|c|c|c|c|c|c|c|c|}
\hline \multicolumn{3}{|c|}{ collection } & \multirow[b]{2}{*}{ Healthy } & \multirow[b]{2}{*}{ Diseased } & \multirow[b]{2}{*}{ Difference } & \multirow[b]{2}{*}{8} & \multirow[b]{2}{*}{ Increase } \\
\hline No. & Dat & & & & & & \\
\hline 1 & June & 10 & 4.36 & 4,42 & 0.06 & & 1.3 \\
\hline 2 & June & 30 & 0.61 & 1.12 & 0.51 & & 83.6 \\
\hline 3 & July & 20 & 0.57 & 0.73 & 0.16 & & 28.1 \\
\hline 4 & Aug, & 9 & 0.25 & 0.35 & 0.10 & & 40.0 \\
\hline 5 & Aug. & 29 & 0.22 & 0.30 & 0.08 & & 36.0 \\
\hline 6 & Sept. & 18 & 0.19 & 0.23 & 0.04 & & 21.1 \\
\hline
\end{tabular}




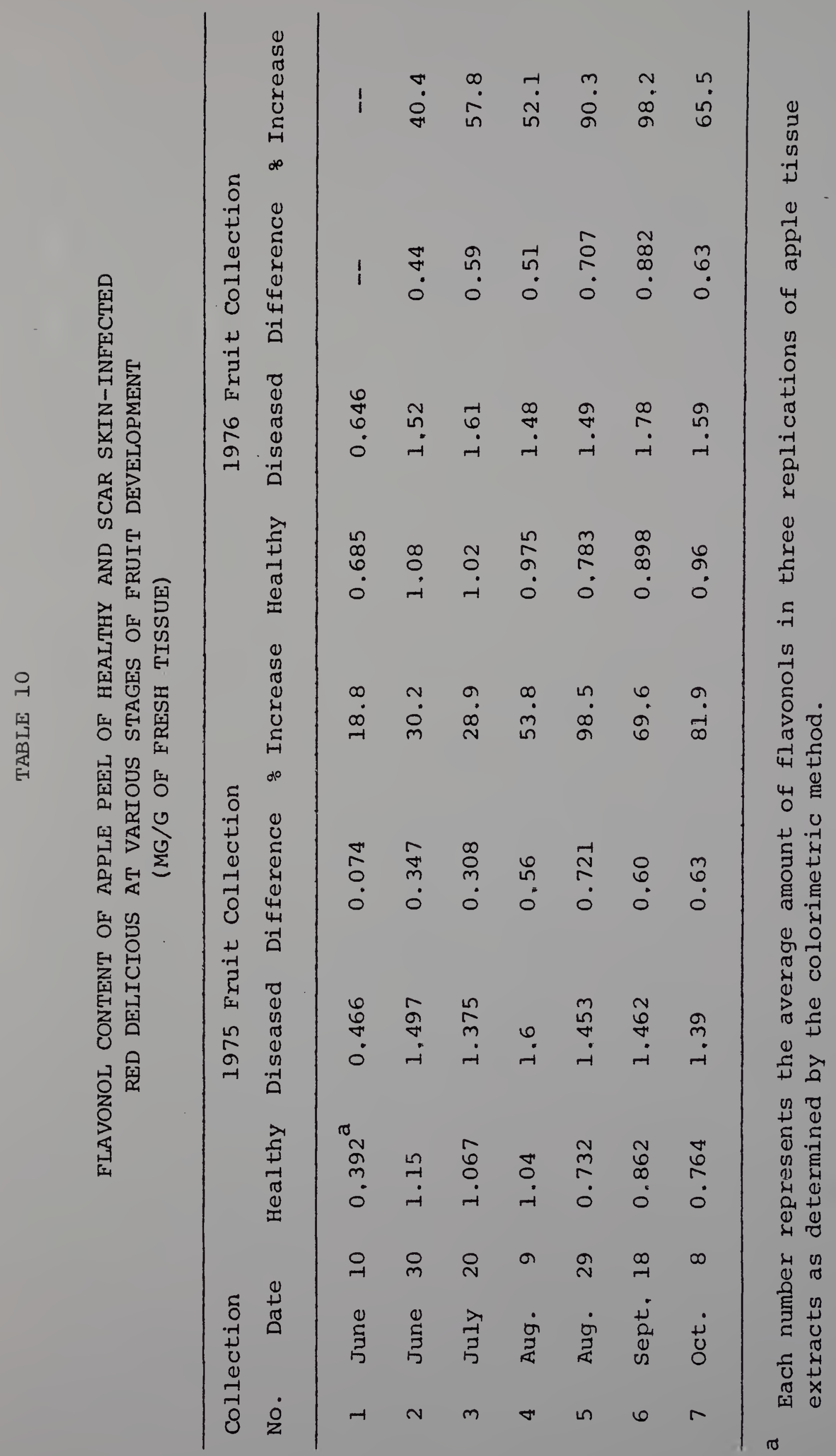


Figure 9. Changes in concentration of flavonols in the apple peel during development of healthy and scar skin-infected Red Delicious fruit. Each point represents the average of three replications; the bar represents the standard deviation of these measurements. Figure 9a is Data of 1975 fruit samples; Figure $9 b$ is Data of 1976 fruit samples. 

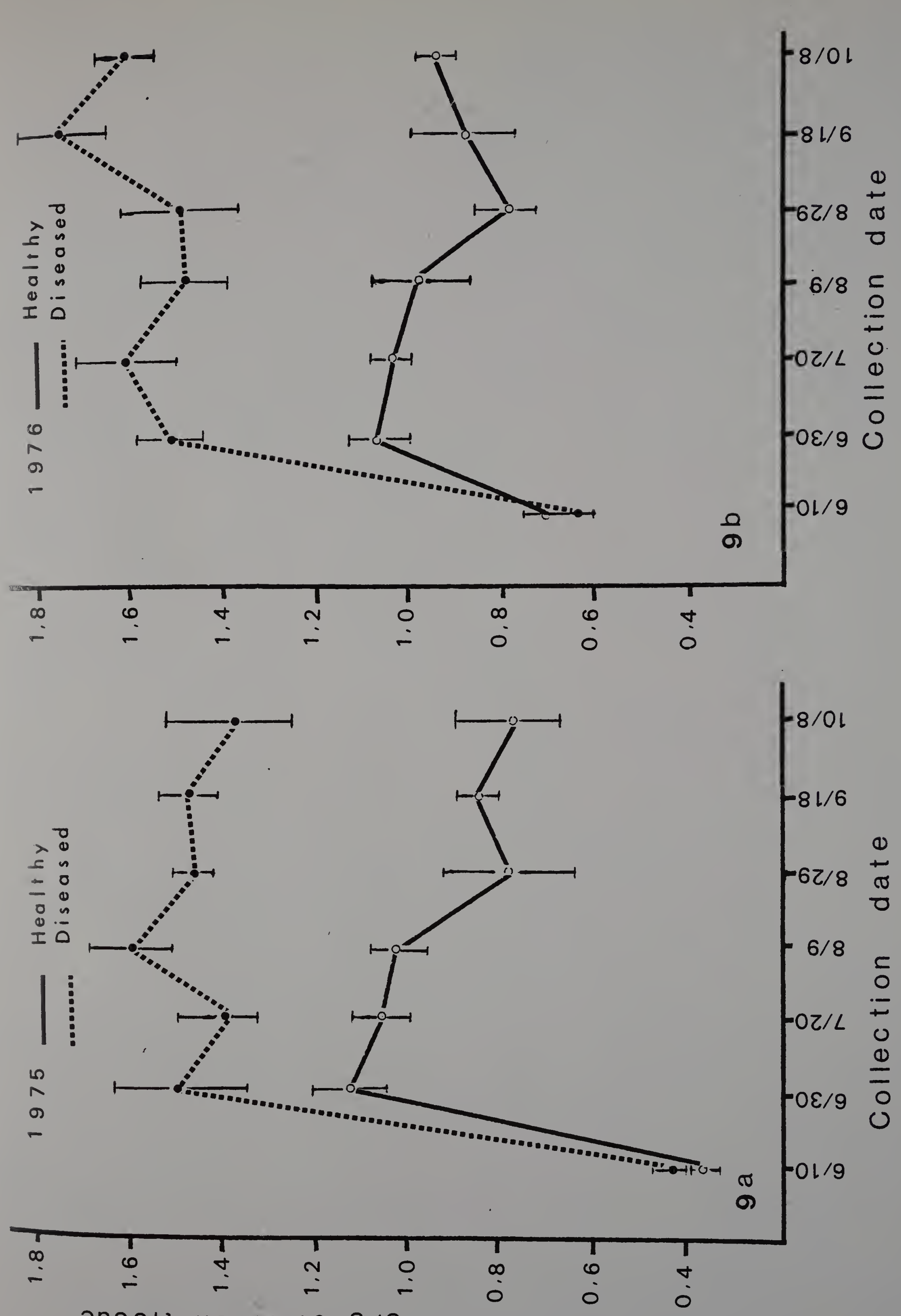

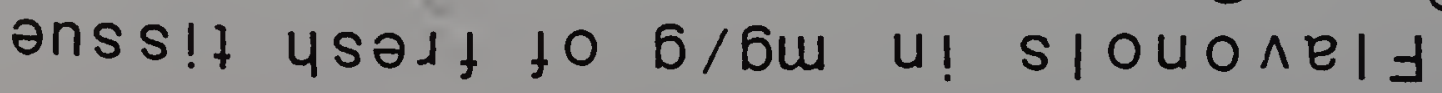


Figure 10. One-way chromatograms of ethyl ether and ethyl acetate extracts containing flavonols and chlorogenic acids from healthy and scar skin-infected Red Delicious apples. Each pair of streaks from left to right represent healthy (left) and diseased (right) samples from fruits collected at 20-day intervals starting June 10 and ending October 8, 1976. Figure 10a is photographed in UV light; Figure 10b is marked with pencil under UV light and photographed in visible light. 
10 a

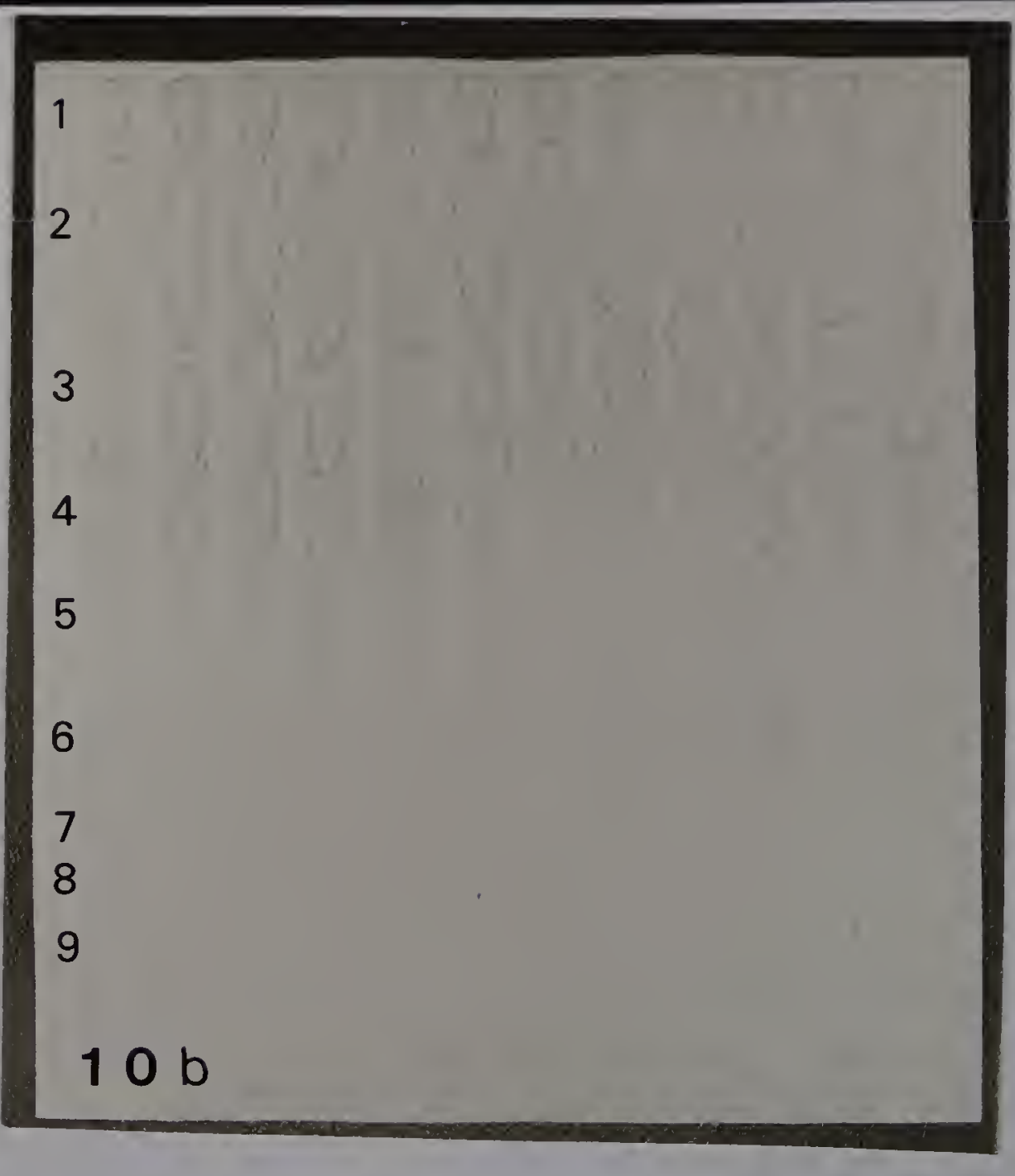


indicated as band $1,2,3$, and 9 in Figure 10. No obvious differences in the major components of healthy and diseased apples was detected except for certain blue fluorescent bands which were considered as phenolic acids. Bands 1, 2, 3, and 4 were found in all fruit collections. Bands 2 and 3 were the major components of flavonols and their quantities were determined. The amount of band 2 was noticeably higher in the diseased than in the healthy apples (Table 11). The pattern of changes of band 2 was similar to that of total flavonols (Figure lla). Band 2 was further separated by paper chromatography into three bands designated as band $2 A^{\prime}$ ${ }^{2}$ and $2 C^{\circ}$ Band 3 appeared to consist of one component and its concentration was slightly lower in diseased than in healthy apples (Figure 1lb). It would appear, therefore, that the increase in total flavonols is due to increased concentration of band 2. The amount of band 6 , the bright blue band, identified as chlorogenic acids, showed a pattern of changes similar to that observed when using crude extracts of chlorogenic acids (see Table 5 and paragraph on chlorogenic acids). Attempts at identification of certain isolated flavonols by spectral analysis. Based on their UV absorption spectrum, the compounds in bands 1 and 4 did not behave as flavonols; they had a maximum absorption peak around 280-300 $\mathrm{nm}$ instead of 350-380 $\mathrm{nm}$ maximum of flavonols (Table 12). The UV spectra of bands $2 \mathrm{~A}^{\prime},{ } \mathrm{B}^{\prime}$ and ${ }^{2} \mathrm{C}$ agreed almost exactly with that of quercetin-3-galactoside reported in the literature, but the UV spectra of these three bands were indistinguishible from each other. The UV spectrum of band 3 was very similar to that of quercetin-3-rhamnoside reported in the literature (Table 12). 


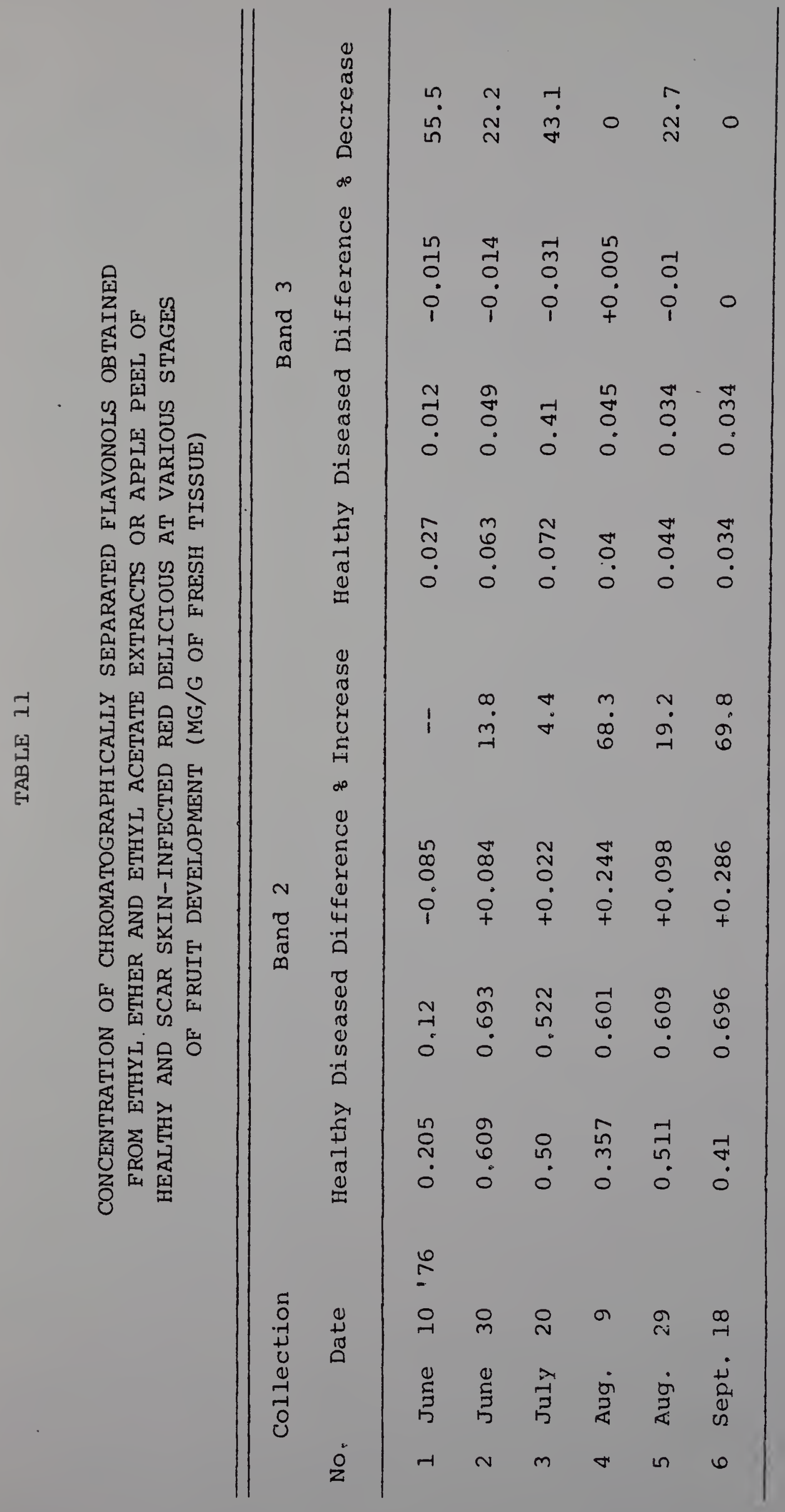


59

Figure 11. Changes in concentration of chromatographically separated flavonols from apple peel during development of healthy and scar skininfected Red Delicious fruits, Each point represents the average of two replications. Figure Ila is Data of band 2; Figure 11 b is Data of Band 3. 


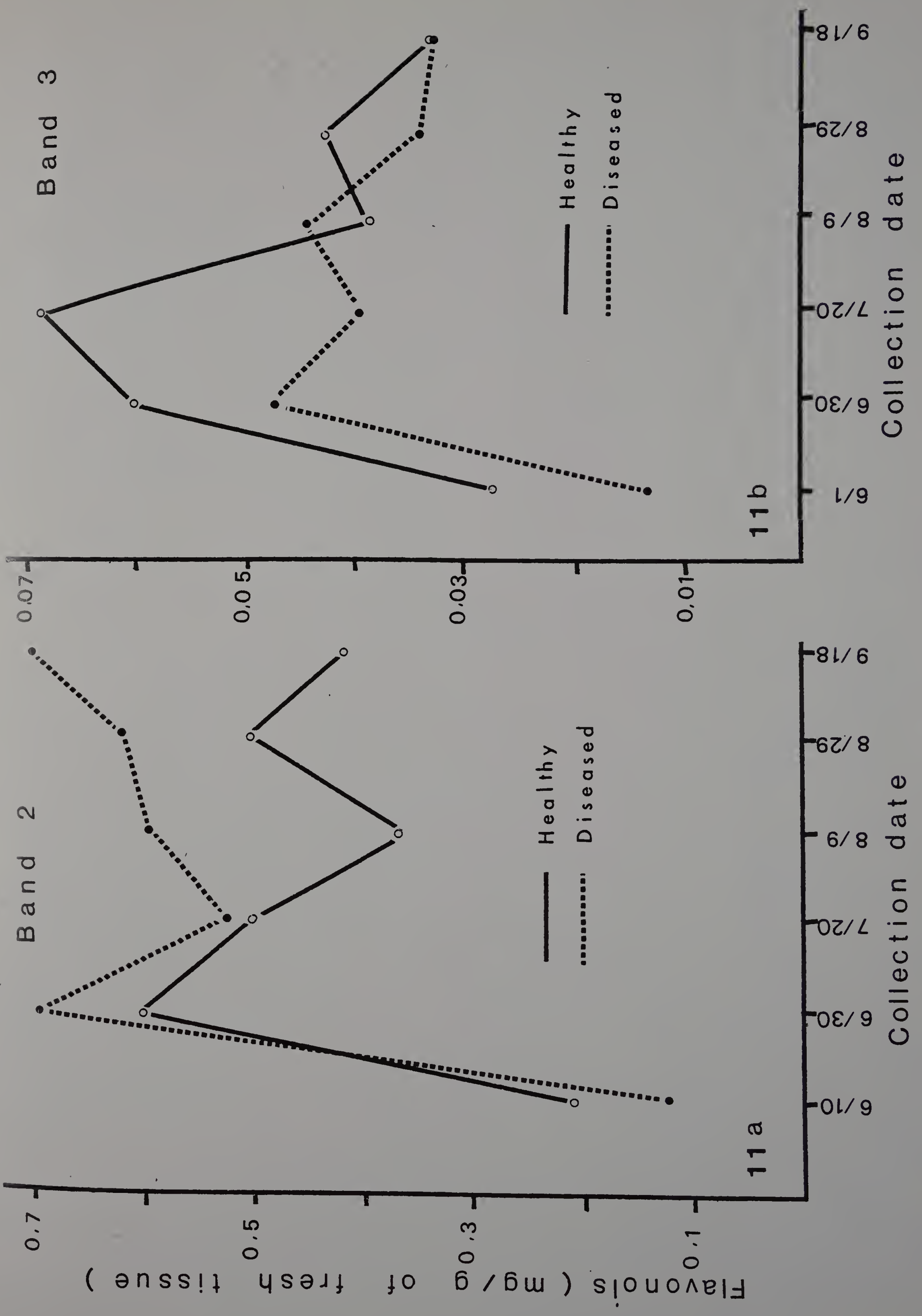




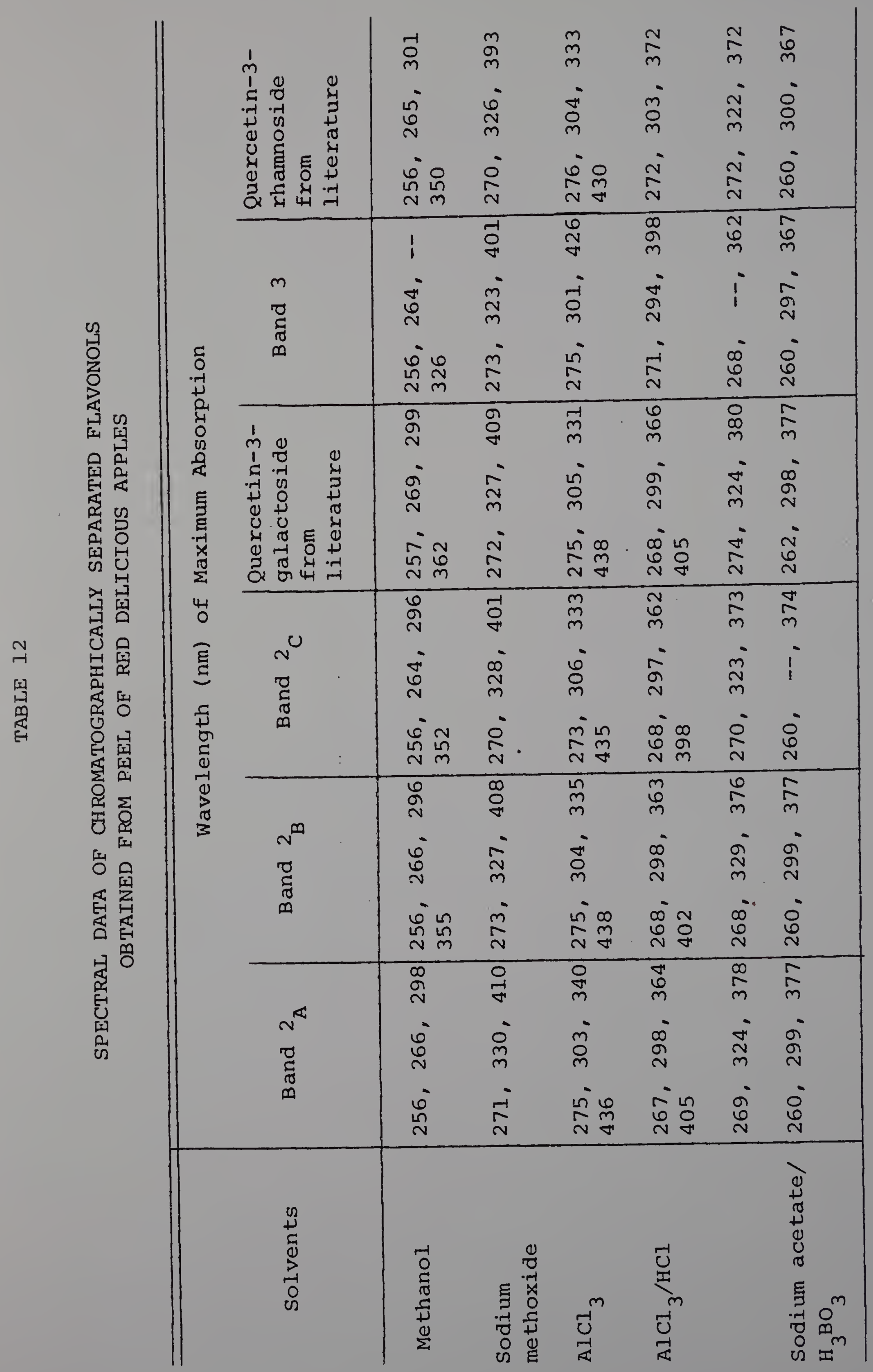


Effect of Dapple Apple on Flavonols

Determination of flavonols by the colorimetric method. Table 13

and Figures $12 \mathrm{a}$ and $12 \mathrm{~b}$ illustrate the changes in flavonol concentration in healthy and dapple apple-infected Hyslop Crab. Dapple apple infection appeared to have no significant effect on flavonol metabolism.

Determination of flavonols by paper chromatography. Extracts from healthy and from dapple apple-infected Hyslop Crab apples also separated into 9 bands upon paper chromatography (Figures $13 a$ and 13b). No difference in the major bands was detected between healthy and diseased apples. The amounts of bands 2 and 3 given in Table 14 show no significant quantitative changes between healthy and dapple appleinfected apples (Figures $14 \mathrm{a}$ and $14 \mathrm{~b}$ ). The amount of band 6 , identified as chlorogenic acids, was slightly higher in diseased than in healthy tissues (Table 9). This result did not agree with that obtained from paper chromatography using chlorogenic acid extracts (see Tables 7 and 8 and the paragraph on chlorogenic acids).

\section{Anthocyanins}

\section{Effect of Scar Skin on Anthocyanins}

Determination of anthocyanins by the colorimetric method.

Anthocyanins were produced primarily in the later stages of fruit growth. A rapid synthesis of anthocyanins in both the infected and uninfected fruits occurred after the fifth collection (Aug. 29), especially between the sixth and seventh collection. Production of anthocyanins was considerably reduced by scar skin infection (Figures $15 a$ and $15 b$ ), which resulted in a decrease of anthocyanins by 41.48 in 1975 and $62.8 \%$ in 1976 


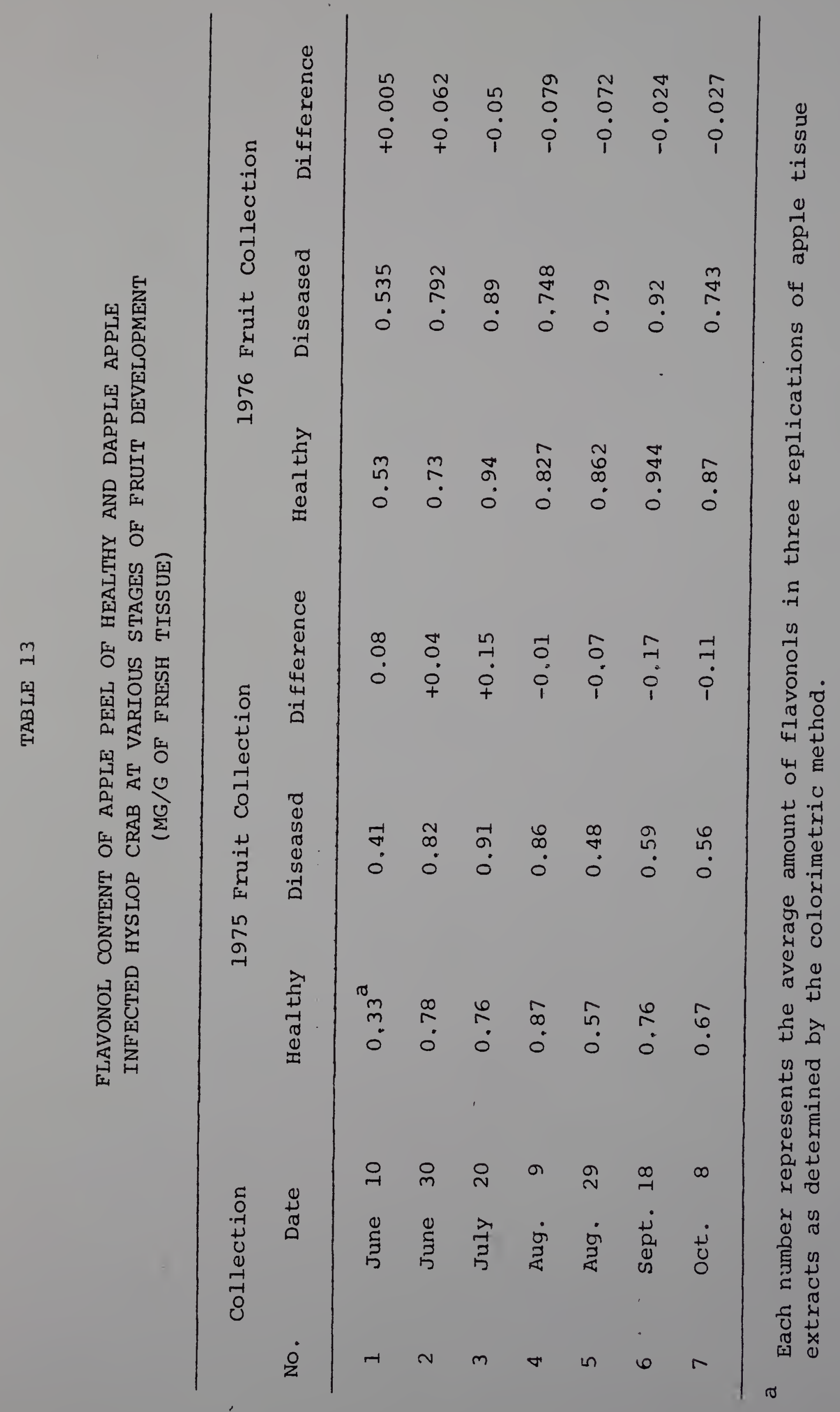


Figure 12. Changes in concentration of flavonols in the apple peel during development of healthy and dapple apple-infected Hyslop Crab fruits. Each point represents the average of three replications; the bar represents the standard deviation of these measurements. Figure $12 \mathrm{a}$ is Data of 1975 fruit samples; Figure $12 b$ is Data of 1976 fruit samples. 

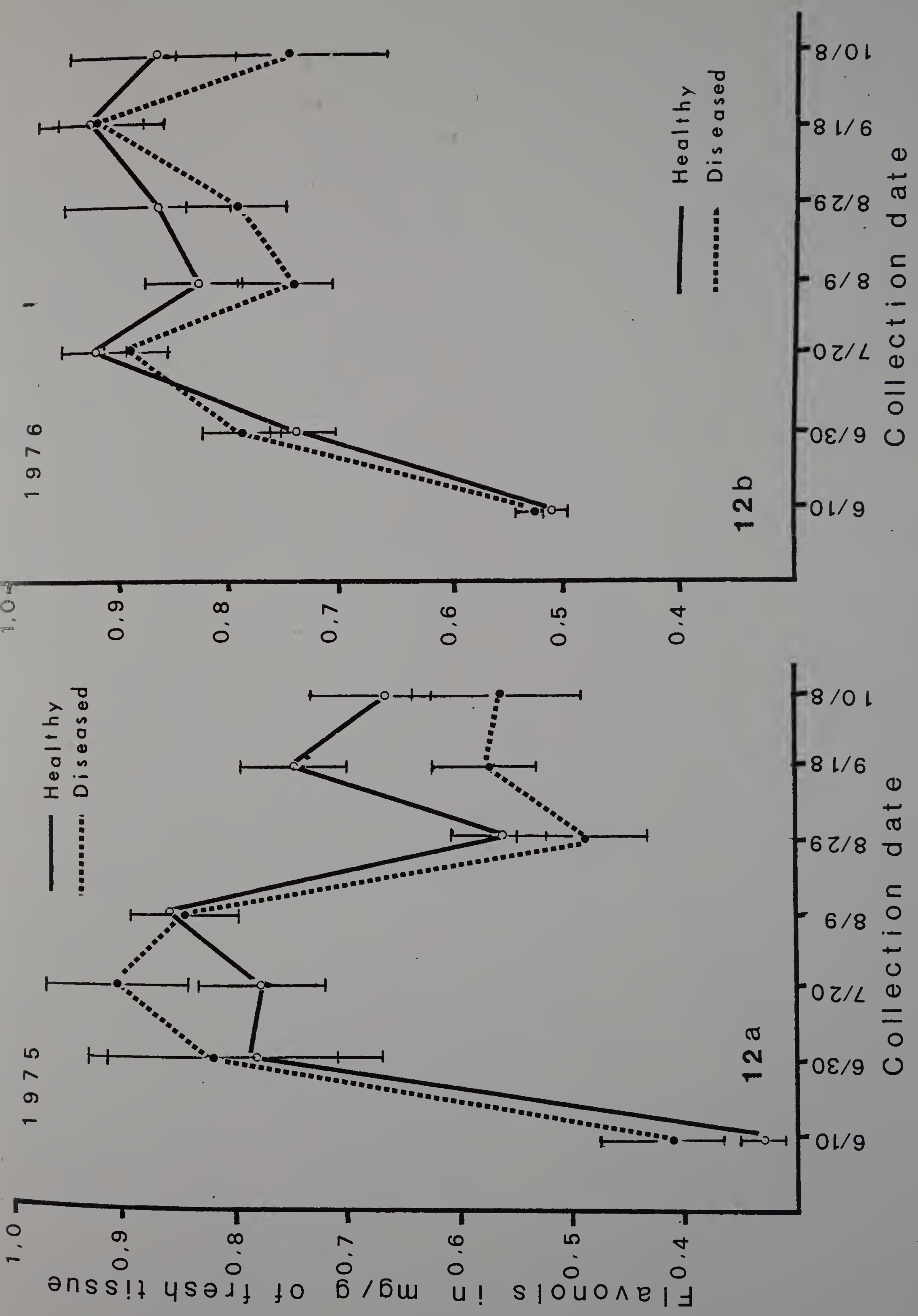
Figure 13. One-way chromatograms of ethyl ether and ethyl acetate extracts containing flavonols and chlorogenic acids from healthy and dapple apple-infected Hyslop Crab apples. Each pair of streaks from left to right represent samples from healthy (left) and diseased (right) fruits collected at 20-day intervals starting June 10 and ending October 8, 1976. Figure $13 \mathrm{a}$ is photographed under UV light; Figure 13b is marked with pencil under UV light and photographed in visible light. 
$13 a$

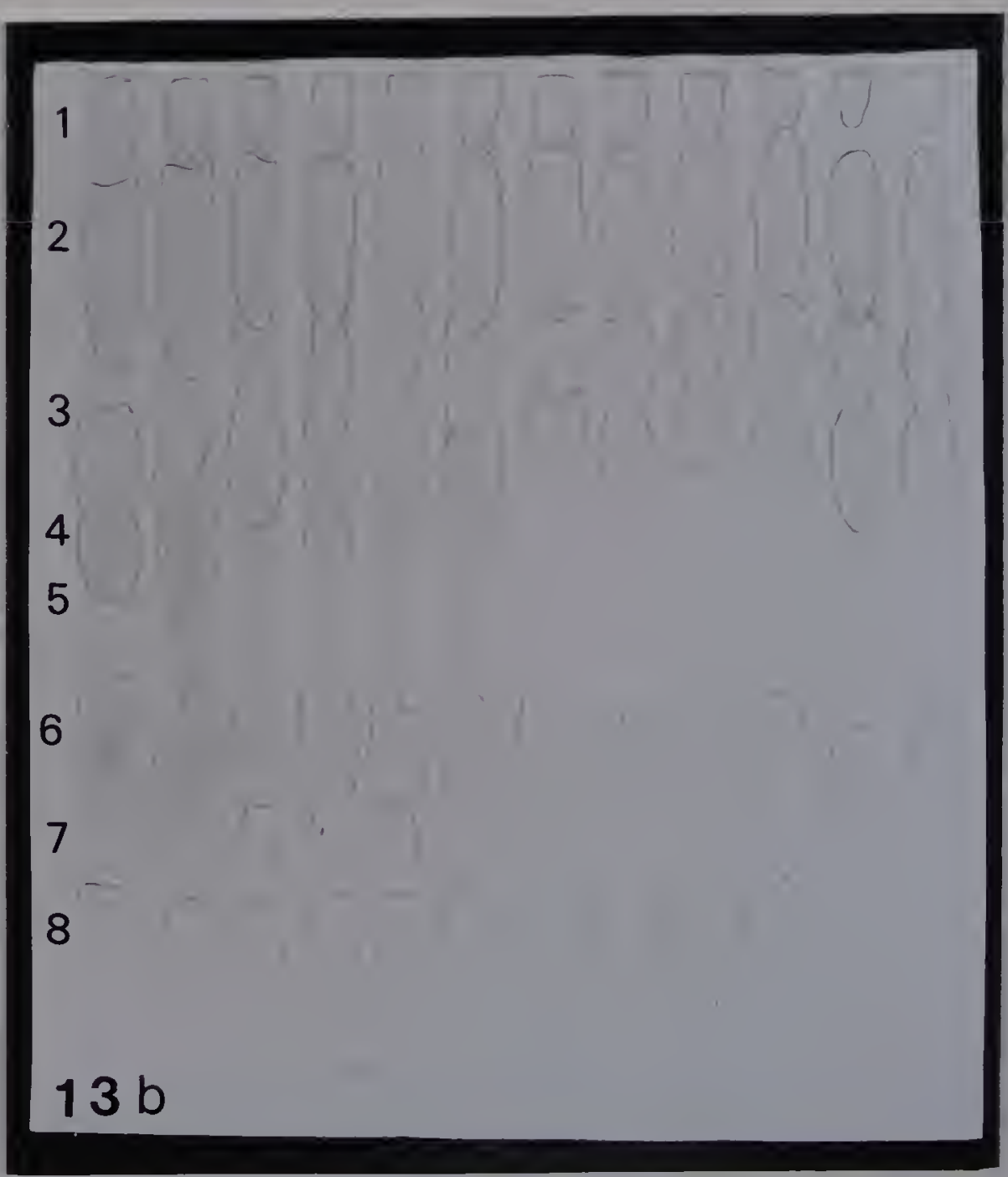




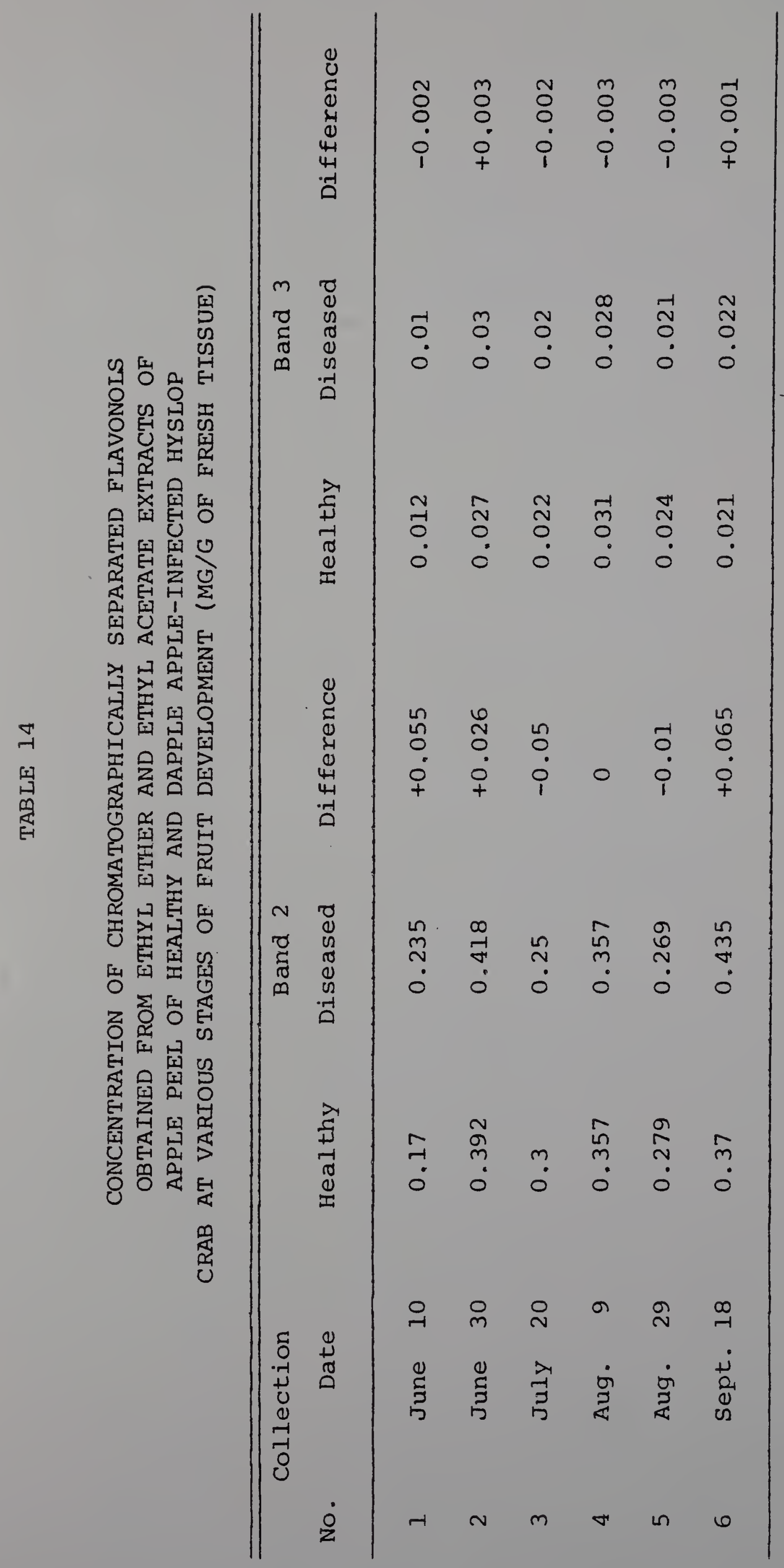


Figure 14. Changes in concentration of chromatographically separated flavonols in the apple peel during development of healthy and dapple apple-infected Hyslop Crab fruits, Each point represents the average of two replications. Figure $14 \mathrm{a}$ is Data of band 2; Figure $14 \mathrm{~b}$ is Data of band 3 . 

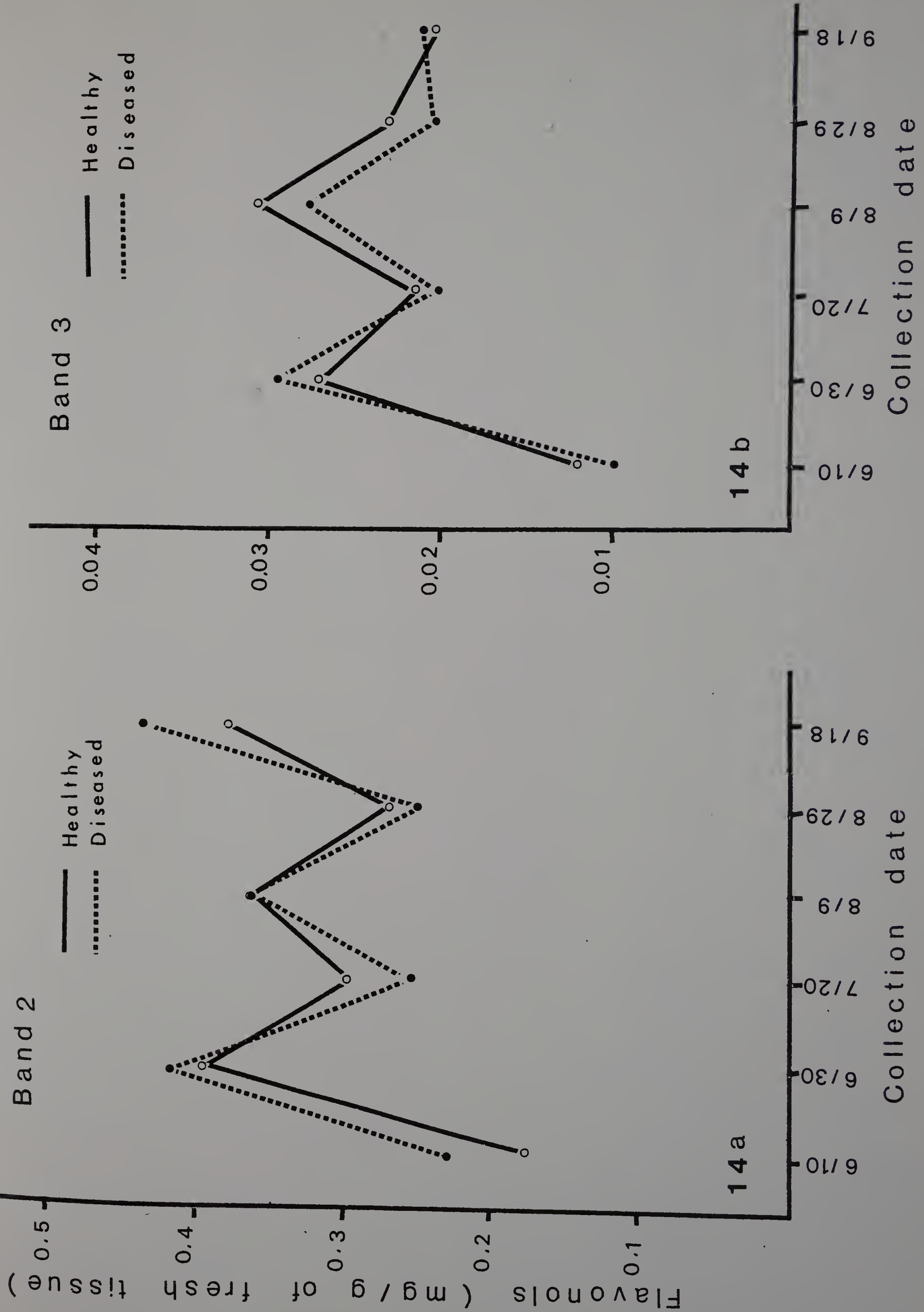
71

Figure 15. Changes in concentration of anthocyanins in the apple peel during development of healthy and scar skin-infected Red Delicious fruits. Each point represents the average of three replications; the bar represents the standard deviation of these measurements. Figure 15a is Data of 1975 fruit samples; Figure $15 \mathrm{~b}$ is Data of 1976 fruit samples. 


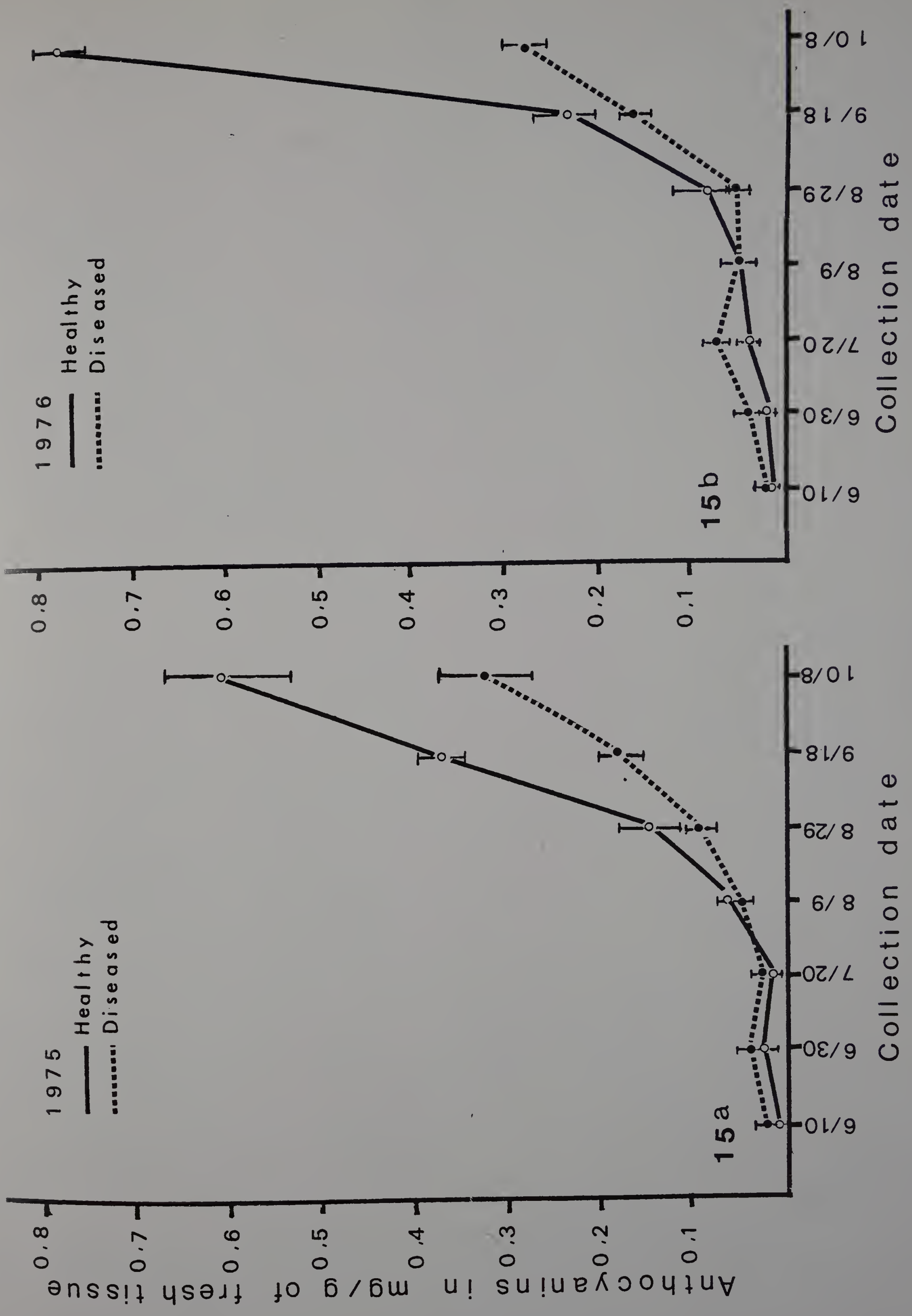


in mature diseased fruit compared to healthy fruit of the same age (Table 15). In healthy fruit, much more anthocyanins were formed in 1976 than in 1975. The pattern of changes of anthocyanins in infected fruits followed that of anthocyanins in healthy fruits.

Determination of anthocyanins by paper chromatography. Crude extracts of anthocyanins from Red Delicious apples separated into three bands, one major and two minor bands designated as bands 1,2 , and 3 . As can be seen in the chromatogram of Figure 16, identical bands were obtained from extracts of healthy and diseased apples. Although there was no change in the kinds of anthocyanin bands detected in virus infected fruit, the intensity of the bands was higher in healthy than in diseased apples. When the amount of each anthocyanin band was measured, it was shown that band 1 comprised the main component, accounting for $84.2 \%$ of total anthocyanins, while band 2 accounted for $11.6 \%$ and band 3 for $4.2 \%$ in the healthy mature fruits. Scar skin infection reduced the amount of band 1 by $61.7 \%$, of band 2 by $76 \%$ and of band 3 by $75 \%$ as compared to the healthy tissues (Table 16). The patterns of changes of band 1 and band 2 were similar to that of total anthocyanins (Figures 17a and 17b).

Some properties of isolated anthocyanins. Spectral data of band 1 were close to that of cy-3-galactoside, but its Rf values in different solvents were not identical to those of cy-3-galactoside (Table 17). The identity, therefore, of the band 1 pigment remains unknown. Bands 2 and 3 also could not be identified. 


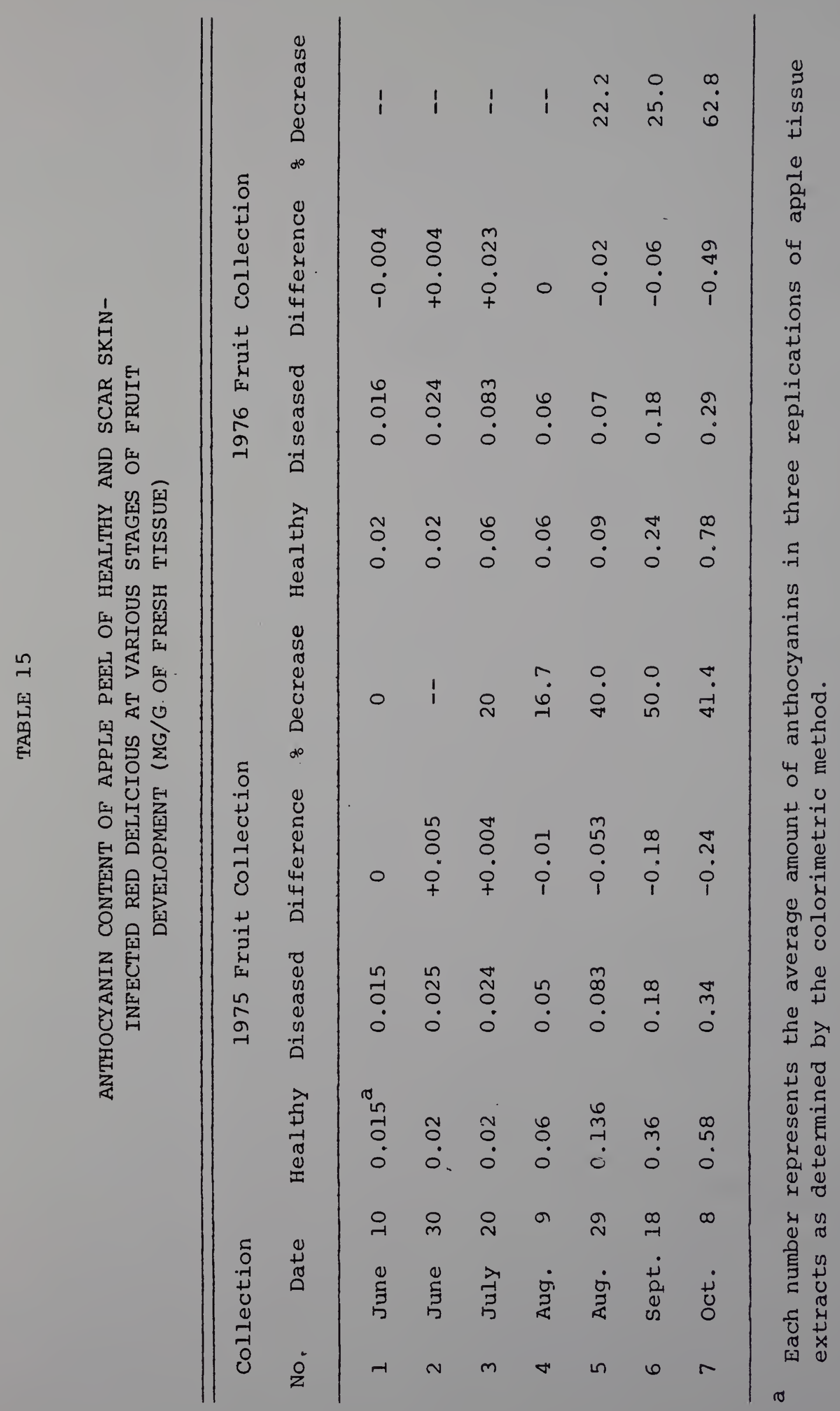


Figure 16. One-way chromatogram of acidified ethanol extracts containing anthocyanins from healthy and scar skin-infected Red Delicious apples. Each pair of streaks from left to right represent samples from healthy (left) and diseased (right) fruits collected at 20-day intervals starting from June 30 and ending October 8, 1976. 
76

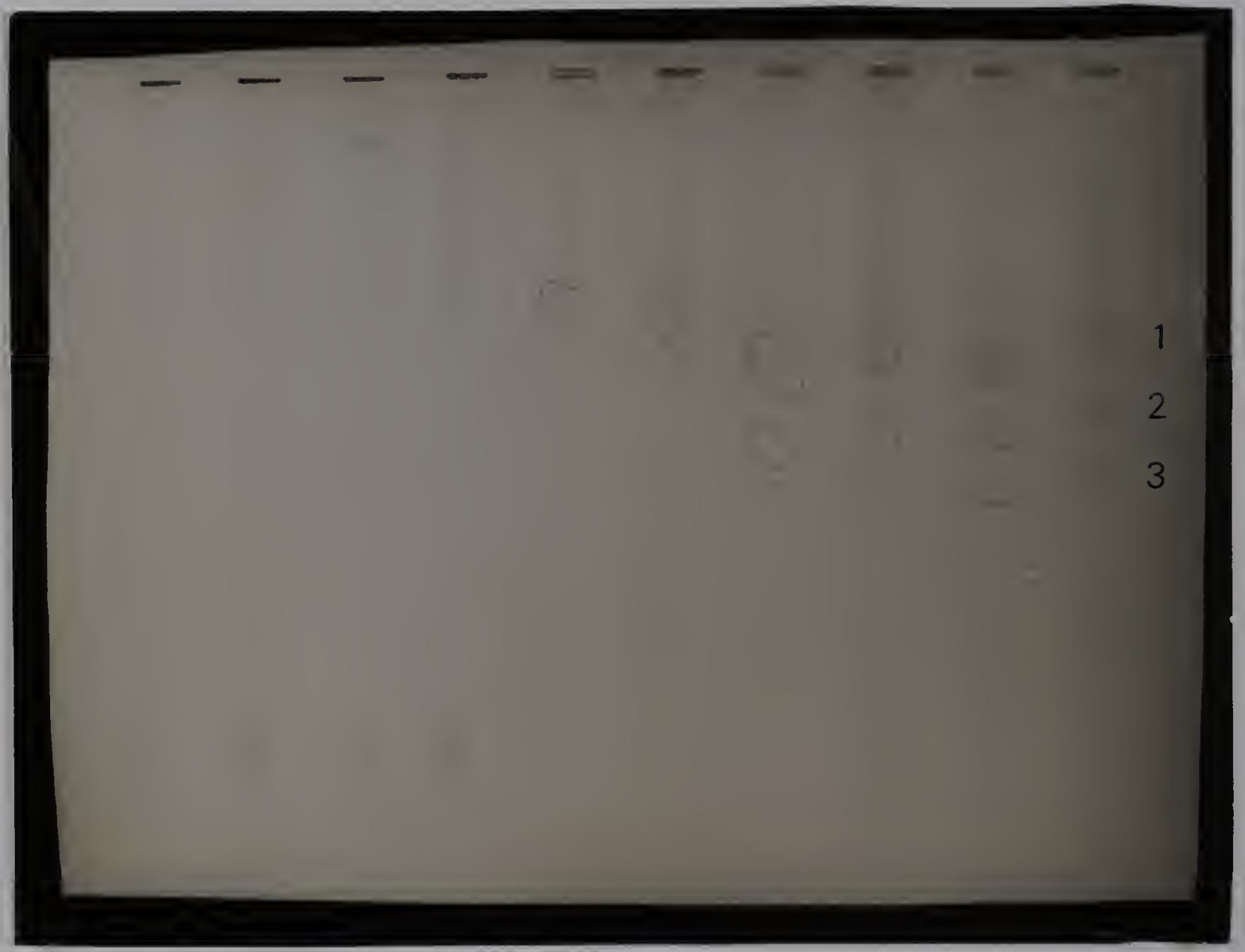




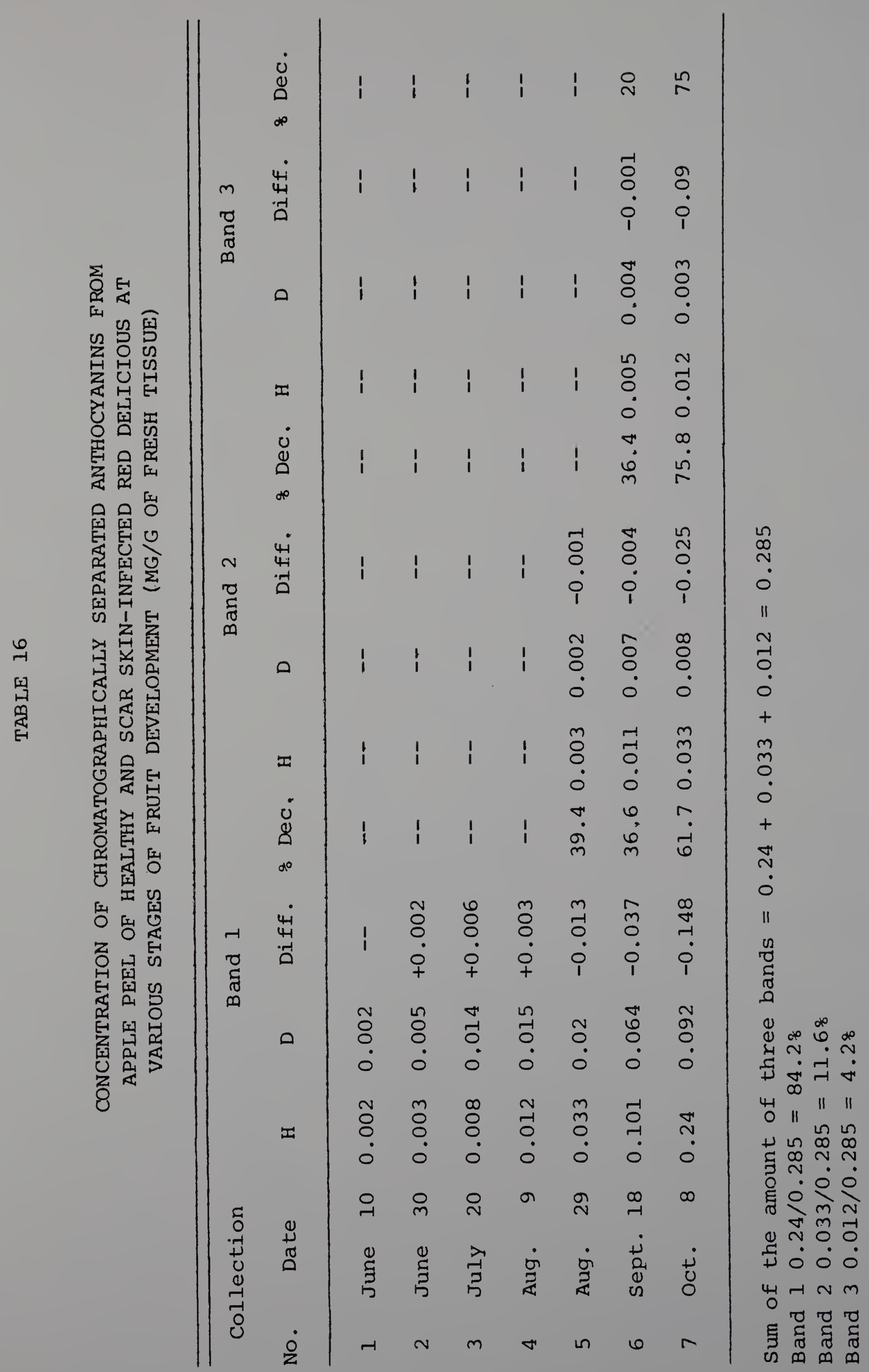


Figure 17. Changes in concentration of chromatographically separated anthocyanins in the apple peel during development of healthy and scar skin-infected Red Delicious fruits. Each point represents the average of two replications. Figure $17 \mathrm{a}$ is Data of band 1; Figure $17 \mathrm{~b}$ is Data of band 2 . 


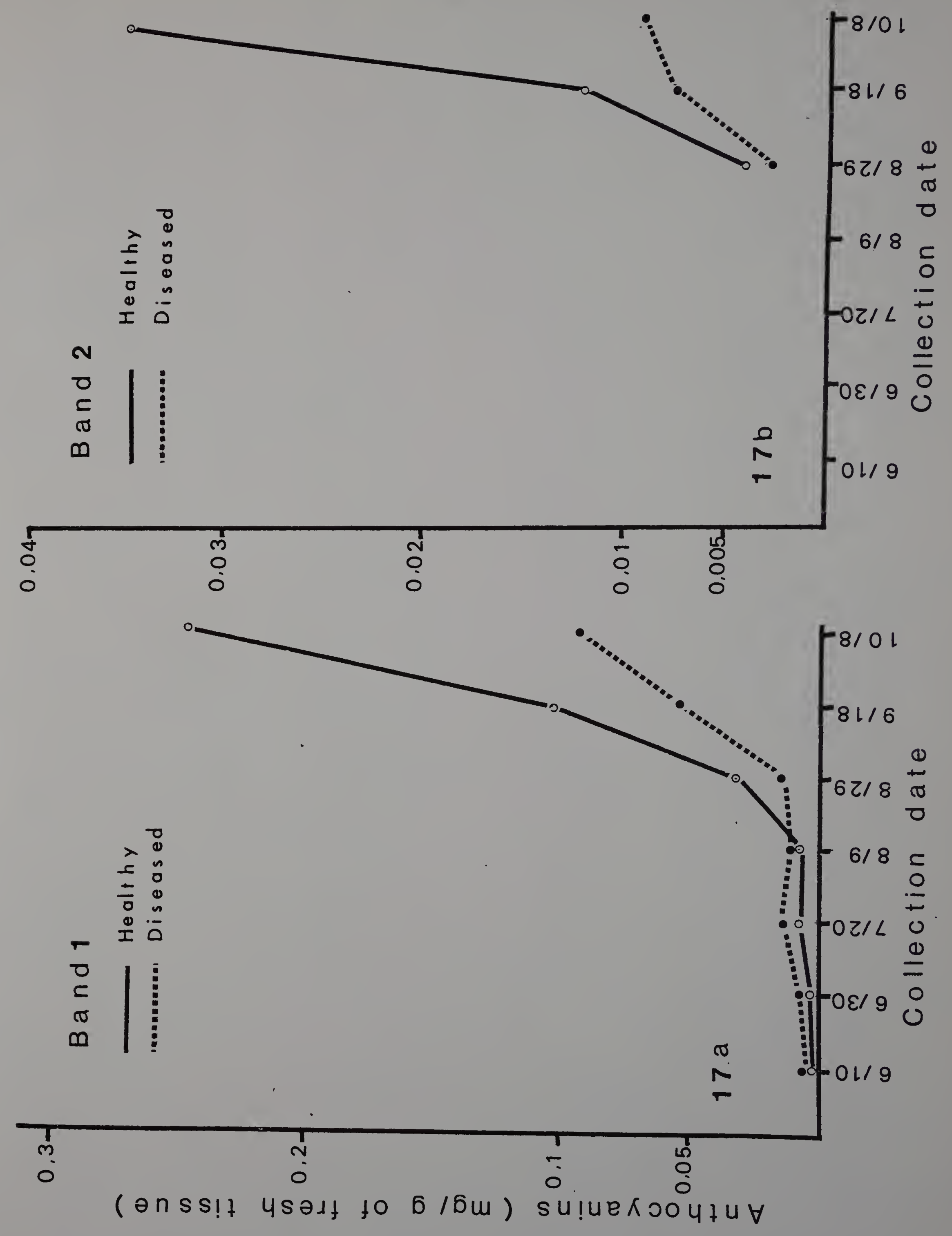


TABLE 17

RF VALUES AND SPECTRAI PROPERTIES OF

SEPARATED ANTHOCYANINS FROM APPLE PEEL

OF RED DELICIOUS AND HYSLOP CRAB

\begin{tabular}{|c|c|c|c|c|}
\hline Pigment Band & BAW & $\mathrm{BuHCl}$ & Forestal & Absorbance Maxima \\
\hline \multicolumn{5}{|l|}{ Rèd Delicious } \\
\hline Band 1 & 17 & 22 & -- & 281,528 \\
\hline Band 2 & 29 & 33 & -- & \\
\hline Band 3 & 42 & 55 & -- & 277,528 \\
\hline \multicolumn{5}{|l|}{ Hyslop Crab } \\
\hline Band 1 & 20 & 21 & 45 & 281,529 \\
\hline Band 2 & 29 & 31 & 45 & 278,526 \\
\hline Band 3 & 40 & 47 & 46 & 277,526 \\
\hline \multicolumn{5}{|c|}{$\begin{array}{l}\text { Literature Values } \\
\text { (Sun and Francis) }\end{array}$} \\
\hline $\begin{array}{l}\text { Band } 1 \\
(C y-3-g a l)\end{array}$ & 34 & 28 & -- & 285,530 \\
\hline $\begin{array}{l}\text { Band } 2 \\
(\text { Cy-3-arab) }\end{array}$ & 45 & 36 & -- & 285,530 \\
\hline Band 3 & 61 & 60 & -- & 275,533 \\
\hline
\end{tabular}




\section{Effect of Dapple Apple on Anthocyanins}

Determination of anthocyanins by the colorimetric method. As in Red Delicious, anthocyanins in Hyslop Crab developed mostly in the later stages of fruit growth. A rapid increase in anthocyanin content was observed after the fourth collection, particularly between the fifth and sixth collection (Figures $18 \mathrm{a}$ and $18 \mathrm{~b}$ ). Anthocyanins were present in lower amounts in dapple apple-infected fruits than in healthy. Mature dapple apple-infected fruits contained $56.6 \%$ less anthocyanins in 1975 and $45.8 \%$ less in 1976 compared to mature healthy fruit (Table 18). However, the pattern of changes of anthocyanins was not affected by infection. In healthy fruit, higher levels of anthocyanins were observed in 1976 than in 1975 ,

Determination of anthocyanins by paper chromatography. Anthocyanin extracts from healthy and diseased Hyslop Crab apples, upon paper chromatography usually separated into three bands, one major and two rinor ones, designated as bands 1, 2, and 3 (Figure 19). After prolonged development of the chromatograms using the extracts of mature fruit extracts, five bands were obtained. Paper chromatography showed no changes in the quality of anthocyanins as a result of infection, but there was a decrease in the amount of each band. Band 1 was decreased by $51.2 \%$, band 2 by $53 \%$ and band 3 by $30 \%$ as compared to healthy apples (Table 19). Band 1 again comprised the main component, accounting for 88.7\%, while band 2 accounted for $9.3 \%$ and band 3 for $2.1 \%$ of total anthocyanins. The combined amount of the three anthocyanins measured after separation by paper chromatography was much less than that determined by the colorimetric method (Table 18). The pattern of changes 
Figure 18. Changes in concentration of anthocyanins in the apple peel during development of healthy and dapple apple-infected Hyslop Crab fruits. Each point represents the average of three replications; the bar represents the standard deviation of these measurements. Figure 18a is Data of 1975 fruit samples; Figure 18b is Data of 1976 fruit samples. 

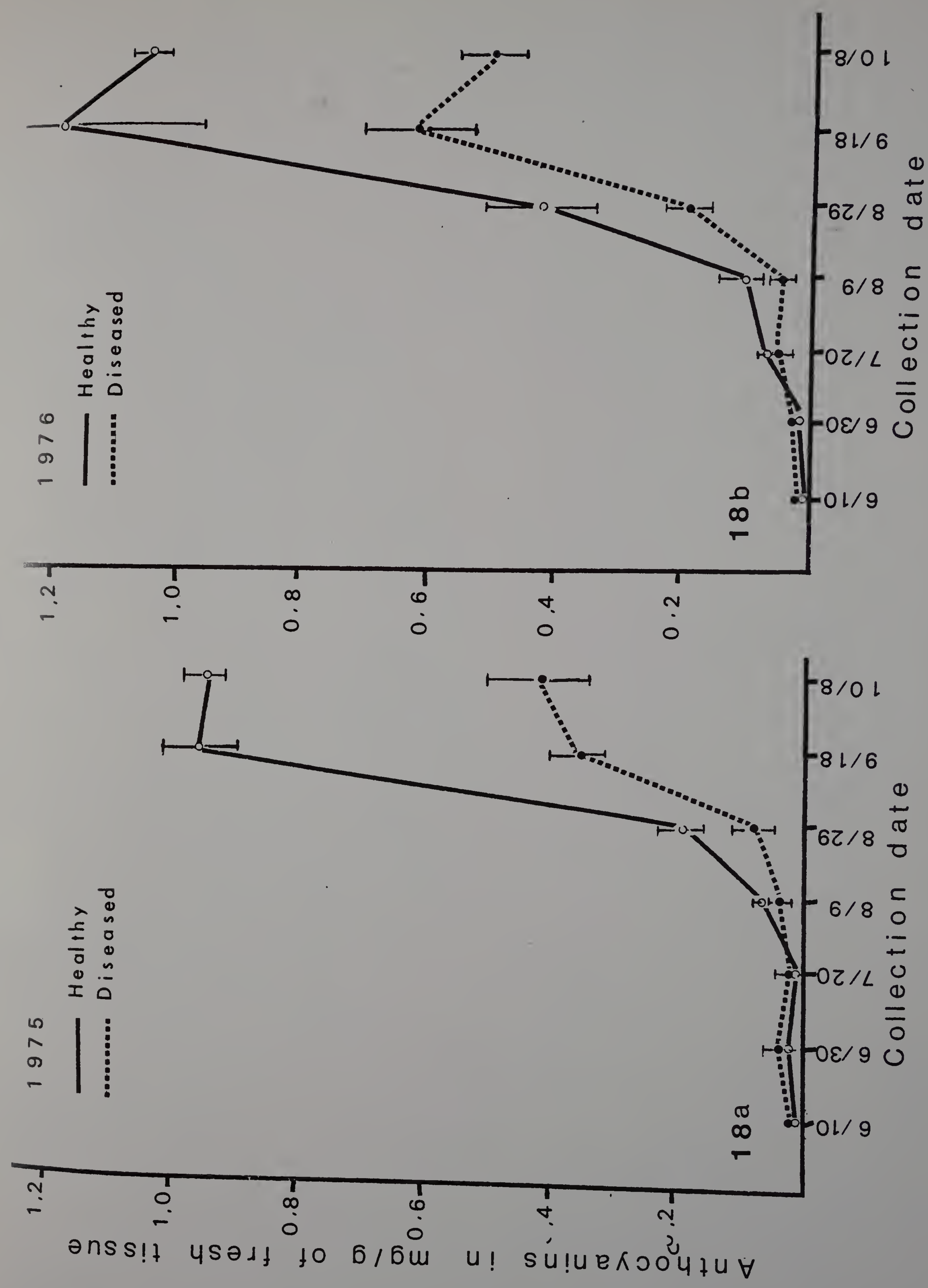


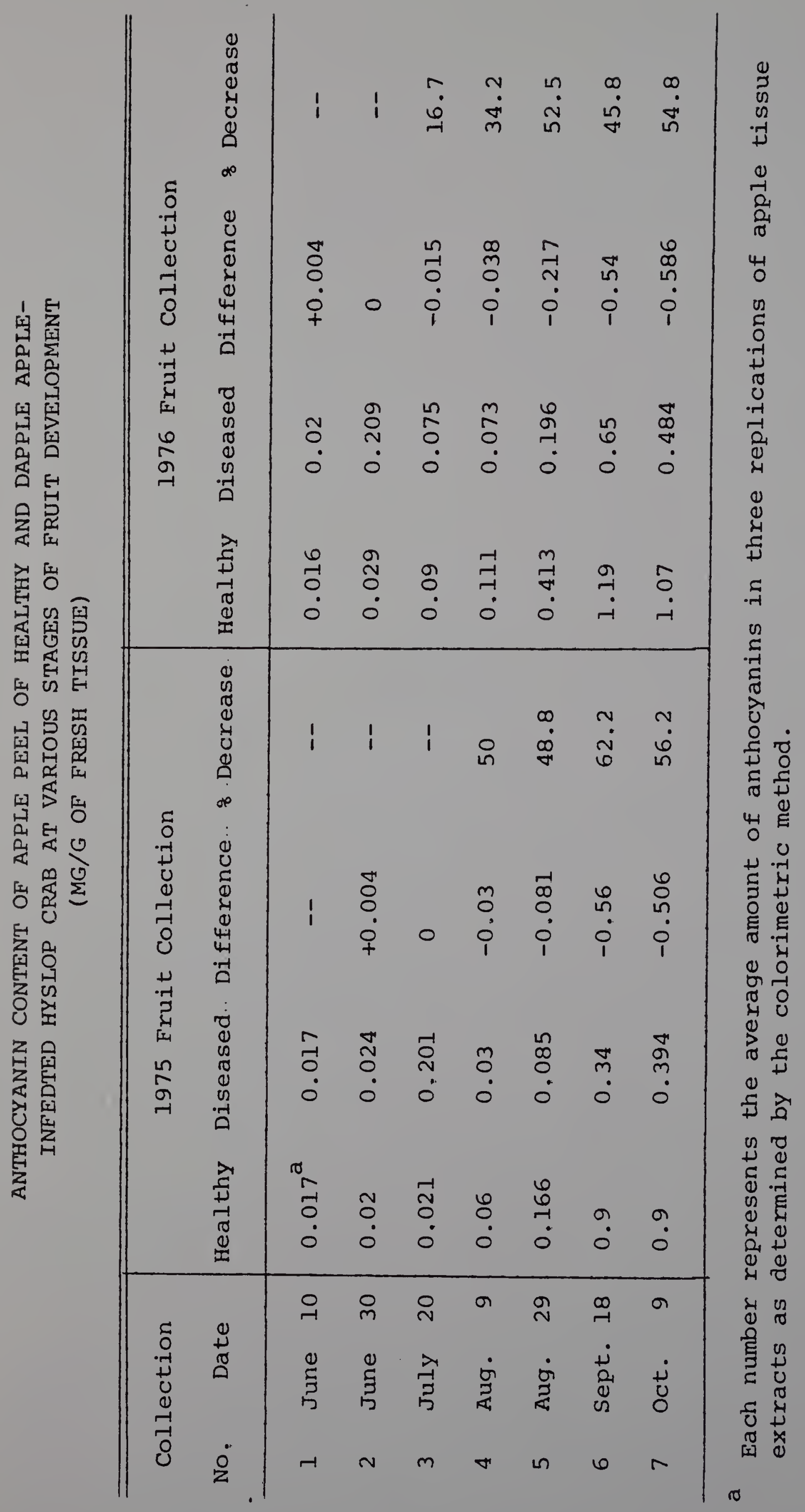


Figure 19. One-way chromatogram of acidified ethanol extracts containing anthocyanins from healthy and dapple apple-infected Hyslop Crab. Each pair of streaks from left to right represent samples from healthy (left) and diseased (right) fruits collected at 20-day intervals starting from June 30 and ending October $8,1976$. 
86

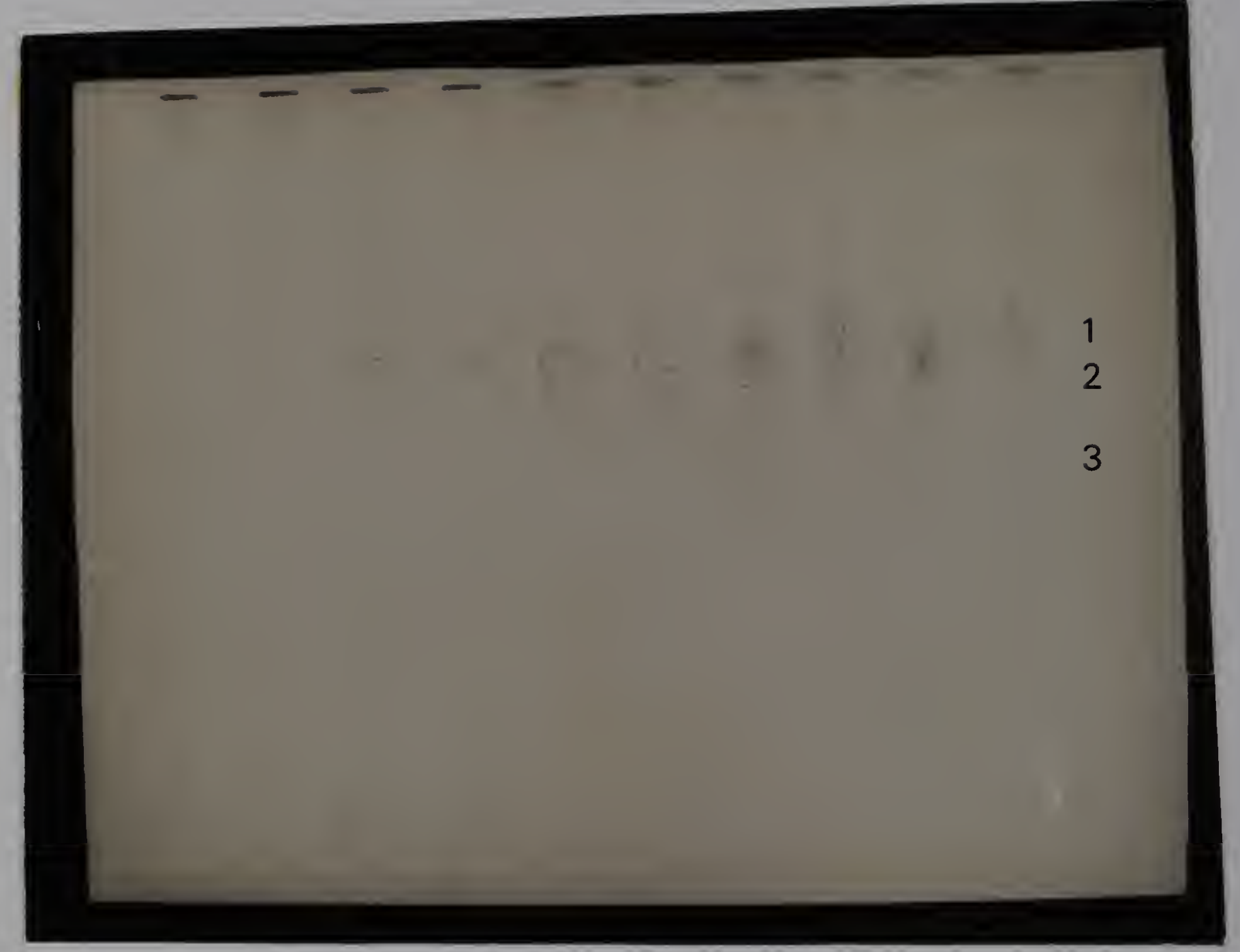




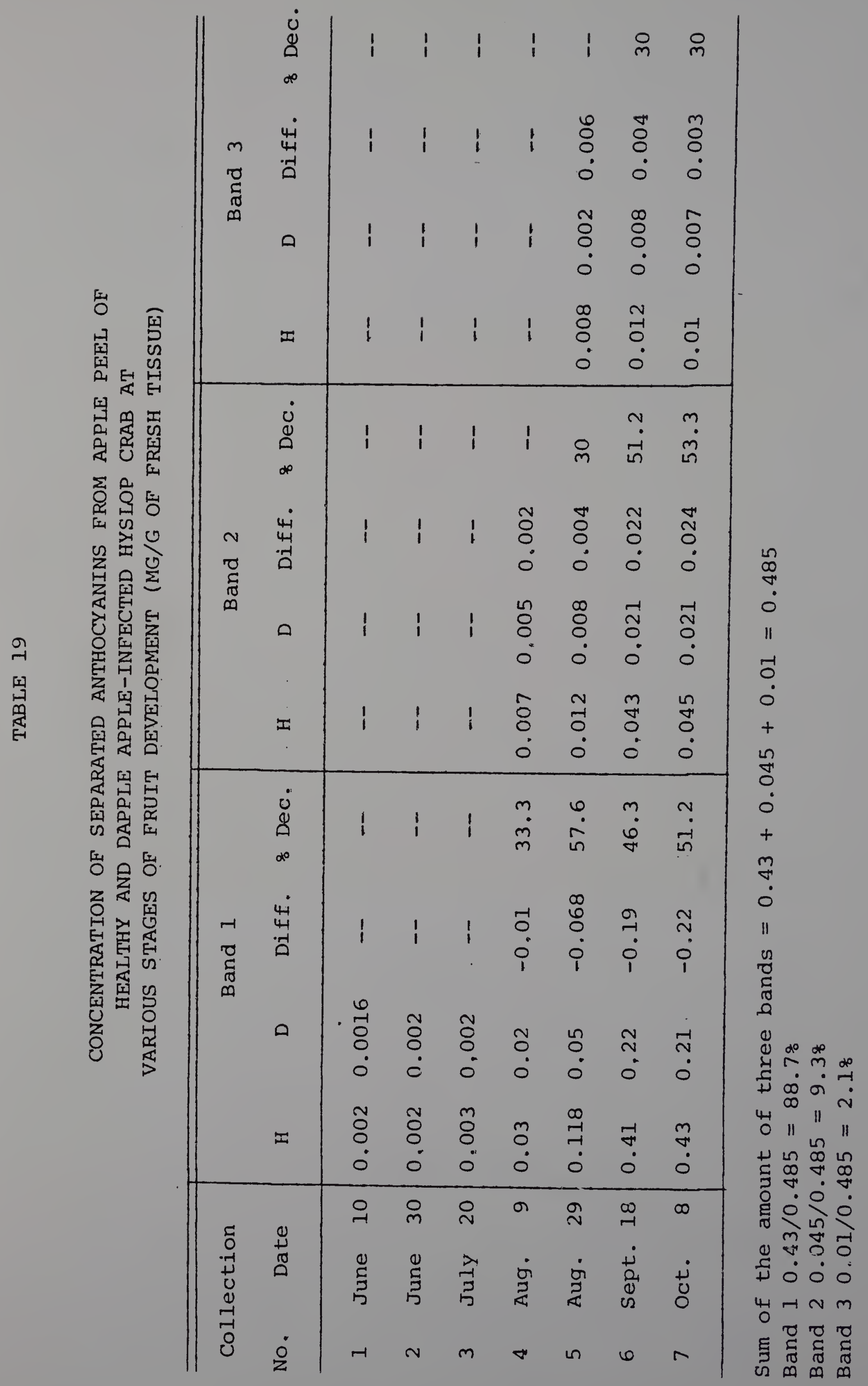


for band 1 and 2 is shown in Figures $20 \mathrm{a}$ and $20 \mathrm{~b}$ and was apparently similar to the pattern of changes of total anthocyanins.

Some properties of isolated anthocyanins. Rf values in different solvents and spectral data of each band are listed in Table 17. They (1968)

were not identical to those reported by Sun and Francis. Therefore, the identity of these pigments remains unclear. 
Figure 20. Changes in concentration of chromatographically separated anthocyanins in the apple peel during development of healthy and dapple apple-infected Hyslop Crab fruits. Each point represents the average of two replications. Figure $20 a$ is Data of band 1; Figure $20 \mathrm{~b}$ is Data of band 2 . 


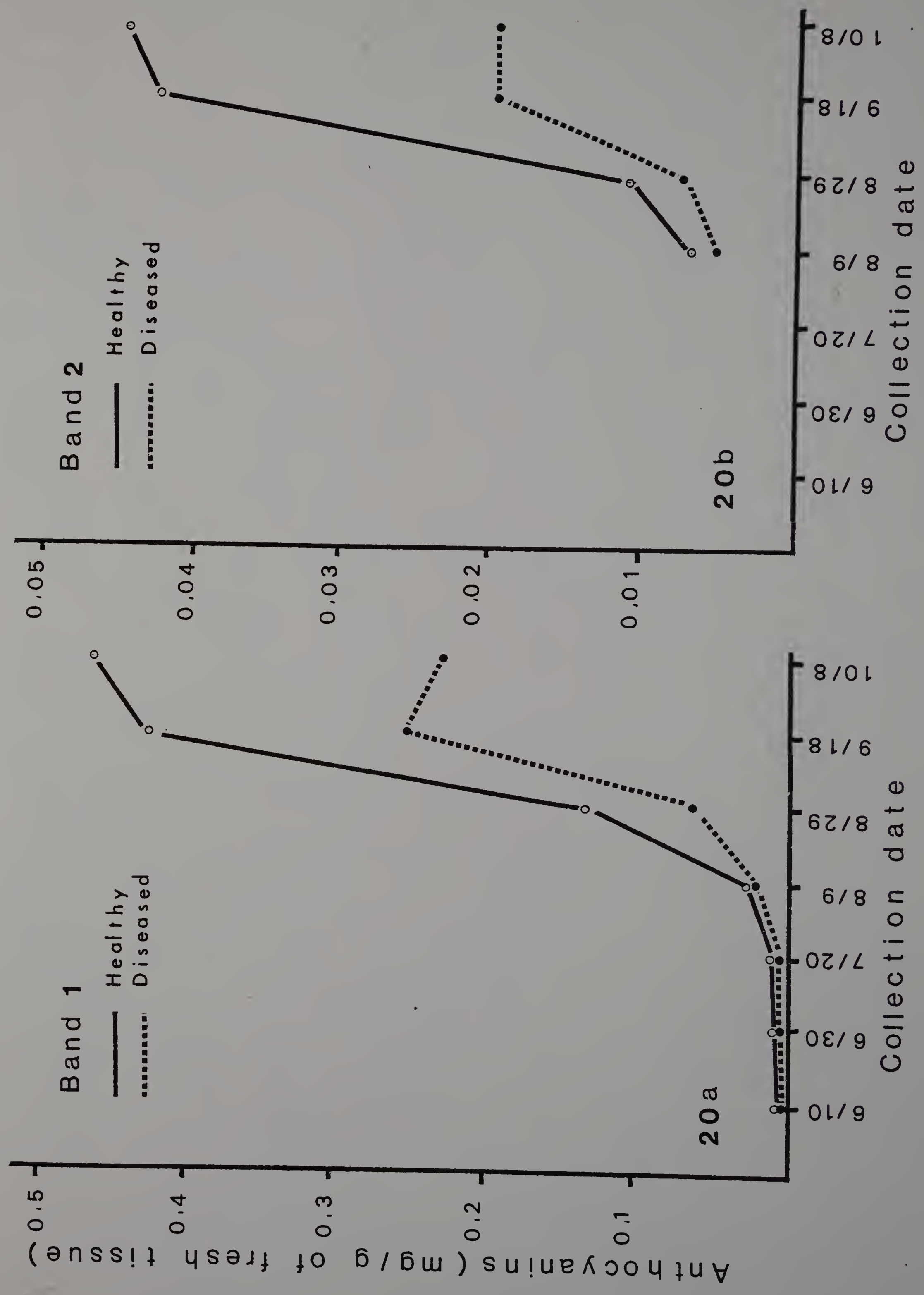




\section{DISCUSSION}

Little work had been done in the past on the sequential changes in the levels of phenolic compounds during fruit development. Walker (1963) and Mosel and Herrmann (1974) reported on some changes of phenolic compounds in whole apples. There is no information on phenolics in apple peel where symptoms such as those caused by scar skin and dapple apple diseases develop. The patterns of phenolic changes observed in apple peel in this study, however, are generally similar to those found by Mosel and Herrmann in whole fruit tissue.

The amounts of apple phenolics reported have seldom been determined exactly (Mosel and Herrmann, 1974). Wide ranges of concentrations of phenolic compounds have been reported in various varieties of apple by various investigators. The amount of total phenols found in apples ranges from $0.05-1.1 \mathrm{~g} / 100 \mathrm{~g}$ of fresh weight (Van Buren, 1970); the amount of flavonols ranges from $0.41-18.8 \mathrm{mg} / \mathrm{g}$; anthocyanins from $0.1-$ $21.6 \mathrm{mg} / \mathrm{g}$ in various varieties of apple (Walker, 1964). In Red Delicious apples, Walker found $2.2-3.45 \mathrm{mg} / \mathrm{g}$ of flavonols; $3.52-18.6 \mathrm{mg} / \mathrm{g}$ of anthocyanins. These figures are much higher than those obtained for the same variety in this study. It is difficult to comapre the data in the two studies, however, because of differences in extracting procedures, methods employed for quantitative determination, varieties, stages and tissues of apple extracted and units in which the phenolic amounts were expressed (in $\mathrm{mg} / \mathrm{g} \mathrm{fr}$. wt., $\mathrm{mg} / \mathrm{dr}$. wt. or $\mathrm{mg} / \mathrm{cm}^{2}$ peel). In the present study, moreover, the goal was to study not so much the absolute amounts 
of phenolic compounds present in apples but rather the relative amounts present in healthy and in symptomatic apple peel. For this reason the procedures were employed same collection, extraction, chromatography, etc.,/and the results

obtained should have been comparable regardless of any imperfections in the methods employed.

The amounts of phenolic compounds obtained after paper chromatography were considerably lower than those determined in crude extracts before chromatography. The reasons for this are not known but several explanations are possible, for example, it is possible that a non-anthocyanin substance, also having absorptivity at $535 \mathrm{~nm}$, the maximum absorbance wavelength of anthocyanins, was present in the crude extract but was later separated by paper chromatography. This substance thus contributed to the abojsbance of total anthocyanins in the crude extract but not of that obtained after elution of the band from the chromatogram. Other possibilities, such as breakdown of anthocyanins during chromatography and incomplete elution of anthocyanins from chromatograms, might also result in the loss of portions of the samples being measured. Similar possibilities could explain the difference in the amounts of flavonols and chlorogenic acids in crude extracts and in the elutes from chromatogram bands.

The Hoepfner color reagent generally used to detect chlorogenic acids is not specific, since it also reacts with other phenolic acids (Zucker and Ahrens, 1958; Ribereau-Gayon, 1972). Therefore, the amount determined by this method as chlorogenic acid actually represents the amount of all the phenolic acids that react with this color reagent to produce red color. 
The identity of minor anthocyanins in most studies has been uncertain, since various anthocyanins have been identified in apple fruits. This was discussed in the literature review. Identification of band 2 and band 3 of flavonols is generally in agreement with the findings of Siegelman (1954), who, in Grimes Golden apples, identified band 2 as quercetin-3-galactoside and three qu-3-glycosides, and band 3 as qu-3-rhamnoside.

Accumulation of flavonols observed in scar skin-infected Red Delicious apples is in accordance with the findings described for rusty mottle on cherry, western x disease on peach (Geissman, 1956) and color breaking virus on Matthiola incana (Feenstra et al, 1963). Consistent increases in the levels of band 2 but slight decreases in flavonols of band 3 after scar skin infection indicate that infection has different effects on different flavonol-glycosides.

Accumulation of phenolic compounds such as chlorogenic acids or total phenols have been reported in many plants infected with various diseases. Several hypotheses have been proposed to explain the mechanism of phenolic accumulation in the infected plants. In general, phenolic accumulation is thought to result from the stimulated shikimic acid pathway and enzymes such as phenylalanine ammonia lyase both of which are involved in the pathway of phenolic synthesis after infection (Pegg and Sequeira, 1968; Kosuge, 1969). Viral infections are generally found to cause an increase in respiration. Stimulated pentose phosphate shunt and glycolysis provide not only erythrose-4-phosphate and phosphenolpyruvic acid, the source for shikimic acid pathway, but also the reducing power of NADPH for the pathway. Hadwiger and Schwochau (1969) proposed an 
induction hypothesis (operon theory) to explain the mechanism of pisatin accumulation in infected pea plants.

Accumulation of phenolic compounds is not a specific response of plants to diseases, since it may also result from physical injuries. Therefore, phenolic accumulation is believed to be a general reaction of the plant for repair of damage (Allen, 1959).

Both scar skin and dapple apple diseases caused significant reduction in fruit anthocyanins. Effect of infection on the levels of three separated pigments is more or less similar in both diseases. Reduction in anthocyanins by virus infection is, of course, rather common in virus infected flowers. The classical breaking of tulips represents localized inhibition of anthocyanin formation (Sosnova and Ulrychova, 1972). Similar symptoms are caused by TMV on flowers of tobacco, by bean yellow mosaic on sweet pea (Matthews, 1970), and by color breaking virus on Matthiola incana (Feenstra et al, 1963).

Reduction of anthocyanins after virus infection has been interpreted as the result of competition between viral nucleic acid and the unstable host nucleic acid (Ulrychova and Sosnova, 1970) since decreased anthocyanin synthesis is accompanied by simultaneous stimulation of virus synthesis or vice versa. Also, the unstable host nucleic acid is suggested to control'the synthesis of anthocyanins and must, therefore, be continually resynthesized (Thimann and Radner, 1962). Feenstra et al (1963) suggested that virus infection stimulates the substitution of a recessive gene, which does not permit anthocyanin formation, for its dominant allele, which gives synthesis of the pigment. In other words, the presence of the recessive allele and virus infection lead to blocking of anthocyanin formation. 
It is unlikely that decreases in anthocyanins result from increases in flavonols, since dapple apple infection causes significant reduction of anthocyanins but has no effect on flavonols. A similar phenomenon was observed by Feenstra et al (1963), who indicated that the effects of virus on synthesis of anthocyanins on one hand and on flavonols on the other are more or less independent. Since IAA, kinetin and perhaps other baen

growth substances have, shown to be required for anthocyanin synthesis in many plants and apple tissue culture (McClure, 1975; Ibrahim et al, 1971), there is the possibility that the decrease in anthocyanin production after infection may result from the altered growth regulator activity brought about by infection.

However, in certain plants, virus infection causes intensification of pigmentation such as bean yellow mosaic on bean flower (Matthews, 1970). It is, therefore, apparent that different viruses may have different effects on anthocyanin synthesis.

In the case of apple scar skin disease, it is apparent that extensive formation of nonfunctional necrotic tissues on the surface of fruits at the time anthocyanins are being synthesized is an important factor in the reduction in anthocyanins. Slightly higher levels of anthocyanins detected in scar skin-infected Red Delicious apples at the second and third collection are in accordance with the findings of Parker and Agrios (1973), who, studying the histopathology of scar skin-infected apple fruit, observed red pigment accumulation in the infected tissues at similar stages of fruit development.

Higher amounts of anthocyanins in Red Delicious and Hyslop Crab apples were formed in 1976 than in 1975. This variation may be due to 
changes in climate from year to year, since environmental conditions like temperature, light and water are known to play important roles in anthocyanin synthesis (McClure, 1975; Creasy, 1968; Siegelman and Hendricks, 1958). Apparently climatic conditions of 1976 favored the formation of higher levels of anthocyanins.

Accumulation of phenolic compounds has long been thought to play an important role in plant resistance to infection in the formation of local lesions in hypersensitive reactions and in the browning of injured or infected tissues. Comparison of the symptoms produced on apples infected with scar skin and dapple apple and of the effects of the two diseases on phenolic metabolism indicates that the altered phenolic metabolism is followed or is accompanied by symptom development. The significant accumulations of chlorogenic acids observed before and after the appearance of symptoms in scar skin-infected apples may be a particularly important factor in the formation of brown necrotic tissues on the surface of infected fruits. The characteristic browning of sliced or injured apples has been regarded as the result of oxidation of phenolic compounds, particularly chlorogenic acids. Younger fruit containing higher levels of chlorogenic acids has greater browning capacity as do apple varieties containing higher levels of chlorogenic acids (Walker, 1962). Similar relationships between phenolic metabolism and symptom development wase previously observed in other diseases by solymosy et al (1959), Parish et al (1965), and Rahe et al (1969).

Flavonol accumulation appeared to parallel the development of necrotic tissues in scar skin-diseased fruit. In dapple apple, decreases in anthocyanins correspond closely to the discoloration observed in 
infected fruits. In these cases also, then, symptom expression is associated with phenolic metabolism.

Phenolic compounds apparently are not the primary event that trigers necrosis, the primary event probably being a change in membrane permeability which then leads to the death of cells (Kosuge, 1969). In at least some cases, tannins accumulated on inner tonoplast are thought to cause precipitation of membrane protein leading to tonoplast breakdown (Gene-Albrigo and Childers, 1970). Accurmulation of phenolic compounds may also play a role in the inhibition of virus replication in infected tissues since phenolic compounds have been found to inactivate the infectivities of various virusesin vitro (Mink, 1965; Wood and Agrios, 1974).

Changes in the levels of chlorogenic acids and flavonols may regulate the activity of IAA by influencing the IAA oxidase. Chlorogenic acids also act as inhibitors of several other enzymes such as phosphorylase, transaminases and dihydroxyphenylalanine decarboxylase. The oxidation products of chlorogenic acids, quinones, are even more active enzyme inhibitors. As described by Wheeler (1975), phenolic compounds play diverse physiological roles in the plant, and even small changes in phenol metabolism may severely disrupt many processes which are essential for normal plant growth and development. No doubt symptoms are the total result of all altered biochemical reactions after infection. 
SUMMARY

Scar skin, a graft-transmissible disease of Red Delicious apples, causes corky, scarred, necrotic areas on the surface of affected fruits. Brown necrotic tissue may cover up to $50 \%$ or more of the fruit surface. Affected fruits show a marked reduction in size compared to unaffected fruits of the same variety. Dapple apple, another graft-transmissible disease, causes discoloration but no necrosis on the surface of infected Hyslop Crab apples. Both scar skin and dapple apple are diseases of presumed but as yet unproven viral etiology.

Changes in the concentration of total phenols, chlorogenic acids, flavonols and anthocyanins were determined colorimetrically in apple peel extracts from both healthy and scar skin-infected Red Delicious, and healthy and dapple apple-infected Hyslop Crab. Crude extracts containing flavonols, chlorogenic acids or anthocyanins were chromatographically separated. The number and kind of bands were compared and following elution, the amounts of compounds in the bands were measured colorimetrically.

Quantitative rather than qualitative differences were observed in the phenolic compounds of healthy and diseased Red Delicious apples. Scar skin infection results in consistently higher amounts of total phenols, flavonols, and chlorogenic acids in apples during the various stages of fruit development, but in lower amounts of anthocyanins, especially at fruit ripening. 
Dapple apple infection appears to have no significant effect on the quality or quantity of total phenols, flavonols or chlorogenic acids. Dapple apple infection, however, also causes a decrease in the concentration of anthocyanins and it is particularly apparent at fruit maturity

Attempts were made to identify chromatographically separated bands of chlorogenic acids, flavonols and anthocyanins. Chlorogenic acid was identified in both Red Delicious and Hyslop Crab apples. One of the four flavonol-glycosides was identified as quercetin-3-rhamnoside, and the other three behaved as quercetin-3-galactoside. The identity of anthocyanins remains unknown.

Comparison of the effects of these two diseases on phenolic metabolism with the symptoms caused by the diseases on the fruits, indicates that changes in phenolic metabolism are associated with the events observed in symptom development. Scar skin disease, causing formation of brown necrotic areas on the fruits, also increases in total phenols, flavonols and chlorogenic acids, while dapple apple disease, causing fruit discoloration but no necrosis, has no effect on the concentration of these compounds. Both diseases cause reduction in anthocyanins which reflects the discoloration and necrosis in scar skin diseased fruits and only the discoloration in dapple apple affected fruits. 


\section{REFERENCES}

Addy, S. K. 1976: Leakage of electrolytes and phenols from apple leaves caused by virulent and avirulent strains of Erwinia amylova.

Phytopathology $66: 1403-1405$.

Allen, P. J. 1959. Physiology and biochemistry of defense. In Plant Pathology, I, 435-467. Horsfall, J. G. and Dimond, A. E. (Eds.). (New York: Academic Press).

Barnes, E. H. and Williams, E. B. 1960. A biochemical response of apple tissue to fungus infection. Phytopathology 50:844-846.

Barrat, J. G. 1958, Studies on some apple virus diseases in New Hampshire. Ph. D. discussion at the University of New Hampshire.

Bazarova, V. I. and Samorodova, G. B. 1971. Comparative study of apple anthocyanins (Inst. Sov. Torg. in Engelsa Leningrad, U.S.S.R.) Iiv. Vyssh. Ucheb. Zard. Pishch. Tekhnol. 5:46-49 (Russ.).

Carling, D.; Ross, J. A.; and Millikan, D. F. 1969. Changes in protein and nucleic acid fractions associated with lethal virus infection in apple leaf tissue. Phytopathology 59:1020-1021 (Abs.).

Chi, S. Y. and MCCrum, R. C. 1975. Properties of a flexuous rod-shaped virus associated with scar skin disease of apple. Prec. Am. Phytopathol. Soc. 2:95-96.

Creasy, L. L. 1968. The role of low temperature in anthocyanin synthesis in McIntosh apples. Proc. Am. Soc. Hort. Sci. 93:716724 .

Faust, M. 1965. Physiology of anthocyanin development in McIntosh apple II. Relationship between protein synthesis and anthocyanin development. Proc. Am. Soc. Hort. Sci. $87(1): 10-20$.

Fawcett, C. H. and Spencer, D. M. 1967. Antifungal phenolic acids in apple fruit after infection with Sclerotinia fructigena. Ann. Appl. Biol. 60:87-96.

- 1968. Sclerotinia fructigena infection and chlorogenic acid content in relation to antifungal compounds in apple fruits. Ann. Appl, Biol, 61:245-253.

Feenstra, W. J.; Johnson, B. L.; Ribereau-Gayon, P.; and Geissman, T. A. 1963. The effect of virus infection on phenolic compounds in flowers of Matthiola incana. R. Br. Phyto-chemistry 2:273-279. 
Fish, D. J. 1965. Phenolic compounds of the apple fruit cuticle. Ann. Rep. Hort. Res. Sta. Long Ashton, England. 18:255-258.

Fric, F. 1976. Oxidative enzymes. In Physiological plant pathology. R. Heitefuss and P. H. Williams (eds.). Springer-Verlag Berlin, Heidelberg, New York. pp. 617-627.

Geissman, T. A. 1954. The flavonoid constituents of normal and virusinfected peach and cherry leaves. Arch. Biochem. Biophys. 60:2126.

Gene-Albrigo, L. and Childers, N. F. 1970. Peel flavonols and their relationship to superficial scald in Stayman apples. Am. Soc. Hort. Sci. $95(6): 798-800$.

Hadwiger, L. A. and Schwochau, M. E. 1969. Host resistance responses an induction hypothesis. Phytopathology 59:223-227.

Hahlbrock, K.; Knobloch, K. H.; Freuzaler, F.; Potts, J. R. M.; and Wellmann, K. 1976. Coordianted induction and subsequent activity changes of two groups of metabolically interrelated enzymes: Light-induced synthesis of flavonoid glycosides in cell suspension cultures of Petéroselinum hortense. Eur. J. Biochem. 1:199-206.

Hampton, R. E. and Fulton, R. W. 1961. The relation of polyphenol oxidase to instability in vitro of prune dwarf and sour cherry necrotic ringspot viruses. Virology $13: 44-52$.

Hanks, R. W. and Feldman, A. W. 1969. Changes in amounts of hesperidin and growth promoters and inhibitors in healthy and exocortis infected citrus trees $I$. Consideration in exocortis virus diagnosis (Trifoliate oranges). Soil and Crop Sci. Soc. Florida Proc. 29:306-312.

Herrmann, K. 1959. Catechin and catechin-tannins and their importance in foods. Z. Lebensmittelunters. u. -Forsch. 109:487-507.

Hoster-Auer, S. 1964. Papierchromatographische untersuchungen uber flavonol-3-glykoside in der Schale der Apfelsorte "Golden Delicious" Naturwissenschaften 51:267.

Hulme, A. C. and Edney, K. I. 1960. Phenolic substances in the peel of Cox's Orange Pippin apples with reference to infection by $\mathrm{G}$. perennans. In"phenolics in plants in healthy and disease. J. B. Pridam (ed.). Pergamon Press, London. p. 87.

Ibrahim, R. K.; Thakur, M. L.; and Permanand, B. 1971. Formation of anthocyanins in callus tissue cultures. Lloydia $34(2): 175-182$.

Ingham, J. I. 1972. Phytoalexins and other natural products as factor in plant disease resistance. Botanical Rev. 38(3):343-424. 
Ingle, M. and Hyde, J. F. 1968. The effect of bruising on discoloration and concentration of phenolic compounds in apple tissue. Am. Soc. Hort. Sci. 93:738-745.

Keen, N. T.; Zaki, A. I.; and Sims, J.H. 1971. Biosynthesis of hydroxyphaseollin and related isoflavonoids in disease resistant soybean hypocotyls. Phytochemistry 11:1031-1039.

Kirkham, D. S. 1954. Significance of the ratio between the water soluble aromatic and nitrogen constituents of apple and pear in the host parasite relationships of Venturia species. Nature 173:690691 .

- 1957. The significance of polyphenolic metabolites of apple and pear in the host relations of Venturia inaequalis and Venturia pirina. J. Gen. Microbiol. 17:491-504.

Kosuge, T. 1969. The role of phenolics in host response to infection. Annu. Rev. Phytopathol. 7:195-222.

Kuc, J. 1972, Phytoalexins. Annu, Rev. Phytopathol. 10:207-232.

- 1976. Phytoalexins. In Physiological plant pathology. R. Heitefuss and P. H. Williams (eds.). Springer-Verlag Berlin, Heidelberg, New York. pp. 632-646.

Lees, D. H. and Francis, F. J. 1971. Quantitative methods for anthocyanins. 6. Flavonols and anthocyanins in cranberry. J. Food Sci. 36:1056-1060.

- 1972. Standardization of pigment analyses in cranberries. Hort. Science $7(1): 83-84$.

Loper, G. M. 1968. Accumulation of coumestrol in Barsel medic (Medicage littoralis) . Crop Sci. 8:317-319..

Mabry, T. J.; Markham, K. R.; and Thomas, M. B. 1970. The systemic identification of flavonoids. Springer-Verlag New York, Heidelberg, Berlin. pp. 35-57.

Makarski, J. S., Jr. and Agrios, G. N. 1973. Respiration, organic acids, and sugar composition of apple fruits collected from apple mosaic virus or russet ring virus-infected trees. Phytopathology $63: 1483-1488$.

Martin, C. 1958. Etude de quelques deviations de metabolisme chez les plantes atteintes de malade a virus. These University in Paris.

Matthews, R. E. F. 1970. Plant virology. Academic Press, New York, San Francisco, London. p. 338. 
MCClure, J.W. 1975. Physiology and functions of flavonoids. In the flavonoids, II., pp.970-1055. Harborne et al (ed.). Academic Press, New York.

Millikan, D. F. and Koirtyohann, S. R. 1966. Biochemical patterns in leaf tissue from virus-infected and disease-free apple, III. Effect of virus infection upon the RNA content of a tolerant and sensitive variety. Phytopathol. Z. 55:177-180.

Millikan, D. F. and Saniewski, M. 1972. Phenolase and ascorbic acid oxidase activities in apple leaves after grafting with healthy and virus infected Golden Delicious buds. Phytopathology 62:788 (Abs.).

Millikan, D. F. and Martin, W. R, Jr. 1956. An unusual fruit symptom in apple. Plant Dis. Reptr. 40:229.

Minamikawa, T. and Uritani, I. 1964. Phenylalanine deaminase and tyrosine deaminase in sliced or black rot infected sweet potato roots. Arch. Biochem, Biophys. 108:537-574.

Mink, G. I. 1965. Inactivation of plant viruses by o-quinones. Virology $26: 700-701$.

and Saksena, K. N. 1971, Studies on the mechanism of oxidative inactivation of plant viruses by o-quinones. Virology 45:755-763.

Mosel, H. D. and Herrmann, K, 1974. Changes in catechins and hydroxycinnamic acid derivatives during development of apples and pears. J. Sci. Food Agric. 25:251-256.

Nicholson, R. L.; Van Scoyoc, S.; Williams, E. B.; and Kuc, J. 1977. Host-pathogen interactions preceding the hypersensitive reaction of Malus sp to Venturia inaequalis. Phytopathology 67:108-114.

Noveroske, R. I. 1962. Phloridzin--Its metabolism and role in conditioning resistance in Malus to Venturia inaequalis. Doctoral thesis, Purdue University at Lafayette, Indiana. $107 \mathrm{pp}$.

Pais, I. and Gombkoto, G. 1967. Chemical analysis of types of apples, I. Anthocyanin pigments of Jonathan apple. Kertesz. Szolesz. Foisk. Kemiai. Tanszeke. 31:73.

Parish, C. L.; Zaitlin, M.; and Siegel, A. 1965. A study of necrotic lesion formation by tobacco mosaic virus. Virology $26: 413-418$.

Parker, P. E. and Agrios, G. N. 1973. Histopathology of scar skin disease of apple. Phytopathology 65:707-713.

Pegg, G. F. and Sequeira, L. 1968. Stimulation of aromatic biosynthesis in tobacco plants infected by Pseudomonas solanacearum.

Phytopathology $58: 476-483$. 
Raa, J. 1968. Natural resistance of apple plants to Venturia inaequalis. Doctoral thesis, Univeristy of Utrecht at Utrecht, in the Netherlands, $100 \mathrm{pp}$.

and Overeem, J. C. 1968. Transformation reactions of phloridzin in the presence of apple leaf enzymes. Phytochemistry $7: 721-731$.

Rahe, J. E.; Kuc, J.; Chuang, C. M.; and Williams, E. B. 1969. Correlation of phenolic metabolism with histological changes in Phaseolus vulgaris inoculated with fungi. Neth. J. Pl. Pathol. 75: 58-71.

Ribereau-Gayon, P. 1972. Plant phenolics, Hafner Publishing Company, New York. p. 254.

Rich, A. E. 1967. Influence of dapple apple and stem pitting viruses on tree growth and fruit yields over a fourteen-year period. P1. Disease Rept. 51(4):293-295.

Saniewski, M. and Millikan, D. F. 1972. Changes in some oxidative enzyme activities and auxin content of apple leaves after a grafting with healthy and virus-infected buds of Golden Delicious. Phytopahtology 62:787 (Abs.).

Siegelman, H. W. 1954. Quercetin glycosides of Grimes Golden apple skin. J. Biol. Chem. 213:647-658.

and Hendricks, S. B. 1958. Photocontrol of anthocyanin synthesis in apple skin. P1. Physiol. 33:185-190.

Simons, T. J. and Ross, A. F. 1971. Changes in phenol metabolism associated with induced systemic resistance to tobacco mosaic virus in Samsun NN tobacco. Phytopathology 61:1261-1265.

Smith, W. W..; Barrot, J. G.; and Rich, A. E. 1956. Dapple apple, an unusual fruit symptom of apples in New Hampshire. Plant Disease
Rept. $40: 756-766$.

Solymosy, F.; Farkus, G. L.; and Kiraly, Z. 1959. Biochemical mechanism of lesion formation in virus-infected plant tissues. Nature 184:
706-707. Sondheimer, E. 1958. Chlorogenic acids and related depsides. Arch.
Biochem. Biophys. $74: 131$.

Sosnova, V. and Ulrychova, M. 1972. Tobacco mosaic virus reproduction in plants with an increased anthocyanin content induced by phosporus deficiency, Biologica Planturum. 14(2):133-139. 
Sun, B. H. and Francis, F. J. 1968. Apple anthoxyanins: Identification of cyanidin-u-arabinoside. J. Food Sci. 32(6):647-649.

Swain, T, and Hillis, W, E. 1959. The phenolic constituents of prunus domestica, I. The quantitative analysis of phenolic constituents. J. Sci, Food Agr. 10:63-68.

Swinburne, T. R. 1964.. Rotting of apples of the variety "Bramley's seedling" by Nectria galligena. Bres. Nature 204:493-494.

Thimann, K. and Radner, B. S. 1962. The biogenesis of anthocyanins, VII. The requirement for both purines and pyrimidines. Arch. Biochem. Biophys. $96: 270-279$.

Timberlake, C. F. and Bridle, P. 1971. The anthocyanins of apples and pears: The occurrence of acyl derivative. J. Sci. Food Agric. 22: 509-513.

Ulrychova, M. and Sosnova, V, 1970. Effect of phosphorus deficiency on anthocyanin content in tomato plant. Biologica plantarum 12(3): $231-235$.

Van Buren, J. 1970. Fruit phenolics. In the biochemistry of fruits and their products. A. C. Hulme (ed.). Academic Press, London, New York. 1:269-304.

Walker, J. R. I. 1962. Studies on the enzymic browning of apple fruit. New Zealand. J. Sci. 5:316-324.

- 1963. A note on the polyphenolic content of ripening apples. New Zealand. J. Sci. 6:495-506.

- 1964. Flavonoid pigments in the skins of New Zealand apples. New Zealand. J. Sci. 7:589-595.

Wellmann, E. and Schopeer, P. 1975. Phytochrome-mediated de nove synthesis of phenylalanine ammonia lyase in cell suspension cultures of parsley. Plant Physiol. 55:822-827.

Wheeler, H. 1975. Plant pathogenesis. Springer-Verlag, New York, Heidelberg, Berlin. pp. 67-69.

Whiting, G. C. and Coggins, R. A. 1975. 4-p-coumaryl quinic acid in apple fruits. Phytochemistry. 14:593.

Williams, E. B. and Kuc, J. 1969. Resistance in Malus to Venturia inaequalis. Annu. Rev. Phytopathology 7:233-246.

Wilson, D. M. and Darby, W. B. 1971. Comparison of peroxidase and odiphenol oxidase in postharvest apple decay by pencellium and Physalospora. Phytopathology 61:917 (Abs.). 
Wood, T. L. and Agrios, G. N. 1974. Inhibitory effects of a polyphenolpolyphenol oxidase system on the infectivity of cow-pea chlorotic mottle virus ribonucleic acid. Phytopahtology 64:35-37.

Zucker, M. 1968. Sequential induction of phenylalanine ammonia lyase and a lyase-inactivating system in potato tuber disks. Plant physiology $43: 365-375$.

and Ahrens, J, F, 1958. Quantitative assay of chlorogenic acid and its pattern of distribution within tobacco leaves. Pl. physiol. $33: 246-249$. 
